University of Wollongong

Research Online

Australian Institute for Innovative Materials -

Papers

Australian Institute for Innovative Materials

$1-1-2019$

\title{
3D graphene-containing structures for tissue engineering
}

Jianfeng Li

Xiao Liu

University of Wollongong, xiaol@uow.edu.au

Jeremy Micah Crook

University of Wollongong, jcrook@uow.edu.au

Gordon G. Wallace

University of Wollongong, gwallace@uow.edu.au

Follow this and additional works at: https://ro.uow.edu.au/aiimpapers

Part of the Engineering Commons, and the Physical Sciences and Mathematics Commons

Research Online is the open access institutional repository for the University of Wollongong. For further information contact the UOW Library: research-pubs@uow.edu.au 


\title{
3D graphene-containing structures for tissue engineering
}

\author{
Abstract \\ (c) 2019 Elsevier Ltd Graphene and its derivatives have been extensively explored in various fields and \\ have shown great promise toward energy harvesting, environmental protection, and health care. 3D \\ graphene-containing structures (3DGCSs) are especially endowed with useable features relating to \\ physicochemical properties within the hierarchical architectures. Thus, 3DGCSs are increasingly being \\ applied for tissue engineering because of their supportability of human cells and functionalization \\ potential. This review focuses on recent progress in tissue engineering utilizing 3DGCSs, providing \\ insights into fabrication, application, and constraints in bionic research. \\ Disciplines \\ Engineering | Physical Sciences and Mathematics

\section{Publication Details} \\ Li, J., Liu, X., Crook, J. \& Wallace, G. (2019). 3D graphene-containing structures for tissue engineering. \\ Materials Today Chemistry, 14 100199-1-100199-11.
}




\title{
3D Graphene Containing Structures for Tissue Engineering
}

Jianfeng $\mathrm{Li}^{a}{ }^{a}$, Xiao Liu ${ }^{a}$, Jeremy M. Crook ${ }^{a, b, c *}$, and Gordon G. Wallace ${ }^{a}$

${ }^{a}$ ARC Centre of Excellence for Electromaterials Science, Intelligent Polymer Research Institute, AIIM Facility, University of Wollongong, NSW 2522, Australia.

${ }^{b}$ Illawarra Health and Medical Research Institute, University of Wollongong, Wollongong, New South Wales 2522, Australia.

'Department of Surgery, St Vincent's Hospital, The University of Melbourne, Fitzroy, Victoria 3065, Australia.

* Corresponding authors.

Tel: +61-2-42213127

Fax: +61-2-42213114

E-mail address: xiaol@uow.edu.au; jcrook@uow.edu.au;

\begin{abstract}
Graphene and its derivatives have been extensively explored in various fields and have shown great promise towards energy harvesting, environmental protection and healthcare. 3D graphene containing structures (3DGCSs) are especially endowed with useable features relating to physico-chemical properties within the hierarchical architectures. Thus, 3DGCSs are increasingly being applied for tissue engineering due to their supportability of human cells and functionalization potential. This review focuses on recent progress in tissue engineering utilizing 3DGCSs, providing insights into fabrication, application and constraints in bionic research.
\end{abstract}




\section{Keywords: Graphene; 3D materials; Tissue engineering; Bionic research; Regenerative medicine}

\section{Introduction}

Replication and restoration of tissues/organs via modern tissue engineering techniques promise to mitigate the global health crisis due to insufficient tissue/organ donation, compounded by an aging population and need to treat newly discovered or incurable diseases and disabilities. Specific physicochemical properties of biomaterials combined with novel approaches to their application place them centre stage as next-generation medical devices for regenerative medicine.

In 2004, mono-layer carbon material, i.e. graphene, was discovered and prepared by Geim and Novoselov using a scotch tape method [1,2]. Arranged in a honeycomb lattice, graphene shows exceptional surface to volume ratio, high carrier mobility, and good electrical, optoelectronic and mechanical properties (Fig. 1) [3], paving the way towards a post-silicon era [4, 5]. The exceptional electronic properties of graphene are due to its special crystal lattice structure, whereby bonding between each carbon atom is hybridized $\mathrm{sp}^{2}$ with additional $\pi$ orbitals [6]. There are two $\pi$ orbitals in each unit cell of graphene, which is dispersed to form two $\pi$ bonds: both of which could be considered as bonding and anti-bonding in nature. These unique properties make pristine graphene a mixture of gapless metal and semiconductor [7]. 


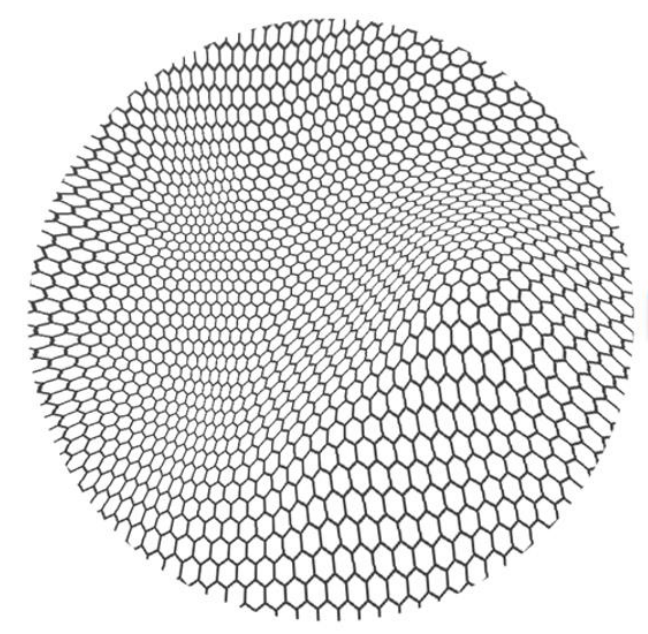

\section{Flexible}

Light

Thin

Robust

Transparent

Thermally conductive

Electrically conductive

Surface modifiable...

Fig. 1. Structure and properties of graphene.

As a soft layered structure, graphene can be decorated with hydroxyl, epoxide, and carboxyl groups on the edge and basal plane through oxidization, rendering graphene oxide (GO). Graphene is hydrophilic and inclined to aggregate, whereas GO is hydrophobic and well dispersible in various solutions, including water. These characteristics make GO easy to process and possess high affinity to biomolecules. In order to expand the bionic applications of graphene and its derivatives, a more detailed comprehension of their properties in the biological context is needed. Most graphene and derivatives have proven to be cytocompatible in vitro and in vivo [8]. However, the physico-chemical properties of the 2D materials, including structure shape, size, surface functionality, concentration and aggregation state, have a major influence on cytocompatibility [9]. Flat 2D graphene materials are considered less toxic than tubular forms (e.g. single-walled carbon nanotubes (SWCNT)), with cell membrane integrity being retained at up to a 1000 fold higher graphene concentration compared with SWCNT, in part due to their softer nature [10]. In addition, it has been demonstrated that penetration of cell membranes is dominated by the graphene edge shape, and so graphene with sharp edge features is more likely to damage the cell membrane [11]. Nanoscale graphene materials, especially in 10-100 nm size, can induce cytotoxicity, inflammation and even genotoxicity when they 
are translocated into cells and cell nuclei with less steric hindrance compared to larger sized graphene materials $[12,13]$. Besides the intrinsic physical properties, the concentration and aggregation state of graphene also affect cytocompatibility, with diluted and less aggregated graphene solutions being more compatible $[10,12]$. Surface chemistry of graphene can also affect its interaction with cells by modulation of hydrophilicity and hydrophobicity, which subsequently affects aggregation. Nanoscale graphene decorated with more oxygen containing groups is more easily internalized by cells, while the influence on the perturbation of the cell membrane becomes more irregular [14]. Although there are generalised effects of graphene on cells, cell specific effects should also be considered, e.g. different endocytic pathways of GO nanosheets are observed with osteoblasts, macrophages and hepatocytes [15].

Structural defects in graphene layers, such as vacancies, adatoms and substitutional impurities, introduced during preparation have significant influence on graphene properties [16]. Epitaxial growth [17], chemical vapour deposition (CVD) [18], micromechanical exfoliation [2] and chemical synthesis [19] are the four principal methods for graphene preparation. Graphene synthesized by epitaxial growth and CVD methods shows superior physicochemical properties and controllability over quality due to continuous bottom-up synthesis procedure [20], but the fabrication process is complicated requiring expensive specialised equipment and raw materials [21]. Micromechanical exfoliation can produce multi-layer, bi-layer and single layer graphene with less defects on the sheet, but this method is hard to scale and layer size is small [22]. Chemical synthesis of graphene is currently the most widely used and processable method for graphene preparation. This approach is more easily scaled than the other three methods, although graphene obtained by the other methods shows fewer defects and better controllability over graphene shape and azimuthal orientation [23]. For the chemical synthesis method, graphene is prepared through exfoliation and oxidation of graphite with additional chemical/thermal reduction treatment [24, 25]. Typically, strong acid and oxidizing agents are employed for graphite expansion and oxidization, with further exfoliation of 
oxidized graphite to GO by mechanical treatment. The obtained GO can be reduced to graphene via a variety of techniques, such as: microwave, thermal annealing, and chemical reduction et.al [26]. Processability of the solution phase, without the need for expensive facilities enable production of large quantities, making graphene more accessible in industry. However, the defects and non-uniform morphology of graphene made by chemical synthesis are possibly due strong acid oxidation during the oxidization procedure and exfoliation during the ultrasonication process [25].

Graphene and its derivatives, as 2D materials, have found applications in many research fields, namely: energy storage [27], drug delivery [28] and tissue regeneration etc. [29]. Transition from 2D structures to $3 \mathrm{D}$ provides new opportunities for graphene containing structures. This is particularly so in the field of bioengineering where the use of $3 \mathrm{D}$ structures has been shown to exhibit significant advantages over 2D [30], because the 3D graphene containing structure (3DGCS) systems not only possess intrinsic graphene properties, but also have high surface to volume ratio, larger surface area for decoration, abundant embedded binding sites and many other remarkable properties. Especially, 3DGCSs with large surface area, micro-pores/channels, improved biocompatibility, mechanical properties and electrical conductivity, are emerging as better platforms for tissue engineering and other bionic applications. In addition, cell activity can be enhanced by using 3D structures through enhanced cell adhesion, interaction, migration, proliferation and differentiation [28, 31].

Although graphene has received enormous attention in tissue engineering application recently, most of the published reviews are focused on introducing the properties of graphene-based materials and general biomedical application. Biomimetics has become a hot research topic and there has been significant accomplishment in biomimetic 3DGCSs for tissue engineering, while there is still no systematic summary in this respect. In this review, application of 3DGCSs in tissue engineering and fabrication methods that enable production of 3DGCSs are summarized and discussed. Biosafety and biodegradability issues are also discussed, with future perspectives provided at the end of the paper. 


\section{Application of 3DGCSs for tissue engineering}

Tissue engineering represents an advanced tool for treating and reconstructing defective tissues/organs using, for example, biomimetic scaffolds, while traditional therapy strategies have limitations, such as matchable donor shortage and post-transplant immune monitoring. Tissue engineering scaffolds are required to be biocompatible and present various cues to guide cell proliferation or differentiation towards diverse lineages both in vitro and in vivo. 3DGCSs with abundant embedded cell attachment/binding sites, supported by appropriate physicochemical properties can meet these criteria for tissue engineering.

2D graphene containing structures have already been extensively investigated by researchers towards tissue engineering, specifically in cardiac, neuronal, bone, skin, adipose and cartilage regenerations [28]. Structural components in human body, from macroscopic tissue/organ to nanoscale DNA/protein, are all explicitly shaped in three dimensions. Therefore, a 3DGCS better mimics extracellular matrix (ECM), not only because it more closely resembles the architecture of in vivo counterparts, but also for its conductivity of bioelectrical signals, interconnected channels, appropriate morphologies and inherent cell differentiation guiding cues. All these properties can increase the chance of successfully implementing cells in various clinical applications towards disease therapy and tissue/organ reconstruction. Compared with traditional biomaterial-based scaffolds, the electrical conductivity of 3DGCSs is especially important in various tissue engineering applications due to the positive effect of in-situ ES on coupling of implanted cells with host surrounding tissues [32]. Furthermore, 3DGCSs have exhibited anti-inflammatory behaviour by their unique surface topographical features while supporting microglial cell growth which has not been observed in 2D corresponding structures [33].

\subsection{Bone tissue engineering}

As a highly dynamic and vascularized tissue, bone undergoes lifelong reshaping in the human body 
and is responsible for pressure bearing, mobility support and internal organ protection [34]. There is a high demand for functional bone implants due to limited supply and infectious disease transmission risk in traditional autograft or allograft processes. Nowadays, bone is currently the second most frequently transplanted human body tissue (2.2 million cases per year), following blood [35]. Fortunately, tissue-engineered bone can serve as an effective alternative to the unmet demand of bone grafts without the risk of infection and immune rejection [36]. Graphene, as a biocompatible material with beneficial physicochemical properties, is capable of supporting stem cell growth and osteogenic differentiation without additional inducers [37]. Additionally, graphene can adsorb dexamethasone and $\beta$-glycerolphosphate via $\pi$ - $\pi$ stacking, which are widely used osteogenic inducers, to condense their concentration on the surface [38]. Differentiation of bone marrow derived mesenchymal stem cells (MSCs) can be accelerated towards osteogenesis by this effect [38]. 3DGCS fabricated by the CVD method can upregulate bone-related genes (MHY10 and MHY10-V2) and proteins expression (COL I, RUNX2, OCN) [39]. Applications of 3DGCS towards bone tissue engineering are summarized in Table 1. 
Table 1 Applications of 3DGCS towards bone tissue engineering

\begin{tabular}{|c|c|c|c|c|}
\hline Scaffold composition & Fabrication method & Cell source & Effect & Reference \\
\hline $\begin{array}{l}\text { Poly-caprolactone } \\
\text { (PCL)/Graphene }\end{array}$ & $3 \mathrm{D}$ printing & $\begin{array}{l}\text { Human adipose-derived } \\
\text { stem cells (ADSCs) }\end{array}$ & $\begin{array}{l}\text { Non-cytotoxic with enhanced cell } \\
\text { viability/proliferation }\end{array}$ & {$[40]$} \\
\hline PCL/Graphene & $3 \mathrm{D}$ printing & $\begin{array}{l}\text { MC3T3 osteoblast and } \\
\text { THP-1 human monocytic } \\
\text { cells }\end{array}$ & $\begin{array}{l}\text { Low inflammatory and immune response; } \\
\text { Enhancement of bone regeneration; } \\
\text { Feasible for further enhancement of bone } \\
\text { regeneration with electrical stimulation }\end{array}$ & [41] \\
\hline HA/Graphene & $3 \mathrm{D}$ printing & hMSCs & $\begin{array}{c}\text { Upregulation of osteogenic gene } \\
\text { expression }\end{array}$ & [42] \\
\hline RGO/PDMS & $\begin{array}{l}\text { Dip-coating (template } \\
\text { assembly) }\end{array}$ & ADSCs & $\begin{array}{c}\text { Promotion of stem cell proliferation and } \\
\text { osteogenic differentiation }\end{array}$ & [43] \\
\hline $\begin{array}{l}\text { Poly(vinylidene fluoride) } \\
\text { (PVDF)/Graphene foam, } \\
\text { PCL/Graphene foam }\end{array}$ & $\begin{array}{l}\text { CVD/Spin coating (template } \\
\text { assembly) }\end{array}$ & & $\begin{array}{c}\text { Enhancement of formation for calcium } \\
\text { phosphate }(\mathrm{Ca}-\mathrm{P})\end{array}$ & {$[35]$} \\
\hline Graphene & CVD (template assembly) & $\begin{array}{l}\text { Human bone marrow- } \\
\text { derived mesenchymal stem } \\
\text { cells (hMSCs) }\end{array}$ & Promoted osteogenic differentiation & {$[44]$} \\
\hline Graphene & CVD (template assembly) & $\begin{array}{l}\text { Periodontal ligament stem } \\
\text { cells (PDLSCs) }\end{array}$ & $\begin{array}{c}\text { Upregulation of bone-related gene and } \\
\text { proteins }\end{array}$ & [39] \\
\hline
\end{tabular}




\begin{tabular}{|c|c|c|c|c|}
\hline $\mathrm{GO} / \mathrm{Car} / \mathrm{HA}$ & $\begin{array}{l}\text { Immersion-coating } \\
\text { (template assembly) }\end{array}$ & MC3T3-E1 cells & $\begin{array}{c}\text { Promotion of HA mineralization and cell } \\
\text { differentiation }\end{array}$ & [45] \\
\hline $\begin{array}{l}\text { RGO/Peptide nanosheets } \\
\text { (PNSs)/HA }\end{array}$ & $\begin{array}{l}\text { Immersion-coating } \\
\text { (template assembly) }\end{array}$ & Fibroblast cells (L-929) & Excellent cytocompatibility & [46] \\
\hline $\begin{array}{l}\mathrm{HA} / \mathrm{RGO} / \text { Chitosan } \\
\text { (CHI) }\end{array}$ & $\begin{array}{l}\text { Hydrothemal (self- } \\
\text { assembly) }\end{array}$ & $\begin{array}{l}\text { Rabbit bone mesenchymal } \\
\text { stem cell (rBMSCs) }\end{array}$ & $\begin{array}{l}\text { Improved cell affinity and } \\
\text { biocompatibility }\end{array}$ & [47] \\
\hline $\begin{array}{l}\text { Graphene nanosheet } \\
\text { (GNS)/HA nanorod }\end{array}$ & $\begin{array}{l}\text { Hydrothermal (self- } \\
\text { assembly) }\end{array}$ & $\begin{array}{l}\text { MC3T3-E1 osteoblast } \\
\text { cells }\end{array}$ & $\begin{array}{c}\text { Good bone bonding ability and improved } \\
\text { biocompatibility with proliferation } \\
\text { upregulation. }\end{array}$ & [49] \\
\hline Starch/GO & $\begin{array}{l}\text { Freeze drying (self- } \\
\text { assembly) }\end{array}$ & Osteoblastic cells MG63 & HA mineralization & {$[52]$} \\
\hline $\mathrm{CHI} / \mathrm{PVA} / \mathrm{GO}$ & $\begin{array}{l}\text { Freeze drying (self- } \\
\text { assembly) }\end{array}$ & & Increased mineralization & [53] \\
\hline
\end{tabular}




\begin{tabular}{|c|c|c|c|c|}
\hline $\begin{array}{c}\text { Agarose/Low oxygen } \\
\text { content graphene (LOG) } \\
\text { nanoparticles }\end{array}$ & Gelation (self-assembly) & hMSCs & $\begin{array}{l}\text { Improved active bone formation and } \\
\text { increased mineralization }\end{array}$ & [54] \\
\hline RGO/PPY/HA & $\begin{array}{l}\text { Layer by layer and } \\
\text { electrochemical deposition } \\
\text { [template assembly and self } \\
\text { (electrochemical) assembly] }\end{array}$ & MC3T3-E1 osteoblast cell & Upregulated cell proliferation & [56] \\
\hline $\begin{array}{c}\text { RGO/PPY/ } \\
\text { Polydopamine } \\
\text { (PDA)/Strontium (Sr) }\end{array}$ & $\begin{array}{c}\text { Layer by layer and } \\
\text { immersion deposition } \\
\text { (template assembly and self- } \\
\text { assembly) }\end{array}$ & MC3T3-E1 osteoblast cell & $\begin{array}{l}\text { Significant enhancement of the early } \\
\text { MC3T3-E1 cell adhesion, proliferation } \\
\text { and osteogenic differentiation }\end{array}$ & [57] \\
\hline $\mathrm{GO} / \beta-\mathrm{TCP}$ & $\begin{array}{l}\text { Dip coating (template } \\
\text { assembly) }\end{array}$ & rBMSCs & $\begin{array}{l}\text { Significantly promote in vivo bone } \\
\text { formation and excellent photothermal } \\
\text { effects towards bone tumor cell killing }\end{array}$ & [59] \\
\hline $\mathrm{Fe}_{3} \mathrm{O}_{4} / \mathrm{GO} / \beta-\mathrm{TCP}$ & $\begin{array}{l}\text { Dip coating (template } \\
\text { assembly) }\end{array}$ & rBMSCs & $\begin{array}{l}\text { Promotion of stem cell proliferation and } \\
\text { bone-related gene expression. Effective } \\
\text { killing of bone tumor cell under an } \\
\text { alternating magnetic field }\end{array}$ & [60] \\
\hline
\end{tabular}




\begin{tabular}{|c|c|c|c|}
\hline Nano-HA/RGO & $\begin{array}{l}\text { Hydrothermal (self- } \\
\text { assembly) }\end{array}$ & rBMSCs & $\begin{array}{l}\text { Not inducing obvious inflammatory and } \\
\text { necrosis. Promotion of bone defect } \\
\text { healing and }\end{array}$ \\
\hline
\end{tabular}


Poly-caprolactone (PCL), as a widely used material in 3D printing, can be modified with a small amount of pristine graphene for improved hydrophilicity and biocompatibility compared with 3D printed pristine PCL [40] (Fig. 2a). The 3D PCL/graphene scaffolds showed improved cell support with $\mathrm{NaOH}$ treatment to further increase its hydrophilicity (Fig. 2b). The PCL/graphene scaffold can be applied with micro electrical stimulation to further improve its capability towards supporting neobone tissue formation [41]. Likewise, Ma et. al introduced GO/ $\beta$-tricalcium phosphate ( $\beta$-TCP) scaffold fabricated by coating GO onto the 3D printed $\beta$-TCP scaffold, which not only significantly promoted in vivo bone formation, but also showed excellent photothermal effects towards bone tumor cell killing [59]. Additionally, the same research group has incorporated the GO/ $\beta$-TCP scaffold with $\mathrm{Fe}_{3} \mathrm{O}_{4}$ nanoparticles, facilitating stem cell proliferation with released $\mathrm{Fe}$ ions while concomitantly being capable of magnetothermal therapy towards bone tumor [60]. These integrated fabrication strategies have taken advantage of 3D printing over structure controllability, while avoiding the complications of graphene ink preparation.

3D graphene foam fabricated by the CVD method with decoration of gelatin could support human bone marrow-derived mesenchymal stem cells (hMSCs) growth and osteogenic differentiation [44]. Li et.al. reported a 3D RGO/polydimethylsiloxane (PDMS) scaffold that was able to support stem cell growth and osteogenic differentiation without additional surface decoration, which may be due to better cell affinity from oxygen containing groups on the RGO surface [43]. In this research, graphene was coated onto 3D PDMS substrate, which was fabricated by a salt leaching method (Fig. 2c). Adipose-derived stem cells (ADSCs) showed enhanced performance in proliferation and osteogenic differentiation on the RGO/PDMS scaffold than on the 2D RGO structure or pristine 3D PDMS scaffold (Fig. 2d).

Enrichment of 3D graphene scaffold with other molecules/polymers can also increase its capability towards stem cell osteogenic induction. Poly(vinylidene fluoride) (PVDF) and PCL, both widely used as bone tissue engineering materials, were integrated into 3DGCS by a spin-coating method [35]. 
After integration of PVDF and PCL, not only the flexibility and handleability of 3DGCS increased, but also calcium phosphate (Ca-P) compound formation and mineralization on the scaffold were enhanced due to the functional groups presented in the integrated polymers.

Carrageenan (Car), as a linear polysaccharide with abundant sulfate groups on the backbone, has shown promise to mimic charged proteins in the ECM. After functionalization with carrageenan, 3D GO scaffold showed better affinity to calcium ions and enhanced ability to increase cell mineralization [45]. MC3T3-E1 cells showed improved proliferation and osteogenesis on the 3D GO/Car composite than pristine GO scaffold.

$\mathrm{CHI}$ is biocompatible, biodegradable and has been proven to be able to support osteoblast cell adhesion, proliferation and formation of mineral bone matrix [62]. A 3D CHI/GO scaffold was fabricated by the freeze-drying method, and GO was proven to play an important role in improving scaffold mechanical properties and pore formation capability. Meanwhile, cells behaved proportionally to the concentration of GO in the composite scaffolds [50] and showed potential for large bone defect reconstruction both in vivo and in vitro without the need of additional growth factors or cells [51]. In order to resemble bone lamellae structure, Liu et.al introduced directional freezing technique to create aligned porous $\mathrm{GO} / \mathrm{CHI}$ scaffold for bone tissue engineering [58]. Similar to $\mathrm{CHI}$, agarose is also biodegradable and biocompatible. 3DGCS fabricated by agarose hydrogel doped with low oxygen content graphene (LOG) nanoparticles and embedded with hMSCs showed capability in increasing mineralization and active bone formation of hMSCs both in vitro and in vivo [54].

Although graphene hydrogel has great potential for being applied in tissue engineering, its poor mechanical strength has hindered its further application. Besides coating graphene on mechanically robust substrate [43] or integrating graphene with PVDF and PCL [35], incorporation of CHI and HA into 3DGCS can also overcome its fragile shortcoming and retain its porous property. Rabbit bone mesenchymal stem cell (rBMSCs) revealed good affinity and viability on the obtained 3D ternary composite [47]. 
HA is an inorganic component of bone and favoured by osteogenic cells, while incorporation with graphene could even enhance its inherent properties with low loading ratios [48, 49]. 3D RGO/PPY/HA scaffold fabricated by using nickel foam as a substrate via electrostatic layer-by-layer assembly and mineralization strategies at room temperature showed superior performance in supporting cell proliferation compared with cells cultured merely in medium [56]. In this scaffold, RGO/PPY substrate not only provided 3D macro-/nano-hierarchical binary structure, but also served as supporting architecture for HA deposition to achieve increased surface area and roughness for enhanced cell supporting capability. Besides, 3D RGO/PPY structure can also serve as substrate for dopamine polymerization and subsequent strontium (Sr) deposition, while the obtained 3D scaffold significantly improves cell early adhesion, proliferation and osteogenic differentiation [57]. Jakus et.al. developed a variety of 3D printable HA/graphene composite inks, and found the obtained hybrid 3D HA/graphene structures can support osteogenic gene upregulation of stem cells over two weeks [42]. 3D HA/graphene composite can also be fabricated without template through a hydrothermal procedure, during which HA nanoparticles are entrapped in the formed 3D graphene network simultaneously [48] (Fig. 2e). After the incorporation with HA, the scaffold showed better cell affinity compared with mere graphene scaffold (Fig. 2f). Su et al. also reported an efficient method to improve HA deposition on 3D graphene scaffold by pre-deposition of peptide nanosheets (PNSs) on the scaffold surface [46]. Nie et.al. reported 20\% nano-HA decorated 3D RGO structure can promote bone defect healing in rabbit within 6 weeks without obvious inflammatory and necrosis inducing [61].

Strontium (Sr) ions can enhance osteogenesis, similar to calcium, and inhibit osteoclast activity, so Kumar et.al. have fabricated Sr decorated 3DGCS with assistance of PCL in macroporous scaffold fabrication via a gas foaming method [55]. Addition of $\mathrm{Sr}$ in the scaffold can significantly enhance proliferation and differentiation of osteoblast cells compared with pristine PCL and PCL/RGO scaffolds. 
Bone morphogenic proteins (BMPs), as important regulators in differentiation and functionalization of bone and cartilage cells, produce serious side effects at large dosages, while the high price and its unstable nature also hinder their further application $[63,64]$. In order to apply BMPs in a controllable and safe way, they were co-electrophoretically deposited with CHI onto 3DGCS precoated with a layer of poly(lactic-co-glycolic acid) (PLGA) [65]. The bilayer coated 3DGCS can release BMPs in an electro-responsive way and showed significantly increased mechanical properties without compromising its porous structure.

Due to the abundant functional groups on the basal planes, GO can be connected with polymer chains like starch [52], poly(vinyl alcohol) [66], polysebacic anhydride [67] via esterification, resulting in more stable composites that have potential to be utilized towards 3D scaffold fabrication. 3DGCS can be obtained from covalently bonded starch/GO composite via a freeze drying method, and the GO component inside could induce HA mineralization [52]. 
(a)

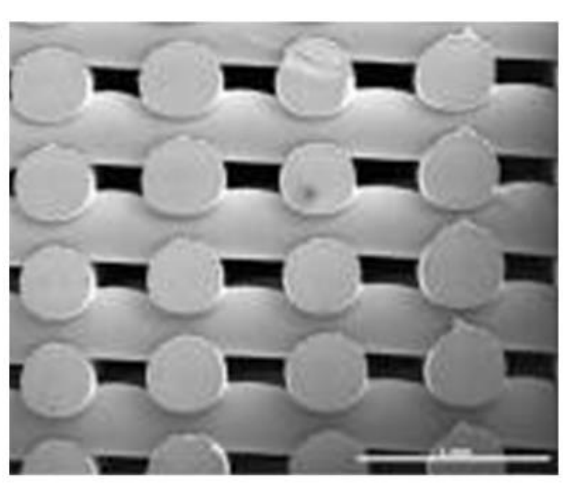

(c)

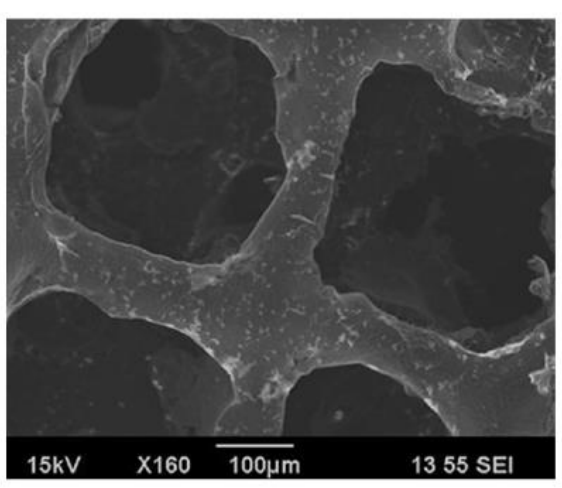

(e)

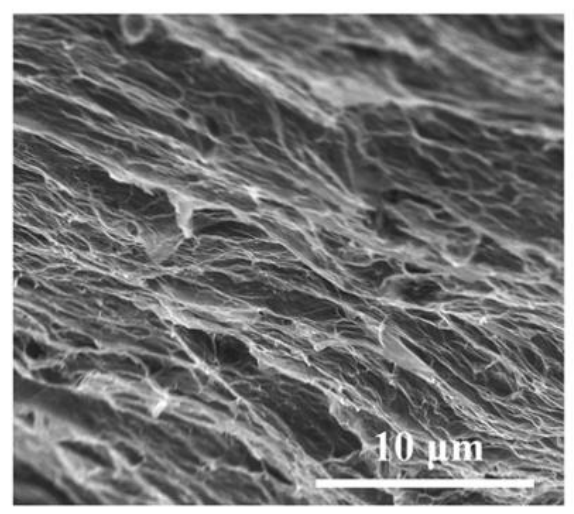

(b)

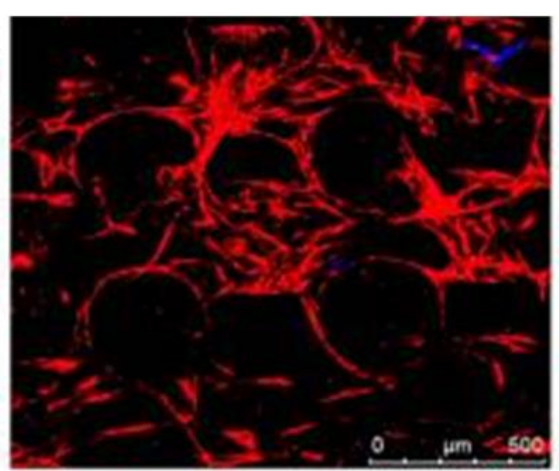

(d)

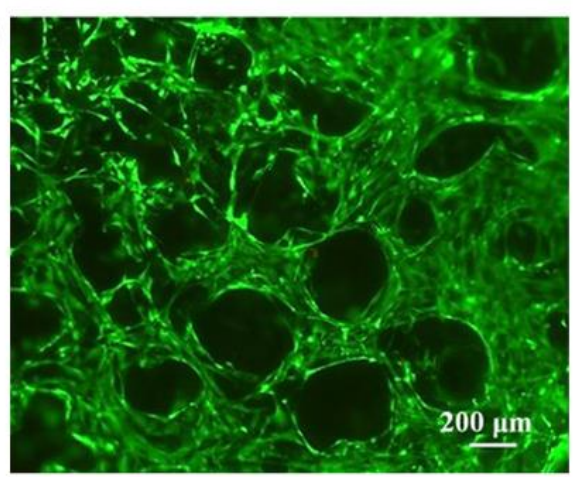

(f)

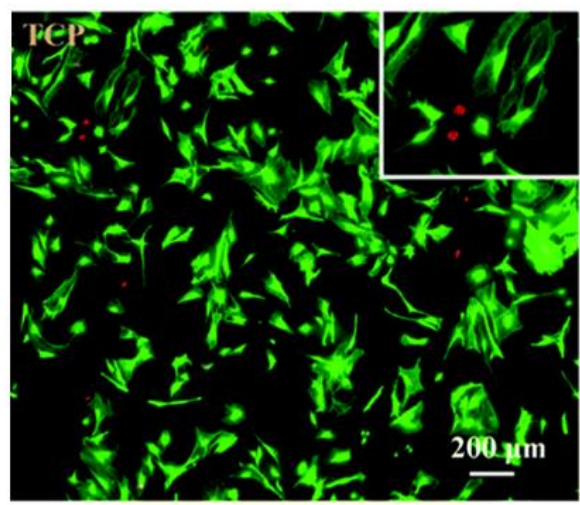

Fig. 2. Typical 3DGCSs and their application for bone tissue engineering. (A) Cross-section SEM image of 3D graphene $(0.78$ wt. \%) /PCL scaffold fabricated via 3D printing method with $\mathrm{NaOH}$ treatment [40]. (B) Confocal image of cells on the 3D printed graphene/PCL scaffold after 28 days culture [40]. (C) SEM image of 3D RGO/PDMS scaffold fabricated via template based method [43]. (D) Fluorescence microscope image of cells cultured on 3D RGO/PDMS scaffold following 10 days culture [43]. (E) SEM image of 3D graphene scaffold with citrate-stabilized HA nanoparticles (RGO/HA scaffold) fabricated via self-assembly method [48]. (F) Fluorescence microscope images of cells cultured on 3D RGO/HA scaffold following 2 days culture [48]. 


\subsection{Cartilage tissue engineering}

Articular cartilage is susceptible to damage through trauma and has poor reparative capability, especially when the avascular structure inside limits its self-healing process [68]. Tissue engineering, especially using 3DGCS, shows promise to tackle these challenges in cartilage regeneration. Applications of 3DGCS towards cartilage tissue engineering are summarized in Table 2. 
Table 2 Applications of 3DGCS towards cartilage tissue engineering

\begin{tabular}{|c|c|c|c|c|}
\hline Scaffold composition & $\begin{array}{l}\text { Fabrication } \\
\text { method }\end{array}$ & Cell source & Effect & Reference \\
\hline $\begin{array}{c}\text { Gelatin methacrylate } \\
\text { (GelMA)/Poly(ethylene glycol) } \\
\text { diacrylate (PEGDA)/GO }\end{array}$ & $3 \mathrm{D}$ printing & hMSCs & $\begin{array}{l}\text { Promotion of glycosaminoglycan, } \\
\text { collagen levels and chondrogenesis }\end{array}$ & [69] \\
\hline Collagen/CHI/GO & $3 \mathrm{D}$ printing & $\begin{array}{c}\text { Human } \\
\text { chondrocytes }\end{array}$ & $\begin{array}{l}\text { Drug carrier and regulation of } \\
\text { Rank/Rank1/OPG pathway }\end{array}$ & {$[70]$} \\
\hline PCL/Graphene & $\begin{array}{l}\text { CVD and dip } \\
\text { coating (template } \\
\text { assembly) }\end{array}$ & hMSCs & $\begin{array}{c}\text { Increased mechanical property to } \\
\text { withstand loads from the de novo tissues } \\
\text { and encourage secretion of aggrecan and } \\
\text { type II collagen }\end{array}$ & [71] \\
\hline $\begin{array}{l}\text { CHI/Hyaluronic acid } \\
\text { (HYA)/GO }\end{array}$ & $\begin{array}{l}\text { Lyophilization } \\
\text { (self-assembly) }\end{array}$ & $\begin{array}{l}\text { Mouse fibroblast } \\
\text { cell line (NIH-3T3 } \\
\text { cell) }\end{array}$ & $\begin{array}{l}\text { Preferred biodegradability, enhanced cell } \\
\text { attachment and proliferation }\end{array}$ & {$[72]$} \\
\hline GO, porous GO and graphene & Self-assembly & MSCs & Enhanced chondrogenic differentiation & [73] \\
\hline GO & $\begin{array}{l}\text { Hanging-drop } \\
\text { (self-assembly) }\end{array}$ & ADSCs & $\begin{array}{l}\text { Accumulation of bioactive molecules and } \\
\text { promotion of interaction between cell and } \\
\text { bioactive molecules }\end{array}$ & {$[74]$} \\
\hline $\begin{array}{c}\text { Methacrylated chondroitin } \\
\text { sulfate (CSMA)/ Poly(ethylene } \\
\text { glycol) methyl ether- } \varepsilon^{-}\end{array}$ & $\begin{array}{l}\text { Free radical and } \\
\text { freeze-dried }\end{array}$ & $3 \mathrm{~T} 3$ cells & Enhanced chondral formation & {$[75]$} \\
\hline
\end{tabular}




\begin{tabular}{cccc}
\hline $\begin{array}{c}\text { caprolactone-acryloyl chloride } \\
\text { (PECA)/GO }\end{array}$ & $\begin{array}{c}\text { method (self- } \\
\text { assembly) }\end{array}$ & \\
\hline GO/Alg & $\begin{array}{c}\text { Crosslinking } \\
\text { (self-assembly) }\end{array}$ & NIH-3T3 & $\begin{array}{c}\text { Improvement of cell viability and } \\
\text { comparable stiffness to articular tissue }\end{array}$ \\
\hline
\end{tabular}


GO doped gelatin methacrylate (GelMA)-poly(ethylene glycol) diacrylate (PEGDA) composition could be applied towards hierarchical structure fabrication via a 3D printing technique [69]. Several chondrogenesis associated genes and proteins of hMSCs were greatly promoted by the fabricated 3DGCS [69] (Fig. 3a-b). Incorporation of GO within hydrogel can enhance its mechanical property and bioactivity, which is important to trigger cellular activity [76].

In comparison, 3D graphene foam fabricated by a CVD method has fewer defects, high porosity, and extraordinary surface area to volume ratio, but it doesn't have sufficient mechanical strength. PCL can be applied to reinforce the 3D graphene foam via a dip-coating method, and the synthesized 3D graphene/PCL foam can support hMSC proliferation and chondrogenic differentiation [71] (Fig. 3cd).

Cartilage regeneration relevant growth factors can be accumulated on the graphene structure due to their specific physicochemical interactions, and then accelerate and induce formation and maturation of chondrogenic tissues [73]. 3D ADSC pellet encapsulated within GO showed enhanced chondrogenic differentiation because of the dual roles of GO, which can adsorb bioactive molecules and induce stem cells towards chondrogenesis simultaneously [74]. In addition, GO nanoparticles can also serve as conditioners that modulate the tissue microenviroment through signalling pathway regulation [70]. GO nanoparticles were employed as both drug delivery vehicles and Rank/Rankl/OPG signal pathway regulation in 3D printed Collagen/CHI/GO scaffold, whereby cartilage can be potentially protected and regenerated [70]. 3D graphene network in the solution state is also applicable for cartilage regeneration. 3D graphene and MSC composites were prepared by incubation-centrifugation and used to preconcentrate growth factors for chondrogenesis. A positive correlation between the graphene concentration and chondrogenic differentiation was demonstrated under threshold concentration [73].

Chondroitin sulfate (CS) and PCL are shown to have a positive effect on cartilage repair by supporting chondrocytes proliferation and differentiation [77, 78]. Methacrylated CS (CSMA) can be prepared 
to improve the controllability and mechanical property of CS through the addition of methacrylate and aldehyde groups on the CS backbone [75]. To improve the hydrophobicity and biodegradation of PCL, it was integrated into methoxyl poly(ethylene glycol)-poly( $\varepsilon$-caprolactone)-acryloyl chloride (PECA) through UV-initiated free radical polymerization [79]. Liao et.al. have synthesized 3D CSMA/PECA/GO hybrid scaffold with highly microporous interconnective morphology to support cartilage regeneration both in vitro and in vivo [75] (Fig. 3e-f). Addition of GO into the composite improved its mechanical property and provided extra electrical and topographical cues for cartilage regeneration.

Negatively charged hyaluronic acid (HYA) is a component in the EMC of cartilage and skin. In combination with cationic CHI, the ability for HYA to support cell attachment can be promoted [80]. Furthermore, 3D porous scaffold with optimized swelling ratio, porosity and degradation properties can be synthesized via addition of GO into the HYA/CHI composition [72]. NIH-3T3 cells showed improved proliferation and morphology on the as-fabricated 3D HYA/CHI/GO scaffold than HYA/CHI scaffold. 

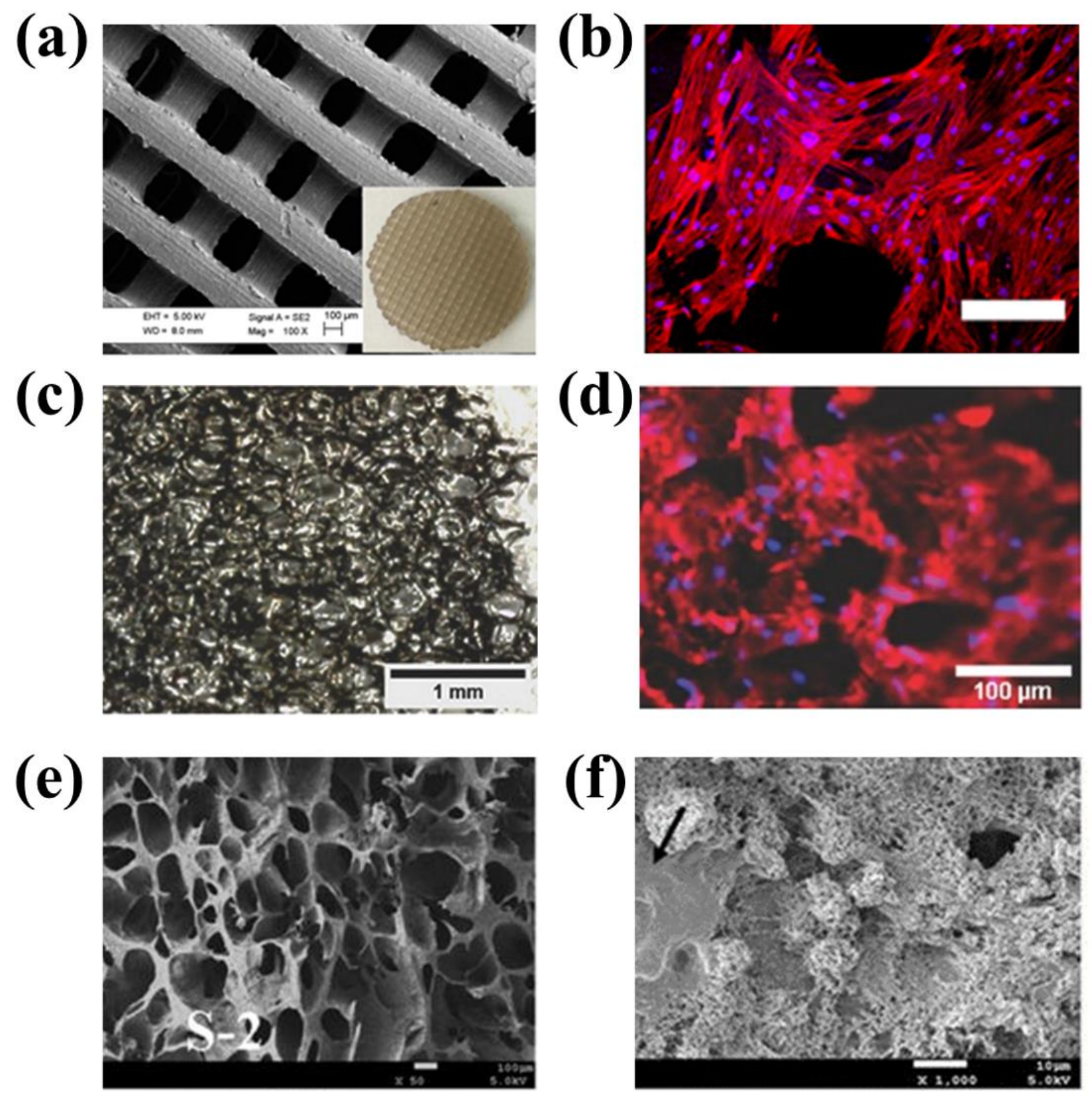

Fig. 3. Typical 3DGCSs and their application for cartilage tissue engineering. (A) SEM image of GelMA-PEGDA scaffold with GO $(0.1 \mathrm{mg} / \mathrm{mL})$ [69]. (B) Fluorescence microscope image of cells cultured on GelMA-PEGDA scaffolds incorporated with $0.10 \mathrm{mg} / \mathrm{mL}$ concentration of GO following 5 days culture $($ Scale bar $=200 \mu \mathrm{m})$ [69]. (C) Optical image of 3D graphene/PCL hybrid scaffold [71] .

(D) Fluorescence microscope image of Type II collagen expressed on graphene foam scaffold [71].

(E) SEM image of cross-section of CSMA/PECA/Graphene porous hybrid scaffold (Scale bar = $100 \mu \mathrm{m}$ ) [75]. (F) SEM image of chondrocytes incubated on the surface of CSMA/PECA/GO scaffold after culturing for 2 days [75]. 
2.3. Neural tissue engineering

3DGCS can not only provide biomimetic niches for cells to dwell or resemble body counterparts, but also afford charge transport pathways to stimulate neural cell functionalities through its conductive property [81]. The 3D bioelectronics interface provided by a CVD synthesized graphene porous scaffold can keep neural stem cells (NSCs) at a more active proliferation state with enhanced differentiation towards astrocyte and neuron compared with 2D graphene film [81]. Applications of 3DGCS towards neural tissue engineering are summarized in Table 3. 
Table 3 Applications of 3DGCS towards neural tissue engineering

\begin{tabular}{|c|c|c|c|c|}
\hline Scaffold composition & Fabrication method & Cell source & Effect & Reference \\
\hline $\begin{array}{l}\text { Polydopamine (PDA)/ } \\
\text { Arginylglycylaspartic } \\
\text { acid } \\
\text { (RGD)/Graphene/PCL }\end{array}$ & $\begin{array}{l}\text { 3D printing and layer- } \\
\text { by-layer casting } \\
\text { (template assembly) }\end{array}$ & Schwann cell (RSC) & $\begin{array}{c}\text { Promotion of axonal regeneration and } \\
\text { remyelination }\end{array}$ & {$[82]$} \\
\hline Graphene/PLG & $3 \mathrm{D}$ printing & hMSCs & $\begin{array}{l}\text { Upregulation of neurogenic gene expression, and } \\
\text { feasible for intraoperative surgical procedures, } \\
\text { such as bundle wrapping. }\end{array}$ & {$[83]$} \\
\hline HA/Graphene & $3 \mathrm{D}$ printing & hMSCs & Upregulation of neurogenic gene expression & {$[42]$} \\
\hline GO/PCL & $\begin{array}{l}\text { Molding and 3D } \\
\text { printing }\end{array}$ & RSC & $\begin{array}{l}\text { Promotion of cell attachment, proliferation, } \\
\text { neural property maintenance in vitro; Promotion } \\
\text { of nerve regeneration process and pro- } \\
\text { angiogenic in vivo. }\end{array}$ & {$[84]$} \\
\hline Graphene & $\begin{array}{l}\text { CVD (template } \\
\text { assembly) }\end{array}$ & Neural stem cells (NSCs) & $\begin{array}{l}\text { Improved cell proliferation and differentiation } \\
\text { towards astrocytes and neurons, while stiff 3D } \\
\text { graphene scaffolds showed superior effect }\end{array}$ & {$[81,85]$} \\
\hline Graphene & $\begin{array}{l}\text { CVD (template } \\
\text { assembly) }\end{array}$ & $\begin{array}{c}\text { Patient-induced pluripotent } \\
\text { stem cell (iPSC) derived neural } \\
\text { progenitor cell (NPC) }\end{array}$ & $\begin{array}{c}\text { Capable of delivering 3D electrical stimulation } \\
\text { to assist maturation of (Rett syndrome) RTT } \\
\text { NPCs cells }\end{array}$ & {$[86]$} \\
\hline
\end{tabular}




\begin{tabular}{|c|c|c|c|c|}
\hline Graphene/HA & $\begin{array}{c}\text { CVD and } \\
\text { electrodeposition } \\
\text { (template assembly) }\end{array}$ & MC3T3-E1 cells & & [87] \\
\hline PCL/GO & $\begin{array}{l}\text { Electrospinning and } \\
\text { coating (template } \\
\text { assembly) }\end{array}$ & NSCs & $\begin{array}{l}\text { Promotion for differentiation into mature } \\
\text { oligodendrocytes }\end{array}$ & [88] \\
\hline $\begin{array}{l}\text { RGO/Porcine acellular } \\
\text { dermal matrix (PADM) }\end{array}$ & $\begin{array}{l}\text { Solution immersion } \\
\text { process (template } \\
\text { assembly) }\end{array}$ & $\begin{array}{c}\text { Rat bone-marrow-derived } \\
\text { mesenchymal stem cells } \\
\text { (rMSCs) }\end{array}$ & $\begin{array}{l}\text { Maintaining active proliferation and promoting } \\
\text { neurite sprouting and outgrowth }\end{array}$ & [89] \\
\hline $\begin{array}{l}\text { Graphene-heparin/Poly- } \\
\text { L-lysine (PLL)/PCL }\end{array}$ & $\begin{array}{c}\text { Layer-by-Layer (LbL) } \\
\text { deposition/ } \\
\text { Electrospinning } \\
\text { (template assembly) }\end{array}$ & Primary cortical neurons & Improved cell attachment and spreading & [90] \\
\hline $\begin{array}{l}\text { Laminin/GO/PET } \\
\text { glasses }\end{array}$ & $\begin{array}{l}\text { Sedimentation }+ \\
\text { rolling (template } \\
\text { assembly }+ \text { self- } \\
\text { assembly) }\end{array}$ & $\begin{array}{l}\text { Human neural stem cells } \\
\text { (hNSCs) }\end{array}$ & $\begin{array}{l}\text { Promotion of proliferation and differentiation } \\
\text { towards neurons. }\end{array}$ & [91] \\
\hline GO & $\begin{array}{c}\text { Ice segregation- } \\
\text { induced self-assembly } \\
\text { (ISISA) technique and } \\
\text { lyophilisation (self- } \\
\text { assembly) }\end{array}$ & $\begin{array}{l}\text { Embryonic neural progenitor } \\
\text { cells (ENPCs) }\end{array}$ & $\begin{array}{l}\text { Promotion of the formation of highly viable and } \\
\text { interconnected neural networks. }\end{array}$ & [92] \\
\hline
\end{tabular}


Chemical crosslinking and freeze drying (self-assembly)
Supporting hippocampal neurons and astrocytes development, improved synaptic networks. 
Due to the inherent neuronal-inducing capability of graphene, 3D graphene/PLG scaffold printed by Jakus et al. can significantly stimulate upregulation of glial and neuronal genes upregulation of hMSCs without additional neurogenic stimuli [83]. Alongside excellent biocompatibility of the scaffolds in vivo, feasibility of intraoperative procedure was also illustrated by implanting the scaffold into a human cadaver nerve model. The same group also developed a variety of $3 \mathrm{D}$ printable HA/Graphene composite inks, and neurogenic genes expression of hMSCs was significantly improved by the 3D printed HA/Graphene structures [42]. Besides MSCs, addition of graphene into polyacrylamide (PAM) hydrogel was proven to be capable of supporting brain cells: hippocampal neurons and astrocytes development, while keeping synaptic networks active [93].

Polydopamine (PDA) and arginylglycylaspartic acid (RGD) can be used for cell adhesion improvement in tissue engineering, both of which were incorporated with graphene and PCL by Yuan`s group to manufacture multi-layered porous scaffold through a combination of 3D printing and layer-by-layer (LBLC) casting methods [82]. Neural expression can be enhanced by the scaffold both in vivo and in vitro, with promotion of axonal regeneration and remyelination. 3D GO/PCL conduit fabricated by Yuan`s group was pro-angiogenic and supported $15 \mathrm{~mm}$ sciatic nerve defect regeneration in vivo efficiently [84]. These 3DGCSs are promising for peripheral nerve regeneration application.

Cell adhesion, proliferation and differentiation can be influenced by scaffold mechanical strength. Stiff 3D graphene scaffolds fabricated with extruded Ni substrate via CVD method can enhance NSC attachment and proliferation with up-regulated neural regeneration associated genes [85] compared with previously reported soft 3D graphene scaffold [81].

Electrospun nanofiber scaffolds can mimic in vivo ECM with high porosity and surface to volume ratio. 3DGCS fabricated by coating GO onto electrospun PCL construct can guide NSC differentiation into oligodendrocyte with significantly higher biomarker expression compared with 2D graphene and pristine 3D PCL substrates (Fig. 4a-b) [88]. 3D cylindrical GO scaffold fabricated 
by rolling up laminin functionalized GO/PET glasses can guide human neural stem cell (hNSC) proliferation and differentiation along the structure`s main axis (Fig. 4c-d) [91]. After applying ES via the 3D scaffold, hNSC proliferation and differentiation to neurons were promoted significantly. In another study, embryonic neural progenitor cells (ENPCs) remained highly viable on flexible, porous 3DGCSs fabricated by a freeze-casting method [92]. Additionally, the 3DGCS can also support ENPC differentiation, with interconnected neural networks with abundant dendrites.

Heparin can form nano-layers with the assistance of poly-L-lysine (PLL), and it has effective antiinflammatory effects. 3DGCS fabricated by assembling graphene-heparin/PLL onto 3D electrospun nanofibers via layer-by-layer deposition method can support neuron cell adhesion and neurite outgrowth [90].

Porcine skin derived porcine acellular dermal matrix (PADM) composed of collagen shows good biocompatibility, tuneable biodegradability and porosity. It was incorporated with RGO to gain electrical conductivity towards neural tissue engineering by assembling RGO on the surface of 3D porous PADM [89]. The as-fabricated 3D RGO/PADM scaffold can maintain rat bone-marrowderived mesenchymal stem cells (rMSCs) in an active proliferation and neurogenic differentiation state, whilst at the same time promoting sprouting and outgrowth of neurites efficiently. 


\section{(a)}

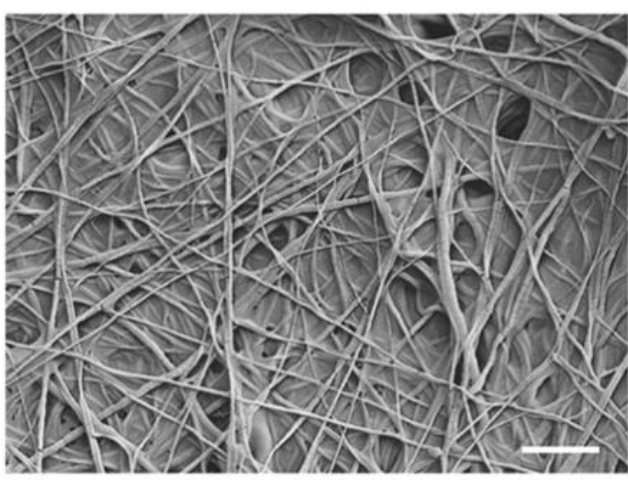

\section{(b)}

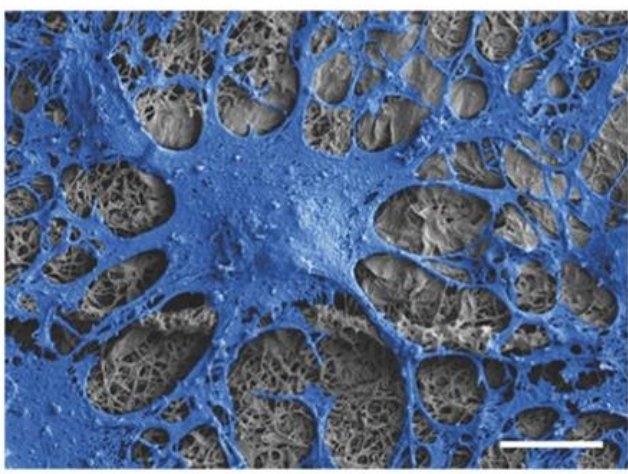

(c)
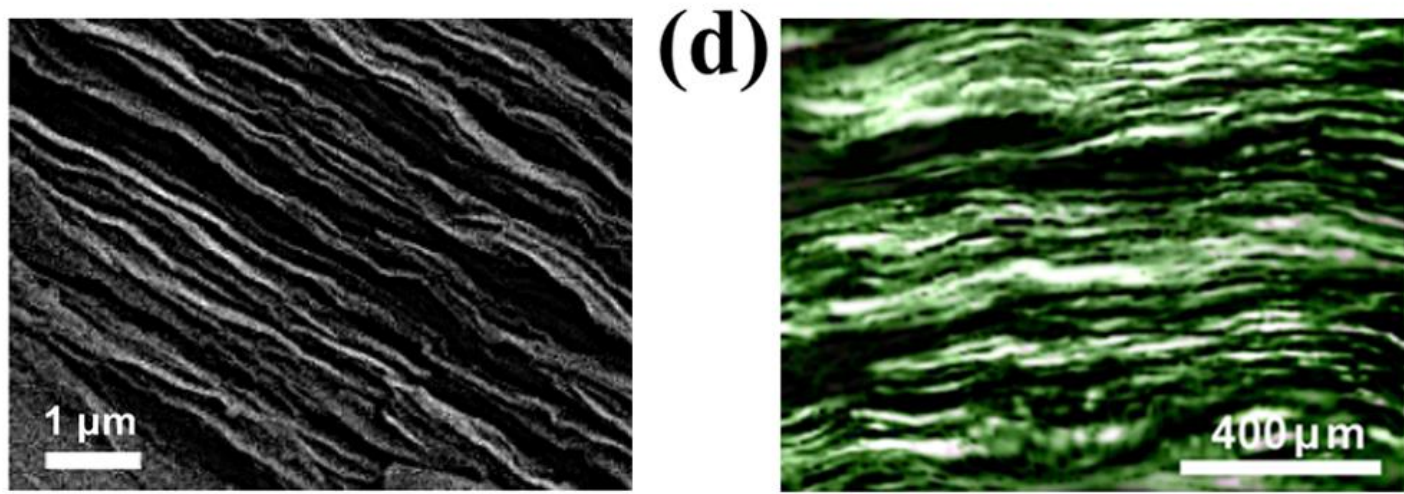

Fig. 4. Typical 3DGCSs employed for neural tissue engineering. (A) SEM image of 3D PCL nanofiber scaffolds coated with GO $(1.0 \mathrm{mg} / \mathrm{mL}$, scale bar: $2 \mu \mathrm{m})$ [88]. (B) SEM image of differentiated NSCs cultured on 3D GO/PCL scaffold after 6 days (scale bar: $10 \mu \mathrm{m}$ ) [88]. (C) SEM image of cross-section of a rolled 3D GO foam [91]. (D) Fluorescence image of hNSCs on crosssection of rolled 3D GO foam [91].

\subsection{Skin tissue engineering and wound healing}

As the largest organ of the body and exposed to environmental damage, skin is vulnerable to surrounding hazard and an obvious application for tissue engineering. Engineering skin involves a complicated and systematic process; with several cell types and biological processes. 3D graphenebased skin tissue engineering represents an approach with significant potential for reconstructing skin substitutes.

Poly(lactic acid) (PLA) and thermoplastic polyurethane (TPU) are two widely used biocompatible 
materials, where blending of both materials can render a composite with shape memory property, improved impact resistance and mechanical strength [94]. Addition of GO into the composite can further improve a range of properties, and the obtained TPU/PLA/GO blend is 3D printable with various GO loading ratios [95] (Fig. 5a). NIH/3T3 fibroblast cells showed excellent cell viability and improved proliferation on the 3D printed GO/PLA/TPU scaffold (Fig. 5b).

3DGCS fabricated by doping graphene in electrospun CHI/poly(vinyl alcohol) (PVA) nanofibers can benefit wound healing, where graphene also served as an anti-bacterial agent [96].
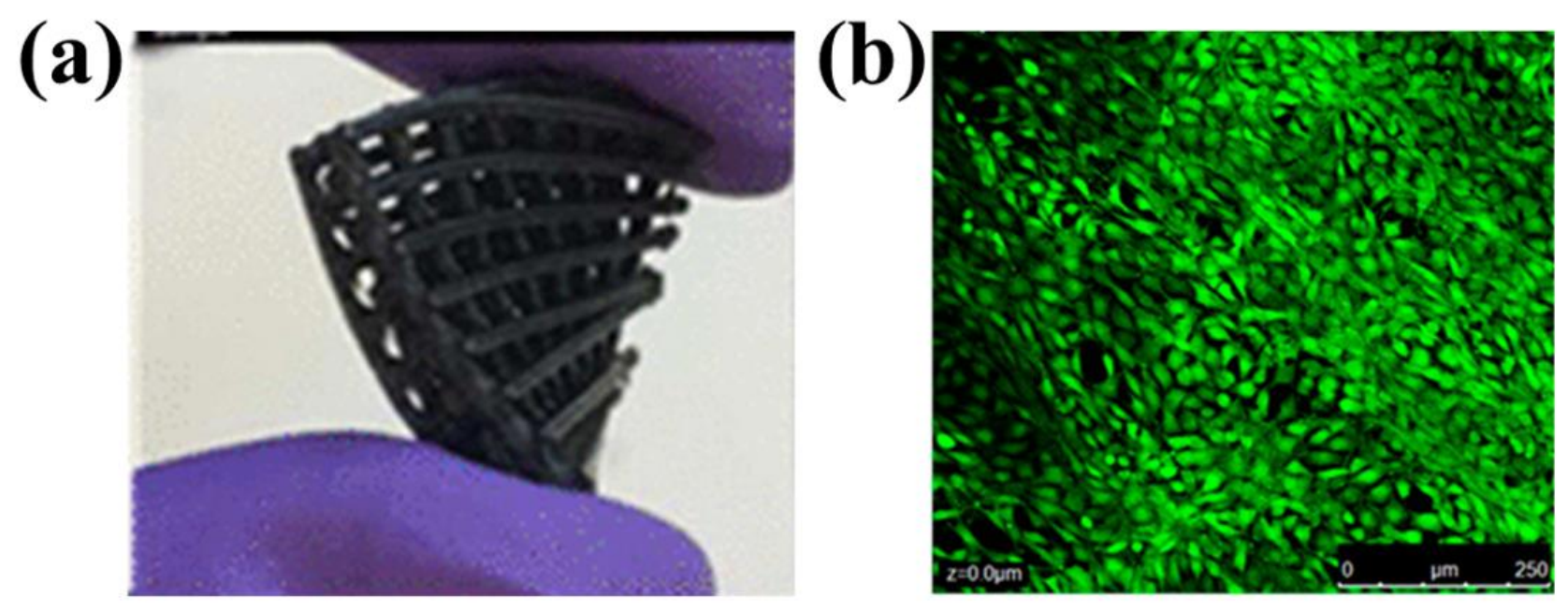

Fig. 5. Typical 3DGCS and their application for skin tissue engineering and wound healing. (A) 3D printed scaffold from TPU/PLA/GO composites, (B) Fluorescence image of NIH3T3 cells on 3D printed TPU/PLA with 0.5 wt \% GO loading after $96 \mathrm{~h}$ cell culture. Green colour indicates live cells, whereas red colour indicates dead cell [95].

\subsection{Cardiac tissue engineering}

Cardiac diseases, including stroke, arrhythmia, and high blood pressure are leading causes of death globally, partially fuelled by the intrinsic inability of cardiac tissues to regenerate. Cardiac tissue engineering is challenging partly due to the difficulty with reproducing sophisticated cardiac tissue architecture and function, besides supporting transplanted cells growth and vascularization [97]. Traditional materials can`t meet these requirements, lacking electrical conductivity and appropriate 
mechanical properties, which are two essential requirements for cardiac tissue engineering. Addition of graphene to traditional biomaterials can significantly enhance mechanical and electrical properties of host materials, consequently appealing for cardiac tissue engineering. 3DGCS fabricated by using GO/GelMA hybrid hydrogel as a substrate and PLL/GO as a stacking layer via layer-bylayer (LbL) have been used as synthetic cardiac scaffold (Fig. 6a) [31]. This 3D multilayer construct can encapsulate and support human MSC, endothelial cell and cardiomyocyte growth with high cell viability, elongation and proliferation (Fig. 6b-c). The embedded GO supported faster cell attachment, spreading and elongation compared to scaffolds without GO or with other carbon materials.

Poly(ethylene glycol) (PEG), as a biocompatible oligomer, can generate hydrogel via hydrogen bond forming between oxygen containing groups from different molecules. 3D GO mesh scaffold can be manufactured by mixing of GO and PEG through a salt-leaching method, while vascular endothelial cells and perivascular fibroblasts grown on the scaffold showed similar morphology with their in vivo counterparts [98].

Without other materials, mere graphene can also be fabricated into 3D foam that is not only supportive of cardiac cell growth, but also presents in-situ electrical recording capability [99]. Cardiac cells were placed spatially within a more uniform electric field strength distribution, and their extracellular potential could be monitored simultaneously through the scaffold. 

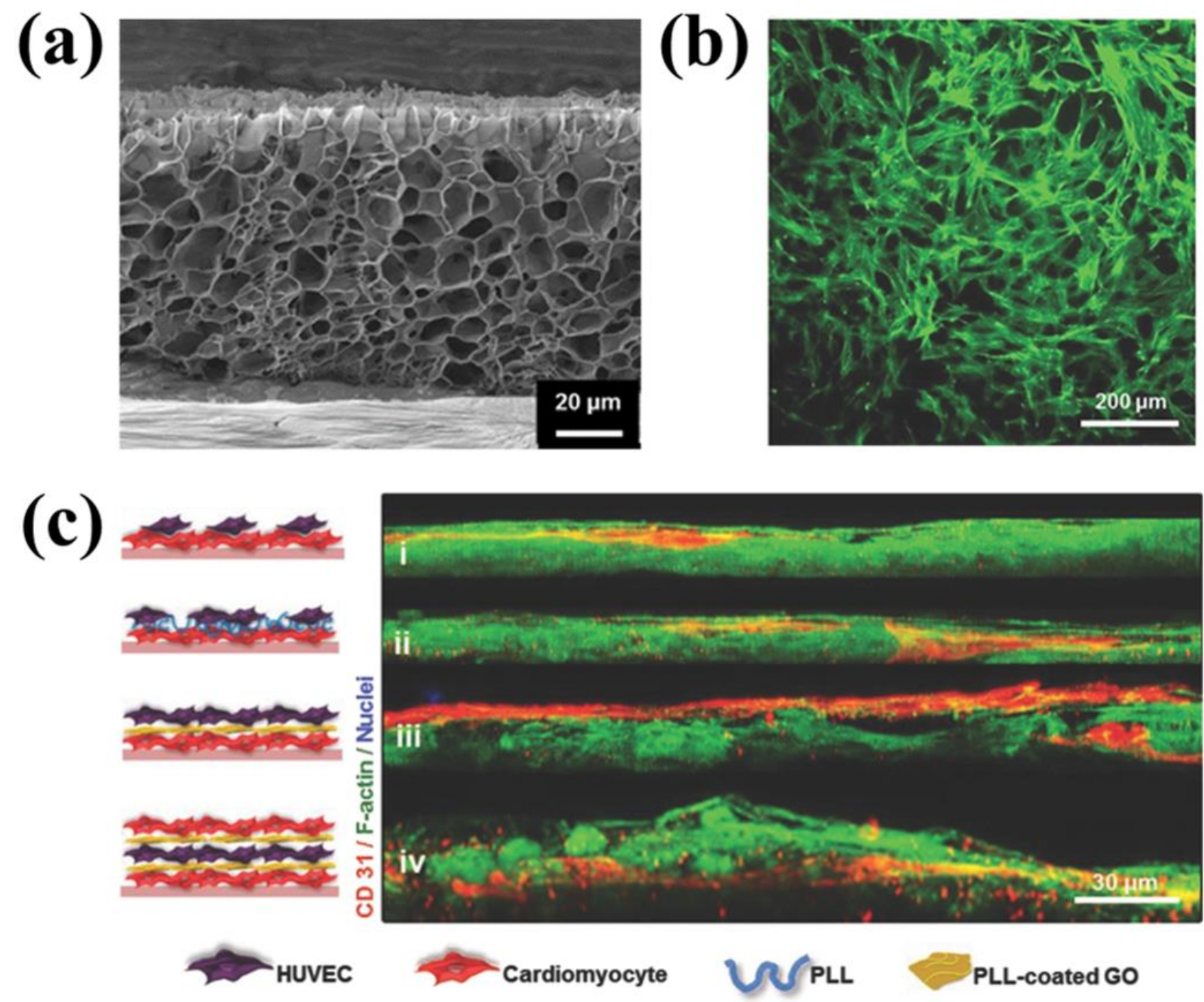

PLL-coated GO

Fig. 6. Typical 3DGCSs used for cardiac tissue engineering. (A) Cross-sectional SEM image of GO/GelMA hydrogel substrate $(1.0 \mathrm{mg} / \mathrm{mL})$. (B) Fluorescence image of cultured hMSCs with deposition of PLL/GO particles. (C) Schematic illustration of layered cellular structures (left) and 3D reconstructed confocal fluorescence cross-sectional image of the layered structure (right) [31].

\subsection{Adipogenic tissue engineering}

As an ubiquitous tissue throughout the human body, adipogenic tissue is crucial in thermoregulation, energy storage, and physical buffering [100]. Reconstruction of adipogenic tissue usually involves autologous tissue transplantation from other body sites, but the transplanted tissue may suffer from insufficient angiogenesis, limited proliferation capability or infections [101]. Graphene can act as a 
preconcentration platform for insulin, which is an adipogenic differentiation inducer, to guide stem cells toward adipogenic differentiation [38]. So 3DGCS is able to serve as both three-dimensional cell supporting and adipogenic differentiation inducing platforms for stem cell towards adipogenic tissue engineering.

3D GO constructs, fabricated by suspending GO in poly(ethylene glycol)-poly(L-alanine) (PEG-PA) thermogel, are capable of promoting entrapped tonsil-derived mesenchymal stem cells (TMSCs) towards adipogenic differentiation [101]. This 3DGCS was achieved via sol-to-gel transition controlled by temperature, which is amenable for cell and biofactor encapsulation.

\subsection{Other tissue engineering}

Although 3DGCSs are increasingly being applied for the above mentioned tissues/organs, they still have potential for wider application in other related tissue engineering fields.

Collagen, as a widely used bioactive material, can be coated onto oxygen plasma treated 3D graphene scaffolds, able to support liver cell (HepG2) growth with low lactate production [102]. This 3DGCS can also serve as an excellent oxygenation platform with high cell viability. Graphene has also been incorporated with alginate to form a 3D macroporous scaffold that is able to slowly release antigens [103]. Addition of graphene can not only improve mechanical property of the scaffold, but also play an important role in the high loading and controlled releasing of antigens because of a large hydrophobic surface area. Both in vitro and in vivo experiments revealed that the $3 \mathrm{D}$ graphene/alginate scaffold can also serve as efficient multi-functional immunotherapy platform, casting light on future implantable device development.

Sitharaman et al. have reported a scalable process for 3DGCS fabrication [104]. In this method, 3D graphene scaffold was fabricated through single/multi-walled graphene oxide nanoribbon radical initiated thermal crosslinking, and can facilitate human ADSCs and murine MC3T3 preosteoblast cells proliferation with active metabolism [104]. 
Besides being the physical support for various tissue engineering applications, 3DGCS can also be applied for in-situ monitoring differentiation and pluripotency of stem cells [105].

Alongside with new fabrication techniques towards development of 3DGCS, other avenues will be explored in regard to efficient tissue engineering and relevant biosensing applications.

\subsection{Preference of 3DGCSs for tissue engineering}

Graphene, as the main component of 3DGCSs, can possess adverse effects on biosystems when the preparation process involves toxic agents or materials, such as widely used reducing agents: hydrazine, hydriodic acid and sodium borohydride [106]. The residual contamination and impurities should be removed completely before the synthesized graphene can be further processed, while biocompatible agents and materials can serve as safe alternatives to their toxic counterparts. Examples of the latter include ascorbic acid, amino acids, and microorganisms [107]. It`s also noteworthy that widely used metal templates in CVD method may cause cell damage and apoptosis when not completely eliminated [106, 108]. To ensure the bio-safety of 3DGCSs, graphene synthesis should be facile and "green" with efficient purification process.

3D structures are widely used in tissue engineering to better recapitulate natural ECM and provide support for neo-tissue generation. First of all, the 3D structure needs to be porous with interconnected pore networks to allow easy transportation of nutrition and removal of waste. Secondly, in order to imitate complexity of native matrix to reach the maximized performance, the $3 \mathrm{D}$ structure should have graded porosity as observed in native human tissues (e.g. skin and bone), which has proven beneficial for angiogenesis and specific cell migration [109]. Thirdly, a scaffold needs to be pliable with appropriate mechanical strength to fit into the surgical site, especially when the site is complicated and vulnerable.

\section{Fabrication}

The majority of methods devised for fabricating 3DGSCs involve graphene synthesized by chemical 
method. Importantly, a chosen fabrication strategy will impact the performance and clinical approvability and utility of a construct. In this section, principle fabrication strategies and resulting 3DGCSs are summarized and discussed.

\subsection{D printing}

3D printing involves the translation of computer-aided designs into three dimensional objects. This technique can be applied to fabricate 3D structures based on blueprints obtained from either computer 3D drawing programmes or digital data obtained using a 3D scanner. 3D printing enables scalable fabrication of complex graphene containing structures with controllable architecture. Especially for tissue engineering, 3D printed 3DGCSs hold potential to recapitulate intricate architecture, composition and properties of native human tissues or organs with the informative data provided by magnetic resonance imaging (MRI) and computed tomography (CT) technology. For graphene-based materials, extrusion based 3D printing is the most widely used technique, whereby successive layers of materials are deposited vertically to the previously $2 \mathrm{D}$ printed structure to generate true $3 \mathrm{D}$ objects (Fig. 7a-f). The inks comprise the graphene/graphene oxide material and usually a host polymer or other additives that serve as rheological modifier and/or binders to provide mechanical integrity to the printed structure. A summary of graphene-based ink composition, 3D printing parameters and 3D printed graphene scaffold properties are illustrated in Table 4. 
Table 4 Summary of graphene-based ink compositions, 3D printing parameters and 3D printed 3DGCS properties.

\begin{tabular}{|c|c|c|c|c|c|c|c|c|}
\hline \multirow{2}{*}{$\begin{array}{c}\text { Ink composition (Extrusion } \\
\text { based)/Substrate (Laser based) }\end{array}$} & \multicolumn{5}{|c|}{ Printing parameters } & \multirow{2}{*}{$\begin{array}{l}\text { Electrical } \\
\text { property }\end{array}$} & \multirow{2}{*}{$\begin{array}{c}\text { Mechanical } \\
\text { property }\end{array}$} & \multirow{2}{*}{$\begin{array}{c}\text { Referenc } \\
\text { e }\end{array}$} \\
\hline & Printer & Temperature & Pressure & Speed & Resolution & & & \\
\hline $\begin{array}{c}\text { Reduced graphene oxide } \\
\text { (RGO)/Polylactic acid (PLA) }\end{array}$ & $\begin{array}{c}\text { Makerbot } \\
\text { Replicator 2, } \\
\text { USA }\end{array}$ & $210^{\circ} \mathrm{C}$ & & & $1.75 \mathrm{~mm}$ & $\begin{array}{c}4.76 \mathrm{~S} / \mathrm{cm} \\
(6 \mathrm{wt} \% \\
\mathrm{RGO})\end{array}$ & $\begin{array}{c}12.35 \mathrm{MPa} \\
\text { Young`s } \\
\text { modulus } \\
(6 \mathrm{wt} \% \\
\text { RGO) }\end{array}$ & {$[110]$} \\
\hline Graphene oxide (GO)/PLA & $\begin{array}{c}\text { Isun3d 230C } \\
\text { 3D Printer, } \\
\text { China }\end{array}$ & $195^{\circ} \mathrm{C}$ & & $\begin{array}{c}20 \\
\mathrm{~mm} / \mathrm{s}\end{array}$ & $0.4 \mathrm{~mm}$ & $\begin{array}{l}0.8 \Omega / \mathrm{cm} \\
(\mathrm{GO} / \mathrm{PLA} \\
\text { filament })\end{array}$ & $\begin{array}{l}18.6 \mathrm{MPa} \\
\text { (Tensile } \\
\text { strength) }\end{array}$ & {$[111]$} \\
\hline
\end{tabular}




\begin{tabular}{|c|c|c|c|c|c|c|c|c|}
\hline $\begin{array}{c}\text { Chemically converted graphene } \\
\text { (CCG)/ Methacrylated chitosan } \\
\text { (ChiMA) }\end{array}$ & $\begin{array}{c}\text { KIMM } \\
\text { SPS1000 } \\
\text { bioplotter, } \\
\text { Korea }\end{array}$ & $\begin{array}{c}\text { Room } \\
\text { temperature }\end{array}$ & $\begin{array}{c}1-100 \\
\text { psi }\end{array}$ & $\begin{array}{c}150 \mathrm{~mm} \\
/ \mathrm{min}\end{array}$ & $0.2 \mathrm{~mm}$ & $\begin{array}{l}0.25 \mathrm{~S} / \mathrm{m}(3 \\
\mathrm{wt} \% \mathrm{CCG})\end{array}$ & $\begin{array}{l}75 \mathrm{MPa} \\
(3 \mathrm{wt} \% \\
\mathrm{CCG})\end{array}$ & [113] \\
\hline $\begin{array}{c}\text { Graphene/ Acrylonitrile- } \\
\text { butadiene-styrene (ABS) } \\
\text { Graphene/PLA }\end{array}$ & $\begin{array}{l}\text { HOF1-X1 3D } \\
\text { printer, China }\end{array}$ & $230^{\circ} \mathrm{C}$ & & $\begin{array}{c}\sim 20 \mathrm{~m} \\
\mathrm{~m} / \mathrm{s}\end{array}$ & $\begin{array}{c}0.2-0.4 \\
\mathrm{~mm}\end{array}$ & $\begin{array}{c}5 \times 10^{-2} \mathrm{~S} / \mathrm{m} \\
(7 \mathrm{wt} \% \\
\mathrm{CCG})\end{array}$ & & [114] \\
\hline GO/Cu powders/Pluronic F127 & $\begin{array}{c}\text { RoboCAD 3.0, } \\
\text { UK }\end{array}$ & $\begin{array}{c}\text { Room } \\
\text { temperature }\end{array}$ & & $\begin{array}{l}6-12 \\
\mathrm{~mm} / \mathrm{s}\end{array}$ & $0.1-1 \mathrm{~mm}$ & $\begin{array}{c}90 \pm 20 \\
\mathrm{~S} / \mathrm{m}\end{array}$ & & {$[115]$} \\
\hline $\begin{array}{c}\text { Graphene (20-60 vol } \\
\%) / \text { Polylactide-co-glycolide } \\
\text { (PLG) }\end{array}$ & $\begin{array}{c}\text { EnvisionTEC } \\
\text { GmbH 3D } \\
\text { bioplotter, } \\
\text { Germany }\end{array}$ & $\begin{array}{c}\text { Room } \\
\text { temperature }\end{array}$ & $\begin{array}{l}0.5-5 \\
\text { Bar }\end{array}$ & $\begin{array}{l}10-45 \\
\mathrm{~mm} / \mathrm{s}\end{array}$ & $0.1-1 \mathrm{~mm}$ & $800 \mathrm{~S} / \mathrm{m}$ & $\begin{array}{c}3.0 \pm 0.4 \\
\mathrm{MPa} \\
\text { (intrinsic }\end{array}$ & {$[83]$} \\
\hline
\end{tabular}


modulus)

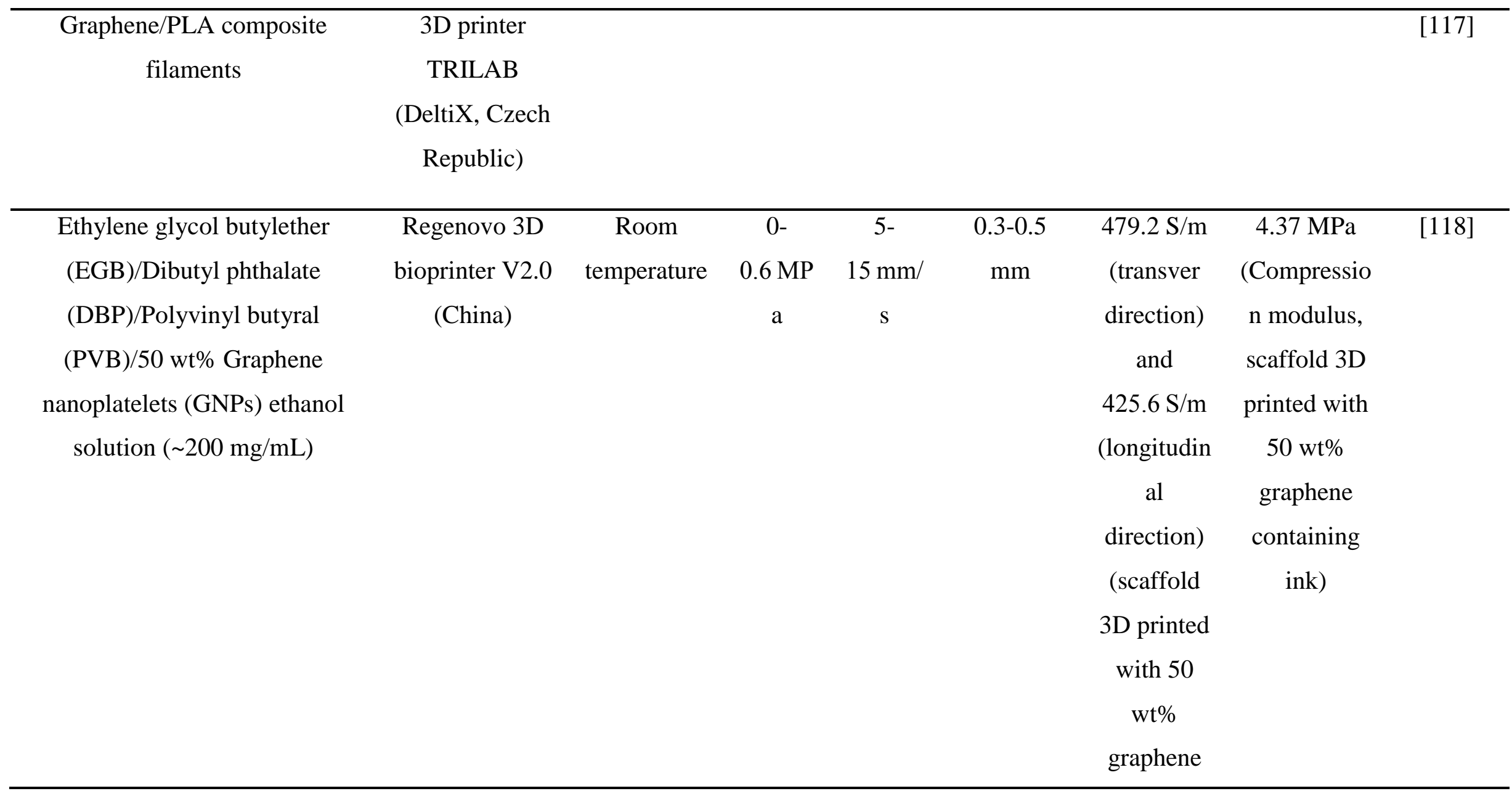




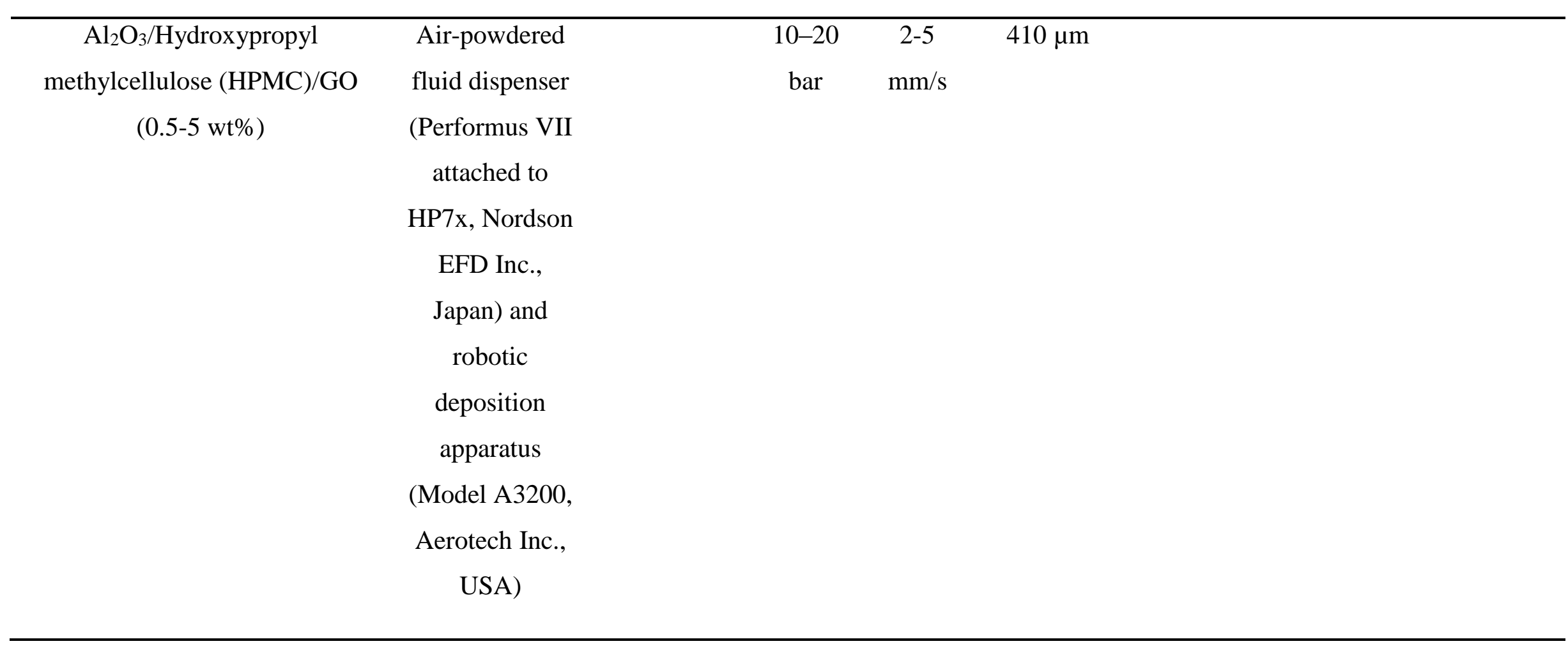




\begin{tabular}{|c|c|c|c|c|c|c|c|c|}
\hline $\begin{array}{l}\text { Hydroxyapatite (HA)/Graphene } \\
(20-60 \text { vol \%)/polylactide-co- } \\
\text { glycolide (85:15) } \\
\text { copolymer/dichloromethane/dibu } \\
\text { tyl phthalate }\end{array}$ & $\begin{array}{c}\text { EnvisionTEC } \\
\text { GmbH 3D } \\
\text { bioplotter, } \\
\text { Germany }\end{array}$ & $\begin{array}{c}\text { Room } \\
\text { temperature }\end{array}$ & $\begin{array}{c}0.5-5 \\
\text { bar }\end{array}$ & $\begin{array}{l}10-75 \\
\mathrm{~mm} / \mathrm{s}\end{array}$ & $0.1-1 \mathrm{~mm}$ & $\begin{array}{l}\sim 560 \mathrm{~S} / \mathrm{m} \\
\text { (40 vol \% } \\
\text { graphene } \\
\text { ink) }\end{array}$ & & {$[42]$} \\
\hline $\begin{array}{c}\text { GO/Fumed } \\
\text { silica/Resorcinol/Formaldehyde }\end{array}$ & $\begin{array}{c}\text { Air powered } \\
\text { fluid dispenser } \\
\text { (Ultimus V, } \\
\text { EFD) and three } \\
\text { axis positioning } \\
\text { stage (ABL } \\
\text { 9000, } \\
\text { Aerotech). }\end{array}$ & & & & $0.25 \mathrm{~mm}$ & $\begin{array}{c}278 \mathrm{~S} / \mathrm{m} \\
(40 \mathrm{mg} / \mathrm{mL} \\
\text { GO ink })\end{array}$ & $\begin{array}{c}0.12-1.6 \\
\mathrm{MPa}\end{array}$ & [119] \\
\hline GO aqueous solution $(1 \mathrm{~g} / \mathrm{L})$ & Home made & $\begin{array}{c}\text { Room } \\
\text { temperature }\end{array}$ & $\begin{array}{l}\text { Capillar } \\
\text { y force }\end{array}$ & $\begin{array}{c}1.2- \\
140.4 \\
\mu \mathrm{m} / \mathrm{s}\end{array}$ & $0.0013 \mathrm{~mm}$ & $11.3 \mathrm{~S} / \mathrm{cm}$ & & [120] \\
\hline
\end{tabular}




\begin{tabular}{|c|c|c|c|c|c|c|c|}
\hline $\begin{array}{c}\text { GO aqueous solution }(\sim 80 \\
\mathrm{mg} / \mathrm{mL}) \text { or with addition of } \\
\text { lithium iron phosphate (LFP) or } \\
\text { lithium titanium oxide (LTO) }\end{array}$ & $\begin{array}{c}\text { Air-powered } \\
\text { fluid dispenser } \\
\text { (DSP501N, } \\
\text { Fisnar) and } \\
\text { benchtop robot } \\
\text { (Fisnar F4200n) }\end{array}$ & $\begin{array}{c}\text { Room } \\
\text { temperature }\end{array}$ & $60 \mathrm{psi}$ & $\begin{array}{c}1-5 \\
\mathrm{~mm} / \mathrm{s}\end{array}$ & $0.3 \mathrm{~mm}$ & $\begin{array}{c}\text { 3-144 S/cm } \\
\text { (rGO, } \\
\text { thermally } \\
\text { reduced) } \\
31.6 \mathrm{~S} / \mathrm{cm} \\
(\mathrm{LFP} / \mathrm{rGO}) \\
\text { and } 6.1 \\
\mathrm{~S} / \mathrm{cm} \\
(\mathrm{LTO} / \mathrm{rGO}) \\
\text { (Thermal } \\
\text { treated) }\end{array}$ & $\begin{array}{l}{[121,} \\
122]\end{array}$ \\
\hline
\end{tabular}




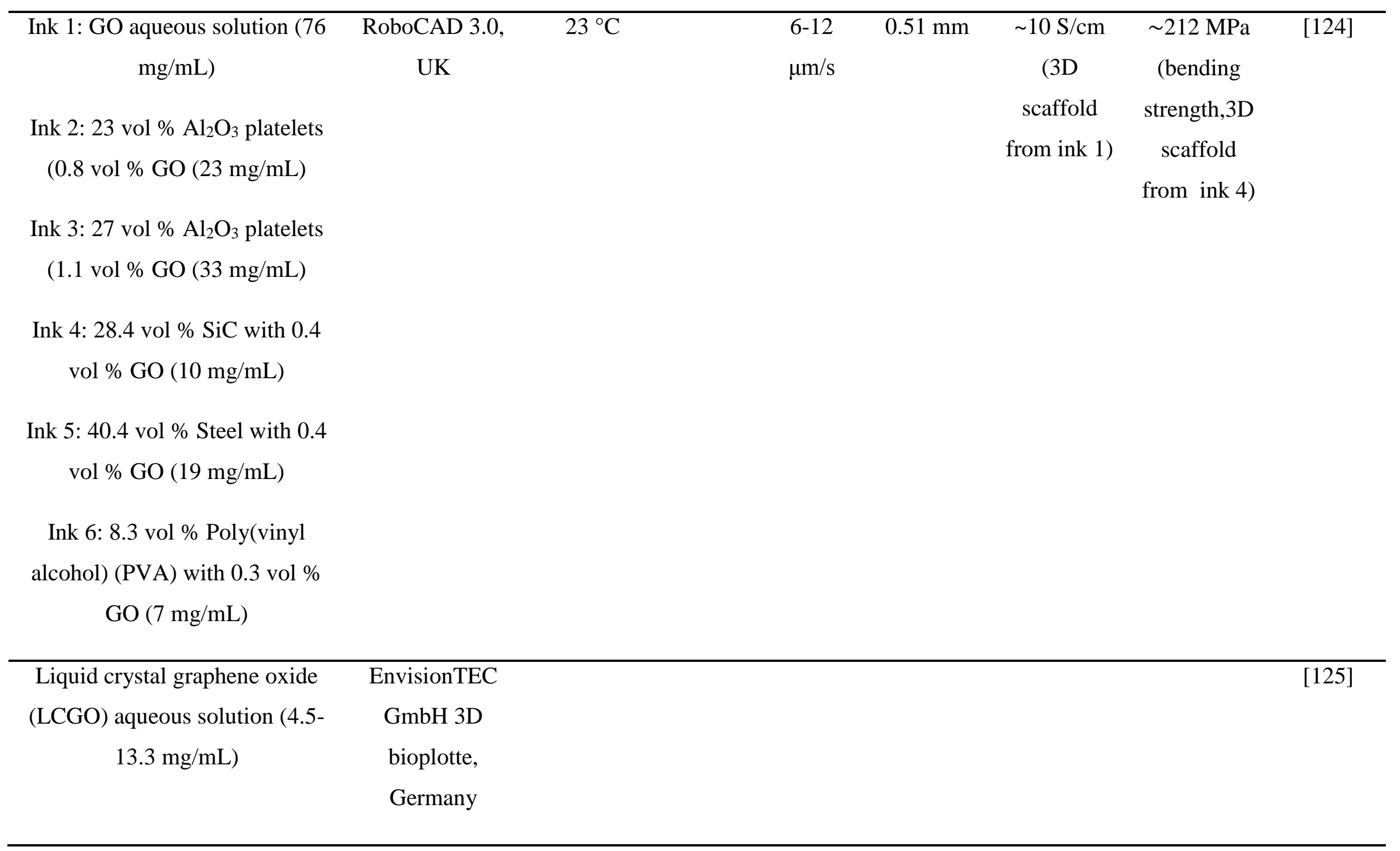




\begin{tabular}{|c|c|c|c|c|c|c|c|c|}
\hline $\begin{array}{c}\mathrm{GO} /(\text { Branched copolymer } \\
\text { surfactant }(\mathrm{BCS})+\text { Glucono- } \delta \text { - } \\
\text { lactone }(\mathrm{G} \delta \mathrm{L})(\mathrm{GO}: 1.75-3 \mathrm{wt} \%)\end{array}$ & $\begin{array}{c}\text { Robocad 3.0, } \\
\text { UK }\end{array}$ & & $1-4$ bar & $\begin{array}{l}\mathrm{4}-10 \\
\mathrm{~mm} / \mathrm{s}\end{array}$ & $\begin{array}{c}0.1-0.5 \\
\mathrm{~mm}\end{array}$ & $0.4 \mathrm{~S} / \mathrm{cm}$ & $\begin{array}{c}0.84 \mathrm{MPa} \\
\text { (Young } \\
\text { modulus) }\end{array}$ & [126] \\
\hline $\begin{array}{c}\text { GO aqueous solution (10 } \\
\mathrm{mg} / \mathrm{mL})\end{array}$ & Home made & $-25^{\circ} \mathrm{C}$ & & & $0.1 \mathrm{~mm}$ & $\begin{array}{c}2.2-15.4 \\
\mathrm{~S} / \mathrm{m}\end{array}$ & $\begin{array}{c}70 \mathrm{kPa} \\
(\text { Strain } 50 \%)\end{array}$ & [127] \\
\hline $\begin{array}{c}\text { Graphene/PCL (Graphene: } 0.1- \\
4 \%)\end{array}$ & & & & & & $\begin{array}{c}6.37 \times 10^{-3} \\
\mathrm{~S} / \mathrm{cm}\end{array}$ & $68.74 \mathrm{MPa}$ & [82] \\
\hline
\end{tabular}




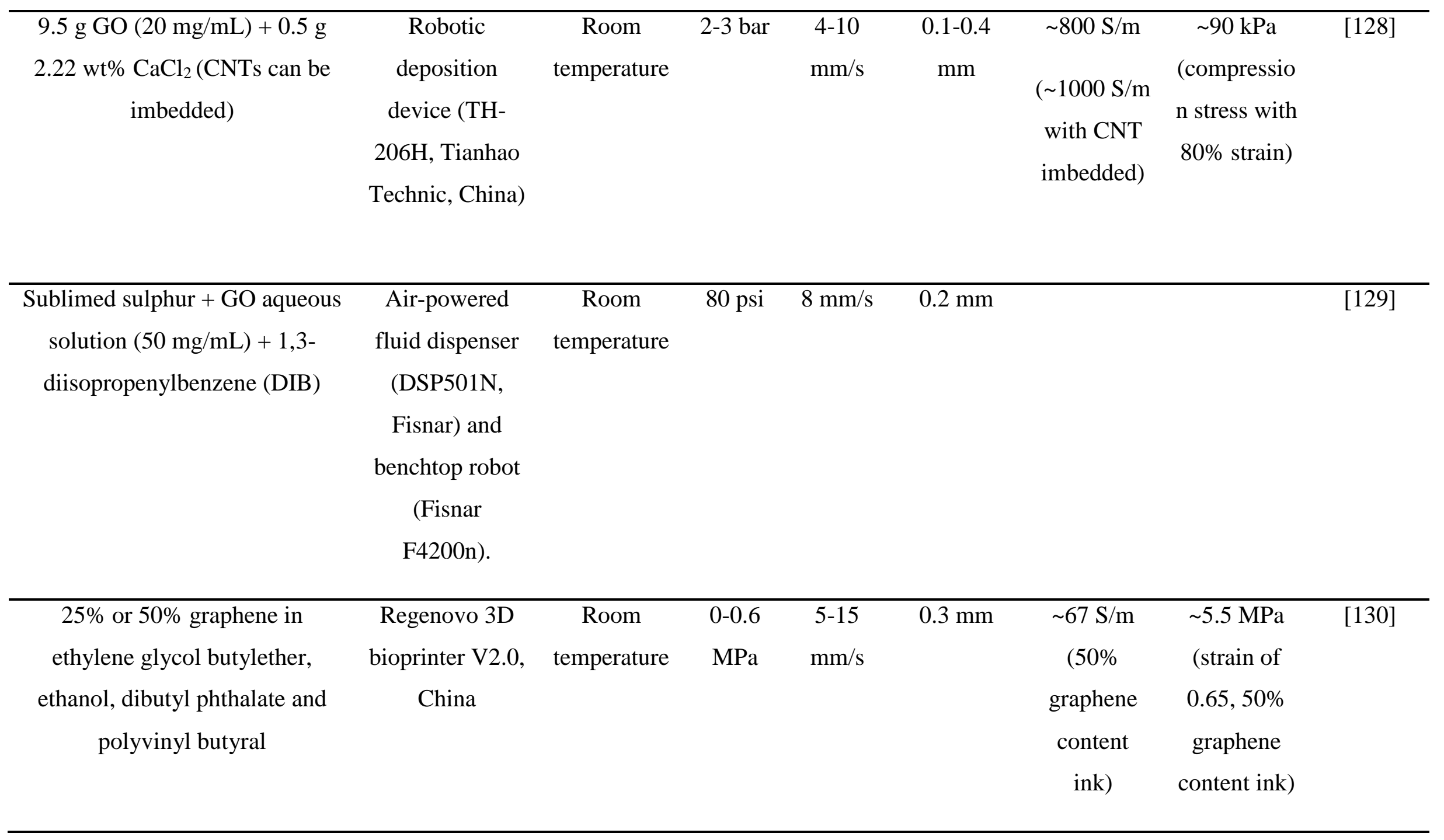




\begin{tabular}{|c|c|c|c|c|c|c|c|}
\hline GO/PCL (GO: 0.5-4\%) & & $\begin{array}{c}\text { Room } \\
\text { temperature }\end{array}$ & & $\begin{array}{c}\text { In } \\
\text { micrometre } \\
\text { s }\end{array}$ & $\begin{array}{c}4.55 \times 10^{-4} \\
\mathrm{~S} / \mathrm{cm}\end{array}$ & $\begin{array}{c}48.32 \mathrm{MPa} \\
\text { (elastic } \\
\text { modulus) }\end{array}$ & [84] \\
\hline $\begin{array}{c}(0.5-2.5 \text { wt \%) Graphene }+ \\
\text { Aluminium }\end{array}$ & $\begin{array}{l}\text { Homemade } \\
\text { selective laser } \\
\text { melting 3D } \\
\text { printer }\end{array}$ & $>500{ }^{\circ} \mathrm{C}$ & $3 \mathrm{~mm} / \mathrm{s}$ & $0.2 \mathrm{~mm}$ & 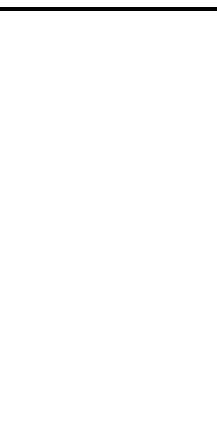 & $\begin{array}{c}\text { 1.77 GPa } \\
\text { (Nano } \\
\text { hardness, } \\
2.5 \mathrm{wt} \% \\
\text { graphene- } \\
\text { aluminium) }\end{array}$ & [131] \\
\hline $\mathrm{Ni} /$ sucrose powder $(6: 1)$ & $\begin{array}{c}\text { XLS10MWH } \\
\text { laser platform } \\
\text { (Universal } \\
\text { Laser Systems) }\end{array}$ & & $\begin{array}{l}304.8 \\
\mathrm{~cm} / \mathrm{s}\end{array}$ & $10.6 \mu \mathrm{m}$ & $\sim 8.7 \mathrm{~S} / \mathrm{m}$ & $\begin{array}{l}11 \mathrm{kPa} \\
\text { (Storage } \\
\text { modulus) }\end{array}$ & [132] \\
\hline Polyimide film & $\begin{array}{c}\text { XLS10MWH } \\
\text { laser platform } \\
\text { (Universal } \\
\text { Laser Systems) }\end{array}$ & & $\begin{array}{c}15 \mathrm{~cm} / \mathrm{s} \\
\text { for } \mathrm{CO}_{2} \\
\text { laser } \\
\text { and } 60 \\
\mathrm{~cm} / \mathrm{s} \text { for }\end{array}$ & $\begin{array}{c}10.6 \mu \mathrm{m} \\
\text { for } \mathrm{CO}_{2} \\
\text { laser and } \\
1.06 \mu \mathrm{m}\end{array}$ & $\begin{array}{c}\text { Plane } \\
\text { conductivit } \\
\text { y }(0.27 \pm \\
0.05 \mathrm{~S} / \mathrm{cm}) \\
\text { and Z- }\end{array}$ & $\begin{array}{c}40 \mathrm{kPa} \\
\text { (elastic } \\
\text { modulus) }\end{array}$ & [133] \\
\hline
\end{tabular}




\begin{tabular}{|c|c|c|c|c|}
\hline & & $\begin{array}{l}\text { fiber } \\
\text { laser }\end{array}$ & $\begin{array}{c}\text { for fiber } \\
\text { laser }\end{array}$ & $\begin{array}{c}\text { conductivit } \\
\mathrm{y}(0.073 \pm \\
0.010 \\
\text { S/cm) } \\
\text { (Polyimide } \\
\text { thickness } \\
\text { of } 50 \mu \mathrm{m})\end{array}$ \\
\hline Graphene $(0.1-2 \mathrm{wt} \%) /$ Resin & $\begin{array}{c}\text { Formlabs Form } \\
2 \text { printer fitted } \\
\text { with violet laser }\end{array}$ & & & \\
\hline
\end{tabular}


The use of 3D printing is accelerating the application of graphene for customised bionics [135]. Generally, the development of 3D printable graphene ink without additive is still a challenge since commonly used graphene or GO dispersions are dilute (usually in the range of several $\mathrm{mg}$ per $\mathrm{mL}$ ), and do not meet the rheological requirement for 3D printing [119]. Graphene or GO is therefore widely incorporated with additional materials to increase viscosity to enable 3D printing. Many materials have been used as additives for 3D printable graphene-based ink development. These include: polylactic acid (PLA) [110, 111], polybutylene terephthalate (PBT) [112], chitosan (CHI) [136], methacrylated chitosan (ChiMA) [113], acrylonitrile-butadiene-styrene (ABS) [114], pluronic F127 [115], poly(trimethylene carbonate) (PTMC) [116], polylactide-co-glycolide (PLG) [83], fumed silica [119], and so on [42, 118, 121, 129, 130, 135] (Fig. 7b). In addition, GO can also serve as a versatile additive for 3D printable ink development, acting as dispersing agent, rheology and binding modifier simultaneously. García-Tuñón et.al have used GO as an additive for a variety of materials, namely ceramic powders, polymers and metals with different sizes and shapes, to manipulate their viscoelastic responses for better 3D printing behaviours [124] (Fig. 7c).

However, 3D printing with other materials compromises the intrinsic properties of graphene and phase separation and aggregation are commonly observed [114]. Although, GO aqueous suspensions exhibit shear thinning behaviour, 3D printing of neat graphene/GO containing ink, especially with high resolution, is still a challenge [137]. Attempts to improve resolution include preparation of a GO aqueous dispersion based paste by water evaporation to achieve concentrated GO of 2.5-3.5 vol $\%$, which can be 3D printed directly [124] (Fig. 7d). Hu et al. attempted to prepare 3D printable highly concentrated GO suspensions by redispersing solid-state GO in water with a concentration of about $80 \mathrm{mg} / \mathrm{mL}[121,122]$. Lacey et al. tried to achieve concentrated 3D printable GO ink $(\sim 100$ $\mathrm{mg} / \mathrm{mL}$ ) by introducing holey GO in the preparation, which met the standards for complicated 3D architecture printing [123]. Naficy et al. have achieved 3D printable liquid crystal GO with relatively lower concentration $(13.3 \mathrm{mg} / \mathrm{ml})$ due to the ultra-large GO sheet and its specific viscoelastic 
behaviours [125]. These methods involve time-consuming ink concentrating process and result in printed scaffolds with high GO content ratio. Lin and co-workers have developed a method for pure low-concentration GO (1 mg/mL) 3D printing, which involved a freeze-casting process [127] (Fig. 7e). In this method, aqueous GO ink was ejected on demand and instantly frozen on a cold sink ( -25 ${ }^{\circ} \mathrm{C}$ ) to maintain its structure, with obtained 3D scaffolds further subjected to freeze drying for water removing and thermal annealing for GO reducing. Since microscale architecture of GO can be controlled by freezing [138], this integrated method can both control macro- and micro-structures of 3D graphene scaffolds. The approach is complicated and requires a peculiar environment. Kim et al. firstly reported 3D printed nanowire structures composed of pure graphene component without supporting materials [120]. In this method, chemically synthesized $1 \mathrm{~g} / \mathrm{L} \mathrm{GO}$ aqueous solution with average flake size of $1-5 \mu \mathrm{m}$ was $3 \mathrm{D}$ printed at nanoscale resolution, whereas the printed structure was limited to a meniscus, greatly restricting future application of the method.

In order to tackle the challenges and inspired from traditional biomaterial 3D printing strategy [139], Gao and his co-workers have developed 3D printable low-concentration GO ink $(8-20 \mathrm{mg} / \mathrm{mL})$ by facile ion-inducing effect to tune its printability, and used the ink for accurate 3D graphene scaffold printing [128]. With a trace amount of ion cross-linker, 3D printability of low concentration GO aqueous solution can be significantly improved without compromising pristine properties of graphene and printing accuracy, which is promising for application in tissue engineering. 3D printed graphene scaffolds derive from GO solution will inevitably inherit its defects obtained from synthesis process. In order to cope with limitation, Tour and his co-workers have invented a new way to print graphene by first printing a mixture of $\mathrm{Ni}$ and sucrose followed by converting the mixture into 3D graphene structure by laser [132] (Fig. 7f). In this method, sucrose served as the carbon source, while nickel served as the catalyst, which can be removed by etching. Fabrication of 3D graphene scaffolds via laser based 3D printing has recently become popular due to the ease of substrate preparation and high resolution inherited from laser technique compared with scaffolds fabricated via traditional extrusion 
based 3D printing [131-134]. The current technique can still cause warping and distortion in the fabricated scaffolds, which need to be addressed. Although 3D printing of only graphene is achievable with additional conditions, the printed scaffolds showed irregular shape, poor mechanical strength and less accuracy. Therefore, greater effort is required to address these limitations.

3D printing technique can be integrated with other fabrication methods towards complex 3DGCS fabrication. Yuan et al. developed a 3D Polydopamine (PDA)/Arginylglycylaspartic acid (RGD)/Graphene/PCL scaffold by an integrated 3D printing and layer by layer deposition technique, with microneedles evenly decorated roller used as the collector [82]. Unlike traditional 3D printing, the described method is more like a multiple coating process with improved controllability over quality, while the diversity of fabricated scaffold is greatly limited. This group has also fabricated 3DGCS via integrated molding and 3D printing methods [84]. In that work, the 3D printer acted like a hole punch to generate multiple aligned pores alongside the multilayered GO/PCL conduit made by molding and jet spraying. In combination with supplementary fabrication techniques, 3D printing method is enabling the fabrication of more complicated 3D scaffolds with multiple functions.
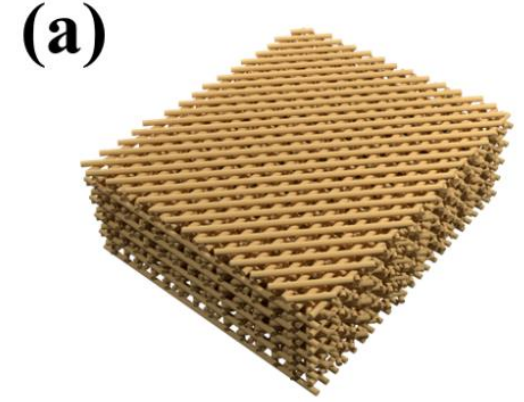

(d)

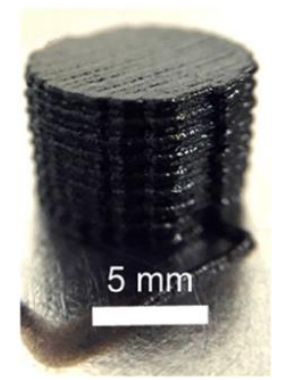

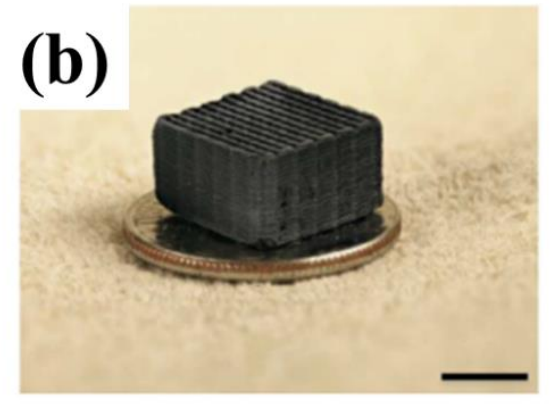

(e)

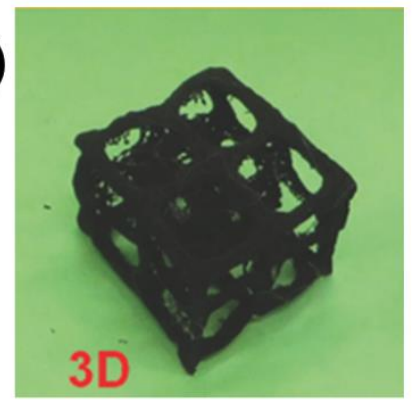

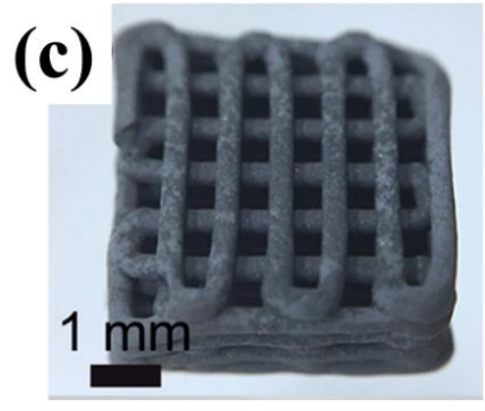

(f)

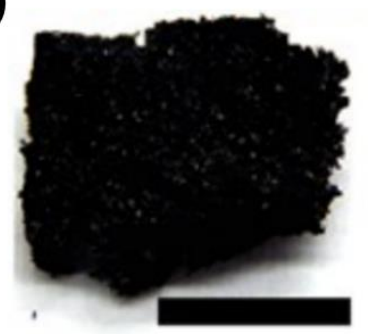

Fig. 7. Examples of typical 3D printed 3DGCSs. (A) Schematic illustration for 3D printed scaffold. Optical image of: (B) a typical 3D printed graphene scaffold, using GO ink with additive (fumed 
silica) [119] (Adapted with permission from ref. 119 Copyright Nature Publishing Group 2015), (C) sintered 3D printed SiC structures using GO as the only additive [124], (Adapted with permission from ref. 124 Copyright American Chemical Society 2017) (D) 3D printed GO cylinder with only GO paste without additive [124], (Adapted with permission from ref. 124 Copyright American Chemical Society 2017) (E) 3D printed graphene aerogel architecture [127], (Adapted with permission from ref. 127 Copyright Wiley-VCH 2016) (F) 3D printed graphene foam after dissolving supporting Ni structure [132] (The scale bars are $5 \mathrm{~mm}$ ) (Adapted with permission from ref. 132 Copyright American Chemical Society 2017).

\subsection{Template assembly}

Using template assembly based 3DGCS fabrication strategy, a variety of graphene structures have been created, like chemical vapour deposition (CVD) [140, 141], dip-coating [43], freeze-drying [142], electrophoretic deposition [143] and autoclaving [144]. In order to facilitate the fabrication process and diversify the final structural complexity, various templates have been explored for the fabrication process, such as metal sponge [140, 145], fabric [146], non-metal sponges [43, 147], different sized polymer particles [148, 149] and ice templates [150]. Fabricated 3DGCS and properties, such as pore size, electrical conductivity, mechanical strength etc., are tuneable over templates applied in the fabrication process. Specific methods and properties of 3DGCSs fabricated by the template assembly approach are summarized in Table 5. 
Table 5 Summary of methods and properties of 3DGCSs fabricated by the template assembly approach.

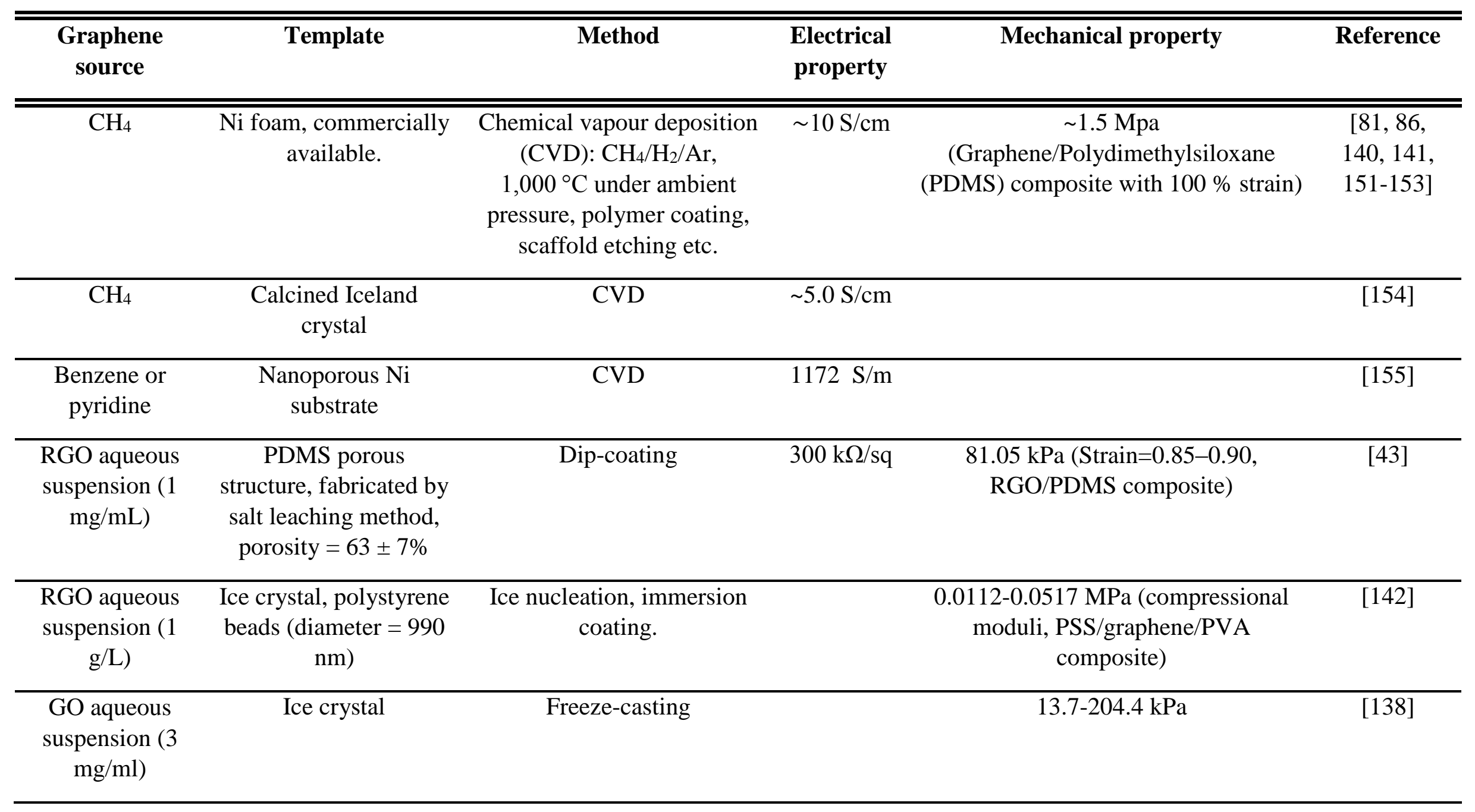




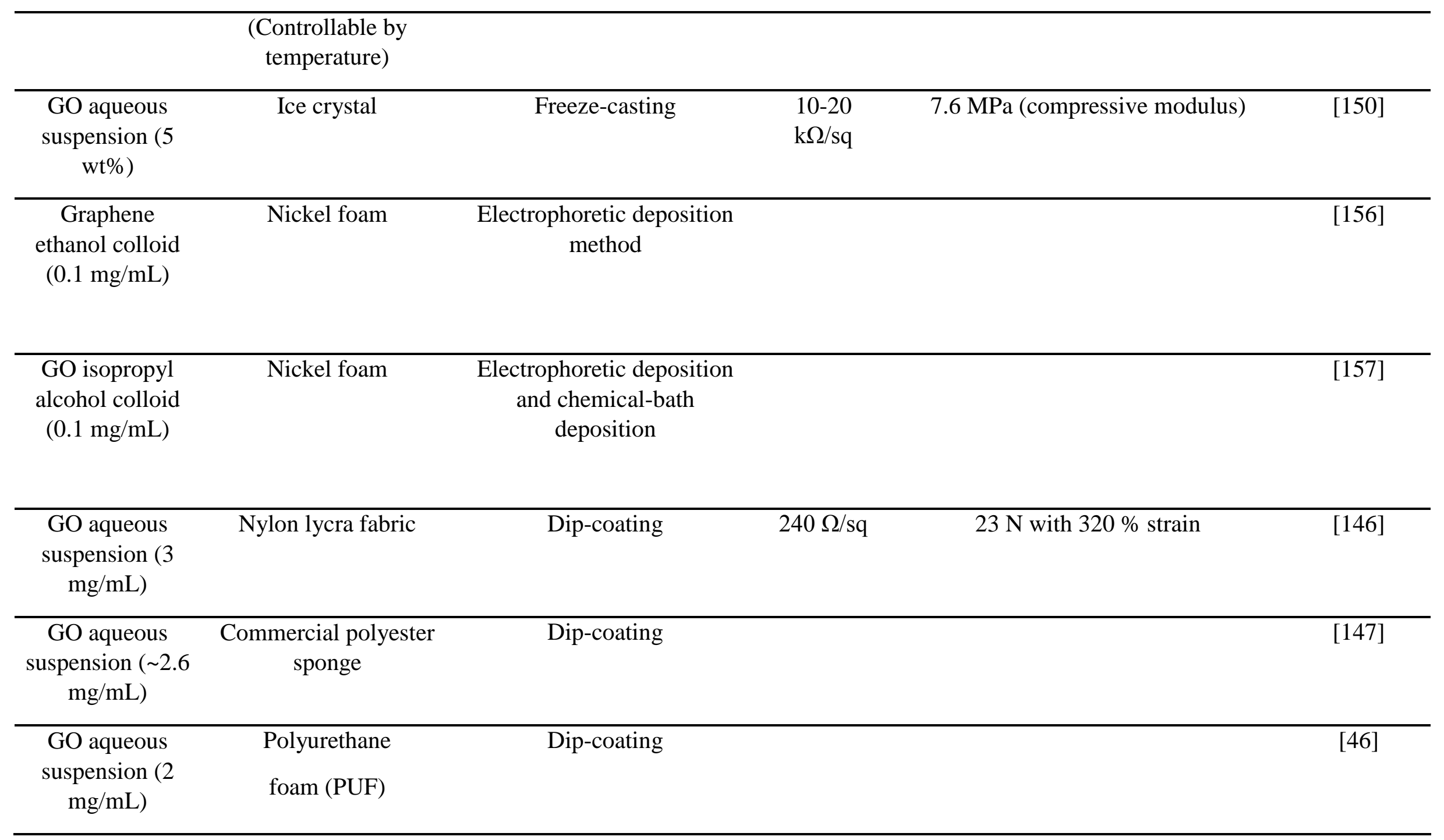




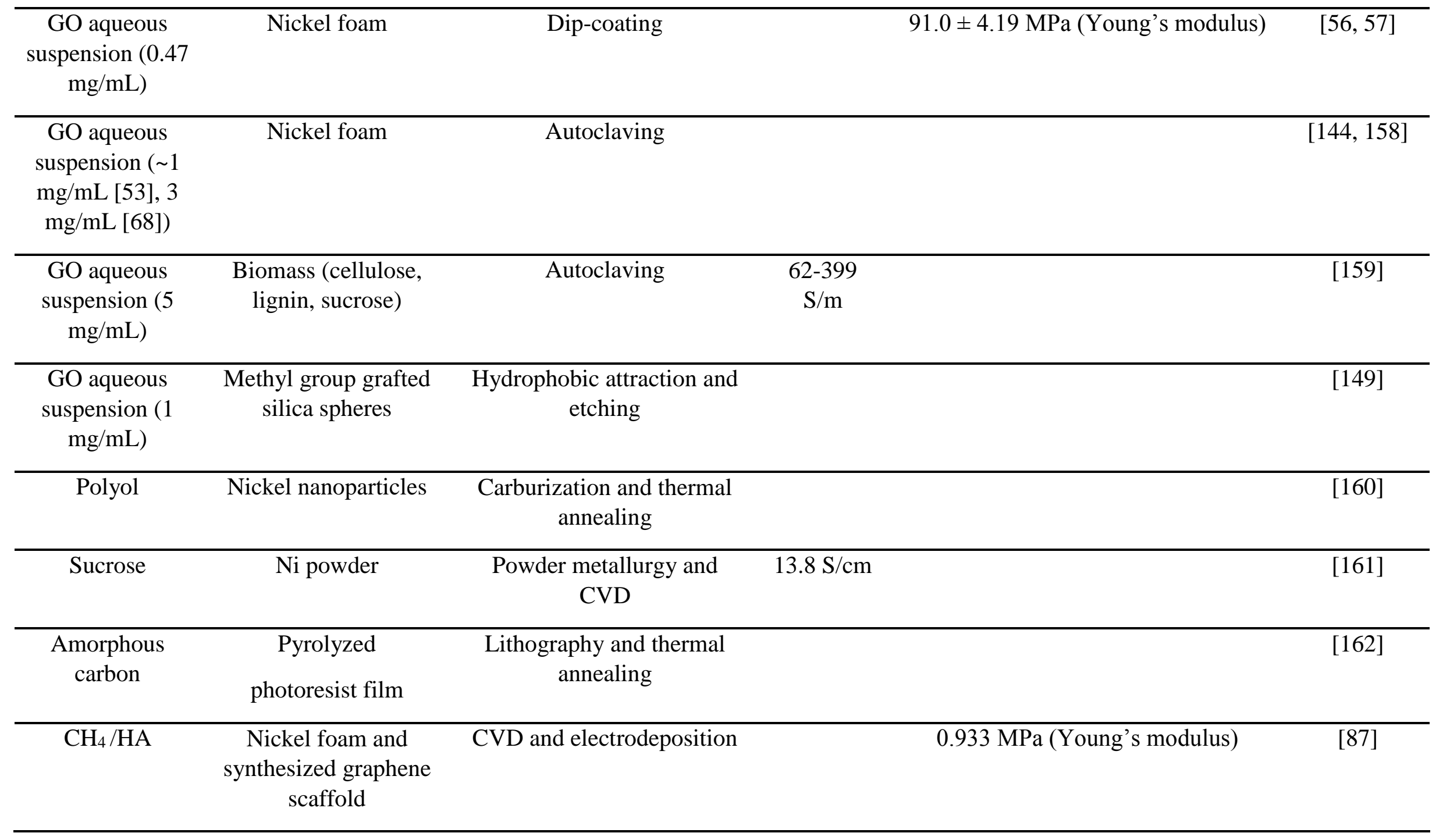




\begin{tabular}{|c|c|c|c|c|}
\hline $\mathrm{CH}_{4}$ & Nickel foam & CVD & & {$[163]$} \\
\hline $\begin{array}{l}\text { Polyamic acid } \\
\text { and urea }\end{array}$ & $\mathrm{Cu}$ foil & Laser-scribing & $\begin{array}{l}35 \mathrm{~S} / \mathrm{cm} \\
(\mathrm{NLSG}-2)\end{array}$ & [164] \\
\hline $\begin{array}{c}\text { GO aqueous } \\
\text { suspension }(1-5 \\
\text { wt } \%)\end{array}$ & Ice crystal & Directional freezing & & {$[58]$} \\
\hline $\begin{array}{c}\text { GO aqueous } \\
\text { suspension } \\
(0.25-1 \mathrm{mg} / \mathrm{mL})\end{array}$ & $\begin{array}{c}\text { 3D printed tricalcium } \\
\text { phosphate }(\beta-\mathrm{TCP}) \\
\text { scaffold }\end{array}$ & Dip-coating & & {$[59,60]$} \\
\hline $\begin{array}{c}\text { GO aqueous } \\
\text { suspension } \\
(0.25-2 \mathrm{mg} / \mathrm{mL})\end{array}$ & $\begin{array}{c}\text { Fluffy polyacrylonitrile } \\
\text { nanofibrous scaffold } \\
\text { made by } \\
\text { electrospinning }\end{array}$ & Reducing and freeze drying & $\begin{array}{l}>90 \mathrm{~Pa} \text { ( compression } \\
\text { modulus) }\end{array}$ & {$[165]$} \\
\hline
\end{tabular}


As a widely used bottom-up strategy for high quality graphene production, CVD is straightforward and capable of maintaining the intrinsic properties of graphene $[151,166]$. For 3DGCS fabrication via CVD technique, graphene sourced from $\mathrm{CH}_{4}$ or other small carbon containing molecules is directly grown as a monolith onto a metal template and organic synthesis procedures are involved in the intermediate steps, during which the templates acts as supporting substrate and catalyst contemporarily [151]. Alongside widely used metal template, mineral template (calcined Iceland crystal) was capable of serving as template in CVD, which offers an alternative approach towards final hierarchical structure control [154]. Meanwhile, other techniques can also be applied in combination with CVD to endow 3DGCS with supplementary properties, such as electro-deposition of hydroxyapatite (HA) [87] or graphene nanoribbon introduced with reactive ion etching on the surface of 3DGCS synthesized by CVD [163]. Although plenty of complex 3DGCSs can be manufactured by template-directed CVD, this method needs delicate fabrication facilities and is not amenable for large scale or sizable 3DGCS fabrication (Fig. 8a-b). Obtained 3DGCSs are generally fragile and easy to collapse after removal of metal template. Meanwhile, the nickel substrate used in the CVD method is cytotoxic, so incomplete removal may present risks for further bio-related applications. As mentioned above (section 3.1), laser scribing is widely applied towards 3DGCS fabrication with capability of heteroatom doping, by which electrochemical function of 3DGCSs can be tuned [164]. Alshareef et. al have fabricated 3D nitrogen-doped graphene scaffolds by using onestep laser scribing urea-containing polyimide on $\mathrm{Cu}$ foil, whereby 3D porous graphene was synthesized from graphitization process of polyimide under high temperature. However, this fabrication process requires specific fabrication conditions and has limited capability for large scale production. For large-scale synthesis of 3DGCS without the need for specialist equipment and laborious procedure, solution processed graphene would be the best graphene source and graphene prepared by this method is applicable for most 3DGCS fabrication strategies previously mentioned, namely: dip-coating (Fig. 8c), freeze casting, electrophoretic deposition etc. [146, 150]. Dip-coating 
process is economic and doesn`t require a complex setup, while coating with large molecules, like graphene, may present uneven deposition throughout the structure due to specific template conditions [43]. Freeze-casting is a versatile technique for 3DGCS fabrication with controllability of microstructure and subsequent easy removal of ice template, while fabrication is time-consuming and needs precise temperature control over freezing and drying processes [138, 150]. Electrophoretic deposition method can deposit graphene on metal template uniformly with high purity, while possessing the same disadvantages as CVD method mentioned before [156]. Templates utilized in the template assembly strategy have direct influence on the final structure details of 3DGCSs, and also play an important role in the obtained 3DGCS if it`s not removed afterwards. In order to fabricate 3DGCS with desirable configurations and properties, it`s essential to design and control the properties of the templates. Salt leaching [43], directional freezing [58], and 3D printing [59] were employed in this regard.
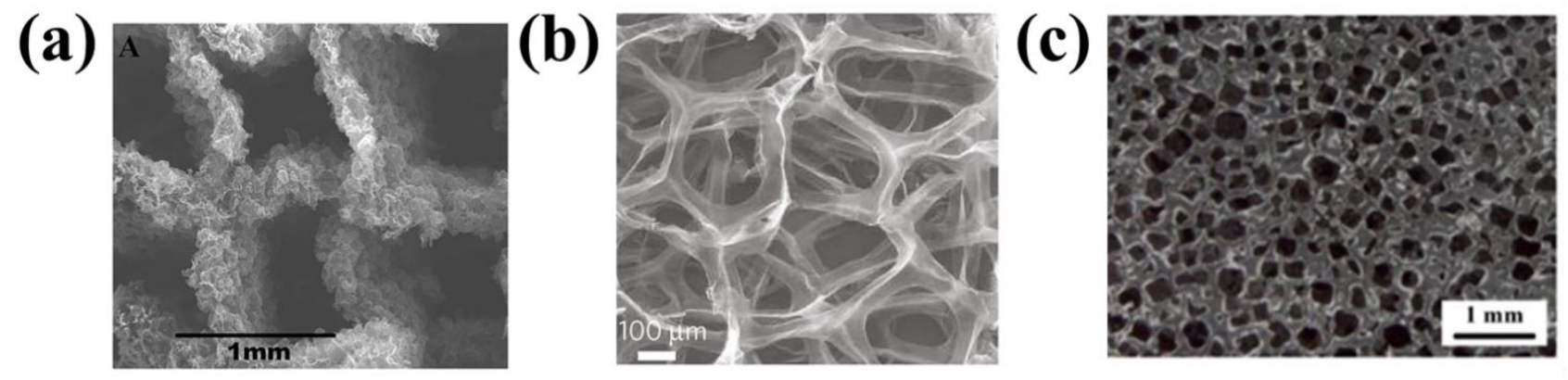

Fig. 8. SEM images of 3DGCSs fabricated by template assembly strategy via (A [141] (Adapted with permission from ref. 141 Copyright The Royal Society of Chemistry 2015), B [151] (Adapted with permission from ref. 151 Copyright Nature Publishing Group 2011) CVD method using $\mathrm{CH}_{4}$ as graphene source; (C) dip-coating method using solution processed graphene as graphene source [43] (Adapted with permission from ref. 43 Copyright Elsevier 2017).

\subsection{Self-assembly}

Self-assembly is an efficient technique for various complex 3DGCS fabrication by manipulating 
graphene interlayer behaviour. GO or reduced graphene oxide (RGO) sheets will be overlapped and interlocked to form enough physical linking sites for 3D construct formation in the dispersion if force balance between GO/RGO layers (mainly hydrophilicity and electrostatics) is interrupted, in which the disturbing factors can be $\mathrm{pH}$ value, temperature, cross-linker or ultrasonication [167-169].

There are three main synthetic strategies for 3DGCS fabrication via the self-assembly mechanism: these are hydrothermal, chemical reduction and electrochemical reduction [170]. 3DGCSs fabricated by the self-assembly approach are summarized in Table 6. 
Table 6 Summary of methods and properties of 3DGCS fabricated by the self-assembly approach.

\begin{tabular}{|c|c|c|c|c|c|}
\hline Graphene source & $\begin{array}{l}\text { Incorporated } \\
\text { material }\end{array}$ & Method & Electrical property & Mechanical property & Reference \\
\hline $\begin{array}{c}\text { GO aqueous } \\
\text { suspension }(2.0 \\
\mathrm{mg} / \mathrm{mL})\end{array}$ & $\begin{array}{l}\text { Polypyrrole } \\
\text { (PPY) }\end{array}$ & $\begin{array}{l}\text { Hydrothermal }\left(180^{\circ} \mathrm{C} \text { for }\right. \\
\text { several hours) }\end{array}$ & $3000 \mathrm{~S} / \mathrm{cm}$ & $\begin{array}{c}\text { Compressive stress of } \sim 0.4 \mathrm{MPa} \\
\text { with strain ratio of } \sim 80 \%\end{array}$ & {$[171]$} \\
\hline $\begin{array}{c}\text { GO aqueous } \\
\text { suspension }(2.0 \\
\mathrm{mg} / \mathrm{mL})\end{array}$ & & $\begin{array}{l}\text { Hydrothermal }\left(180^{\circ} \mathrm{C} \text { for }\right. \\
12 \text { hours })\end{array}$ & $\sim 4.9 \mathrm{mS} / \mathrm{cm}$ & $\begin{array}{c}\text { Compressive elastic modulus: } \\
\sim 290 \mathrm{kPa}\end{array}$ & {$[172,173]$} \\
\hline $\begin{array}{c}\text { GO aqueous } \\
\text { dispersion }(0.1 \\
\mathrm{mg} / \mathrm{mL})\end{array}$ & $\begin{array}{c}\mathrm{Fe}_{3} \mathrm{O}_{4} \\
\text { nanoparticle }\end{array}$ & $\begin{array}{l}\text { Hydrothermal }\left(150^{\circ} \mathrm{C} \text { for }\right. \\
10 \text { hours })\end{array}$ & & & {$[174]$} \\
\hline $\begin{array}{c}\text { GO aqueous } \\
\text { suspension }(1 \mathrm{mg} / \mathrm{mL})\end{array}$ & $\begin{array}{c}\mathrm{Fe}_{3} \mathrm{O}_{4} \\
\text { nanoparticle }\end{array}$ & $\begin{array}{c}\text { Centrifugation and } \\
\text { hydrothermal }\left(180^{\circ} \mathrm{C} \text { for }\right. \\
12 \text { hours })\end{array}$ & & & {$[175]$} \\
\hline $\begin{array}{l}\text { GO aqueous } \\
\text { suspension }(1.5 \\
\mathrm{mg} / \mathrm{mL})\end{array}$ & $\begin{array}{c}\mathrm{Fe}_{3} \mathrm{O}_{4} \\
\text { nanoparticle }\end{array}$ & $\begin{array}{l}\text { Hydrothermal }\left(180^{\circ} \mathrm{C} \text { for }\right. \\
12 \text { hours })\end{array}$ & & & {$[176]$} \\
\hline $\begin{array}{c}\text { GO aqueous } \\
\text { suspension }(2 \mathrm{mg} / \mathrm{mL})\end{array}$ & $\begin{array}{l}\text { Carbon nanotube } \\
\text { and Palladium } \\
\text { nanoparticles }\end{array}$ & $\begin{array}{l}\text { Hydrothermal }\left(180{ }^{\circ} \mathrm{C} \text { for }\right. \\
12 \text { hours })\end{array}$ & & & {$[177]$} \\
\hline
\end{tabular}




\begin{tabular}{|c|c|c|c|c|c|}
\hline $\begin{array}{c}\text { GO aqueous } \\
\text { suspension }(1 \mathrm{mg} / \mathrm{mL})\end{array}$ & $\begin{array}{c}\mathrm{Pb}, \mathrm{Au}, \mathrm{Ir}, \mathrm{Ru} \\
\text { nanoparticles and } \\
\text { glucose }\end{array}$ & $\begin{array}{l}\text { Hydrothermal }\left(120^{\circ} \mathrm{C} \text { for }\right. \\
20 \text { hours })\end{array}$ & $0.0025 \mathrm{~S} / \mathrm{cm}$ & $\begin{array}{c}\text { Compressive stress of } \sim 0.04 \mathrm{MPa} \\
\text { with strain of } \sim 0.25\end{array}$ & [178] \\
\hline $\begin{array}{c}\text { GO aqueous } \\
\text { suspension }(2.5 \\
\mathrm{mg} / \mathrm{mL})\end{array}$ & $\mathrm{Ni}(\mathrm{OH})_{2}$ & $\begin{array}{c}\text { Hydrothermal }\left(180^{\circ} \mathrm{C} \text { for }\right. \\
2 \text { hours })\end{array}$ & $\sim 2.3 \mathrm{~S} / \mathrm{m}$ & & [179] \\
\hline $\begin{array}{c}\text { GO aqueous } \\
\text { suspension }(2 \mathrm{mg} / \mathrm{mL})\end{array}$ & $\begin{array}{c}\mathrm{Fe}_{3} \mathrm{O}_{4} \\
\text { nanoparticle }\end{array}$ & Reduction by metal ions & & $\begin{array}{c}\text { Compressive stress of } \sim 0.5 \mathrm{MPa} \\
\text { with strain ratio of } \sim 80 \%\end{array}$ & [180] \\
\hline $\begin{array}{c}\text { GO aqueous } \\
\text { suspension }(2 \mathrm{mg} / \mathrm{mL})\end{array}$ & & $\begin{array}{l}\text { Reduction by sodium } \\
\text { ascorbate }\end{array}$ & $1 \mathrm{~S} / \mathrm{m}$ & Storage modulus: $275 \mathrm{kPa}$ & [181] \\
\hline $\begin{array}{c}\text { GO aqueous } \\
\text { suspension }(4 \mathrm{mg} / \mathrm{mL})\end{array}$ & & $\begin{array}{c}\text { Reduction by L-ascorbic } \\
\text { acid }\end{array}$ & $\sim 100 \mathrm{~S} / \mathrm{m}$ & & [182] \\
\hline $\begin{array}{c}\text { GO aqueous } \\
\text { suspension }(0.5-3 \\
\mathrm{mg} / \mathrm{mL})\end{array}$ & & $\begin{array}{c}\text { Reduction by } \\
\text { hypophosphorous acid and } \\
\text { iodine }\end{array}$ & $\sim 500 \mathrm{~S} / \mathrm{m}$ & $\begin{array}{c}\text { Up to } 0.14 \mathrm{MPa} \text { with strain ratio } \\
\text { of } \sim 40 \% \text { (prepared from } 3 \mathrm{mg} / \mathrm{ml} \\
\text { GO) }\end{array}$ & [183] \\
\hline $\begin{array}{c}\text { GO aqueous } \\
\text { suspension }(0.1-2 \\
\mathrm{mg} / \mathrm{mL})\end{array}$ & & $\begin{array}{l}\text { Reduction by } \mathrm{NaHSO}_{2}, \\
\mathrm{Na}_{2} \mathrm{~S} \text {, Vitamin } \mathrm{C}, \mathrm{HI} \text {, or } \\
\text { hydroquinone. }\end{array}$ & $87 \mathrm{~S} / \mathrm{m}$ & Elastic modulus $0.13 \mathrm{MPa}$ & [184] \\
\hline $\begin{array}{c}\text { GO aqueous } \\
\text { suspension }(1.5 \\
\mathrm{mg} / \mathrm{mL})\end{array}$ & $\begin{array}{c}\mathrm{Fe}_{3} \mathrm{O}_{4} \\
\text { nanoparticle }\end{array}$ & $\begin{array}{l}\text { Reduction by } \mathrm{NaHSO}_{3}(95 \\
{ }^{\circ} \mathrm{C} \text { for } 3 \text { hours) }\end{array}$ & $15 \mathrm{~S} / \mathrm{m}$ & & [185] \\
\hline
\end{tabular}




\begin{tabular}{|c|c|c|c|c|c|}
\hline $\begin{array}{c}\text { GO aqueous } \\
\text { suspension }(1 \mathrm{mg} / \mathrm{mL})\end{array}$ & & $\begin{array}{l}\text { Reduction by dopamine } \\
\text { (ultrasonication) and } \\
\text { hydrothermal ( } 180^{\circ} \mathrm{C} \text { for } \\
12 \text { hours) }\end{array}$ & $262 \mathrm{~S} / \mathrm{m}$ & & {$[186]$} \\
\hline $\begin{array}{c}\text { GO aqueous } \\
\text { suspension }(2-8 \\
\mathrm{mg} / \mathrm{mL})\end{array}$ & & $\begin{array}{l}\text { Reduction by ascorbic acid } \\
\left(70{ }^{\circ} \mathrm{C} \text { for } 4 \text { hours }\right) \text { and } \\
\text { freeze drying }\end{array}$ & $82-3400 \Omega$ & $\begin{array}{c}\text { Compressive stress of } \sim 20 \mathrm{kPa} \\
\text { with compressive strain ratio of } \\
\sim 50 \%\end{array}$ & {$[187]$} \\
\hline $\begin{array}{c}\text { GO aqueous } \\
\text { suspension }(1 \mathrm{mg} / \mathrm{mL})\end{array}$ & $\begin{array}{l}\text { Silane coupling } \\
\text { agents }\end{array}$ & $\begin{array}{l}\text { Reduction by ascorbic acid } \\
\left(80^{\circ} \mathrm{C} \text { for } 15 \text { hours }\right) \text { and } \\
\text { freeze drying }\end{array}$ & $0.1-10 \mathrm{~S} / \mathrm{m}$ & $\begin{array}{c}\text { Compressive stress of } \sim 20 \mathrm{kPa} \\
\text { with compressive strain ratio of } \\
\sim 60 \%\end{array}$ & {$[188]$} \\
\hline $\begin{array}{l}\text { GO ethanol suspension } \\
(0.05 \mathrm{mg} / \mathrm{mL})\end{array}$ & $\mathrm{TiO}_{2}$ nanocrystal & $\begin{array}{c}\text { Sol-gel process }\left(25^{\circ} \mathrm{C} \text { for }\right. \\
24 \text { hours })\end{array}$ & & & [189] \\
\hline $\begin{array}{c}\text { GO propylene } \\
\text { carbonate suspension } \\
(2 \mathrm{mg} / \mathrm{mL})\end{array}$ & & $\begin{array}{l}\text { Solvothermal }\left(180^{\circ} \mathrm{C} \text { for }\right. \\
12 \text { hours })\end{array}$ & $2 \mathrm{~S} / \mathrm{m}$ & & {$[190]$} \\
\hline $\begin{array}{c}\text { GO aqueous } \\
\text { dispersion with } \\
\text { supporting electrolyte }\end{array}$ & $\begin{array}{c}\text { Polyaniline } \\
\text { (PANI), PPY and } \\
\text { zinc oxide }\end{array}$ & $\begin{array}{l}\text { Cyclic voltammetry and } \\
\text { chronoamperometry }\end{array}$ & $6000 \mathrm{~S} / \mathrm{m}$ & & {$[191,192]$} \\
\hline $\begin{array}{c}\text { GO aqueous } \\
\text { suspension }(3 \mathrm{mg} / \mathrm{mL}) \\
\text { containing } 0.1 \mathrm{M} \\
\text { lithium perchlorate }\end{array}$ & & Potentiostat-galvanostat & & & {$[193,194]$} \\
\hline
\end{tabular}




\begin{tabular}{|c|c|c|c|c|c|}
\hline $\begin{array}{c}\text { GO aqueous } \\
\text { suspension }(2-5 \\
\mathrm{mg} / \mathrm{mL})\end{array}$ & & $\begin{array}{l}\text { Vacuum centrifugal } \\
\text { evaporation }\end{array}$ & $106.85 \Omega / \mathrm{sq}$ & & [195] \\
\hline $\begin{array}{c}\text { GO aqueous } \\
\text { suspension }(1 \mathrm{mg} / \mathrm{mL})\end{array}$ & CNT, cobalt (II) & Pyrolysis & & & [196] \\
\hline $\begin{array}{c}\text { GO aqueous } \\
\text { suspension }(2 \mathrm{mg} / \mathrm{mL})\end{array}$ & $\begin{array}{l}\text { Eosin Y, Rose } \\
\text { Bengal, and } \\
\text { Fluorescein }\end{array}$ & $\begin{array}{l}\text { Hydrothermal }\left(120{ }^{\circ} \mathrm{C} \text { for }\right. \\
12 \text { hours })\end{array}$ & & & [197] \\
\hline $\begin{array}{c}\text { GO aqueous } \\
\text { suspension }(8 \mathrm{mg} / \mathrm{mL})\end{array}$ & $\mathrm{MnO}$ and $\mathrm{Ni}$ & $\begin{array}{l}\text { Sonication, freeze-drying } \\
\text { and pyrolysis }\end{array}$ & $5000 \mathrm{~S} / \mathrm{m}$ & & [198] \\
\hline $\begin{array}{c}\text { GO aqueous } \\
\text { suspension }(3 \mathrm{mg} / \mathrm{mL})\end{array}$ & Ethylenediamine & $\begin{array}{c}\text { Hydrothermal }\left(95^{\circ} \mathrm{C} \text { for } 6\right. \\
\text { hours) }\end{array}$ & & & [199] \\
\hline $\begin{array}{l}\text { GO grafted with } \\
\text { polyhydroxybutyrate- } \\
\text { co-hydroxyvalerate } \\
(\text { PHBV) }\end{array}$ & $\mathrm{Fe}_{3} \mathrm{O}_{4}$ & Freeze drying & & $\begin{array}{c}7.19 \pm 0.57 \mathrm{MPa} \\
\text { (Tensile strength) } \\
171.7 \pm 0.77 \mathrm{MPa} \text { (Modulus) }\end{array}$ & [200] \\
\hline $\begin{array}{c}\text { GO aqueous } \\
\text { suspension }(8 \mathrm{mg} / \mathrm{mL})\end{array}$ & PANI, PPY & $\begin{array}{l}\text { Reduction by ascorbic acid } \\
\text { and hydrothermal }\left(180{ }^{\circ} \mathrm{C}\right. \\
\text { for } 12 \text { hours })\end{array}$ & & $150 \mathrm{MPa}$ (33\% tensile strain) & [201] \\
\hline $\begin{array}{c}\text { GO aqueous } \\
\text { suspension }(10 \\
\mathrm{mg} / \mathrm{mL})\end{array}$ & $\begin{array}{c}\text { CNTs, } \\
\text { vermiculite }\end{array}$ & Cut and paste & & $\sim 40 \mathrm{MPa}(2.2 \%$ tensile strain $)$ & [202] \\
\hline
\end{tabular}




\begin{tabular}{|c|c|c|c|c|}
\hline $\begin{array}{c}\text { GO aqueous } \\
\text { suspension }(3.5 \\
\mathrm{mg} / \mathrm{mL})\end{array}$ & Nano-HA & $\begin{array}{l}\text { Hydrothermal }\left(200{ }^{\circ} \mathrm{C} \text { for }\right. \\
3 \text { hours })\end{array}$ & $0.35 \mathrm{MPa}$ (80\% strain) & [61] \\
\hline $\begin{array}{c}\text { GO aqueous } \\
\text { suspension }(0.05-2 \\
\mathrm{mg} / \mathrm{mL})\end{array}$ & $\begin{array}{l}\text { Polyacrylamide } \\
\text { (PAM) }\end{array}$ & $\begin{array}{l}\text { Chemical crosslinking and } \\
\text { freeze drying }\end{array}$ & $\begin{array}{c}\sim 46 \mathrm{kPa} \text { (compression modulus, } \\
2 \% \text { graphene) }\end{array}$ & [93] \\
\hline $\begin{array}{c}\text { GO aqueous } \\
\text { suspension }(1 \mathrm{mg} / \mathrm{mL})\end{array}$ & Alginate $(\mathrm{Alg})$ & Chemical crosslinking & $\sim 50 \mathrm{kPa}$ (Elastic modulus) & [76] \\
\hline $\mathrm{GO}(0-0.1 \mathrm{wt} \%)$ & Alg & $\begin{array}{l}\text { Hydrogen bonding, } \\
\text { chemical bonding and } \\
\text { freeze drying }\end{array}$ & $\begin{array}{c}\sim 43.7 \mathrm{kPa} \text { (Elastic modulus for } \\
\text { scaffold with } 0.1 \mathrm{wt} \% \mathrm{GO})\end{array}$ & [103] \\
\hline
\end{tabular}


Hydrothermal is the most straightforward 3DGCS fabrication method, which doesn't need extra chemicals or substrates, and is compatible with additional decorative material co-fabrication [179] (Fig. 9a, d). Decoration of 3DGCS can endow the structure with plenty of enhanced or novel properties, like: enhanced mechanical property with incorporation of polypyrrole (PPY) [171], improved electrical, magnetic, catalytic properties with embedded nanoparticles or molecules [61, $174,176,177,185,197,200,201,203]$, increased flexibility and pore size with organic compound [199]. Hydrothermal synthesis requires high reaction temperature (usually $>120{ }^{\circ} \mathrm{C}$ ), and usually takes place in a sealed autoclave with various potential risks, like fluid scalds and burns. Freezedrying technique is often applied after hydrothermal treatment to dehydrate wet 3DGCS, while sometimes being directly used to synthesize 3DGCS [198]. While graphene is applied as a minor additive, 3DGCSs can be efficiently obtained when the majority matrix is chemically cross-linkable $[76,93]$.

Graphene layers tend to self-assemble into a 3D structure with enhanced interlayer $\pi-\pi$ and hydrophobic interaction after chemical reduction of oxygen containing groups on GO (Fig. 9b, e). The pore size of 3DGCS made by the chemical reduction method is in the range of submicrometre to micrometres. A variety of chemical reductants have been investigated for the fabrication process, such as dopamine [186], $\mathrm{NaHSO}_{3}, \mathrm{Na}_{2} \mathrm{~S}$, Vitamin C, HI, hydroquinone and so on [184]. Synthesized 3D structures may present with the residue reducing agents when the purification process is incomplete.

Nano-sized and oriented 3DGCS can be fabricated directly on the electrode by using an electrochemical reduction method (Fig. 9c, f). 3D interpenetrating graphene structure was formed upon applying a driving force of electric field, and oxygenated groups of GO were reduced under electrochemical reduction [193]. However, dimensions of the fabricated 3DGCSs are restricted to the size of the electrode used during the fabrication process. One-pot pyrolysis process can also be employed for 3D interpenetrating graphene matrix fabrication as Zhang and co-workers reported 
[196]. In this method, CNTs was grown in a controlled way on the cobalt (II) decorated graphene surface to form 3D interpenetrating structure showing promise towards battery application, while this method needs to be performed at $900{ }^{\circ} \mathrm{C}$ under argon protection. These three main synthetic strategies have limited controllability over final structure geometry and pore size distribution, which can be avoided by $3 \mathrm{D}$ printing and template assembly approach.

Besides these strategies, a vacuum centrifugal evaporator has also been utilized for GO sponge fabrication, in which GO solutions with different concentrations can be controlled to form sponge or film structures via layer-by-layer self-assembly of GO sheets [195]. Luo et.al. have introduced a cut and paste approach for complex and dynamic 3DGCS fabrication, in which GO paper obtained from filtration can be converted into complex 3D structure by simple folding, bending and pasting[202].
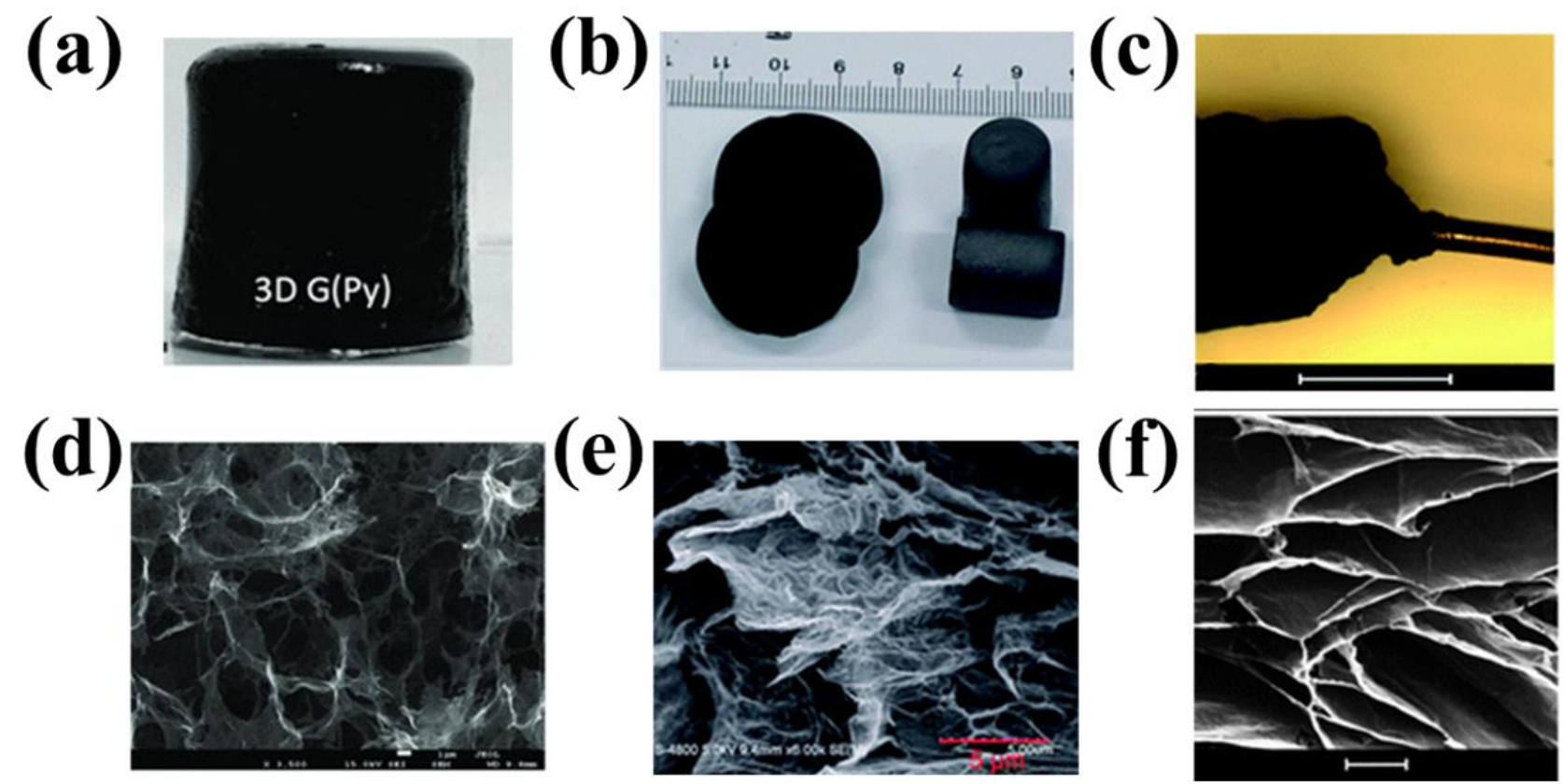

Fig. 9. Optical images of 3DGCSs prepared by: (A) hydrothermal method [171] (Adapted with permission from ref. 96 Copyright Wiley-VCH 2013), (B) chemical reduction method [182] (Adapted with permission from ref. 107 Copyright The Royal Society of Chemistry 2011), and (C) electrochemical reduction method (the scale bar is $500 \mu \mathrm{m}$ ) [191], respectively. SEM images of 3DGCS prepared by: (D) hydrothermal method [171], (E) chemical reduction method [182], and (F) electrochemical reduction method (the scale bar is $2 \mu \mathrm{m}$ ) [191], respectively. 


\section{Biodegradability of 3DGCS}

The advent of graphene has advanced bionic research in the past several years due to its prominent physicochemical properties [28]. Unprecedented progress in bionic applications of graphene has raised concerns for its biopersistance in human tissue and organ, which needs to be addressed before clinical application.

Surface functionalization, lateral size, edge structure, composition, and administered doses are all important factors for graphene biocompatibility [204]. For example, cellular uptake of nano-sized graphene can occur via endocytosis, while internalization of larger sized graphene is mainly by phagocytotic uptake initiated through jagged edges of graphene piercing $[11,205]$. Nonetheless, cytotoxicity of graphene can be reduced by controlling the dimensions of graphene size, reducing the dosage of administration, and functionalization with specific moieties on the structure.

Peroxidase enzyme could induce the degradation of GO efficiently with oxidization of its basal plane [206], while the presence of $\mathrm{H}_{2} \mathrm{O}_{2}$ can improve the degradation process [207]. Even without peroxidase, $\mathrm{H}_{2} \mathrm{O}_{2}$ at physiologically and environmentally relevant concentrations can degrade single/multi-layered graphene by a "cluster effect" [207].

In order to attenuate the toxicity of graphene to macrophages, the graphene surface was coated with bovine serum albumin (BSA) or PEG, but the coated graphene was resistant to horseradish peroxidase induced degradation [208]. A bridging coating layer on graphene through the disulfide bond can retain its bio-degradability whilst, in the meantime, reduce its cytotoxicity. Besides, functionalization with coumarin and catechol conjugations can also increase the biodegradability of GO by horseradish peroxidase [209].

For the biodegradability of $3 \mathrm{D}$ graphene based scaffolds, defects sites (oxygenated zone) in the scaffold are first disrupted by peroxidase and followed by complete dissolution in about 1 year [102]. The biodegradation rate can be tuned to match the ratio of the formation rate of tissue/organ to defect 
rate in the 3DGCS introduced through artificial treatments $\left(\mathrm{O}_{2}\right.$ plasma, laser, chemical oxidization etc.).

In spite of biodegradability, untoward effects of 3DGCSs on relevant physiological systems in vivo should also be extensively investigated before clinical use. For example, GO can cause pulmonary thromboembolism in mice due to its inductive nature of platelet aggregation in blood while RGO was much less effective [210]. This difference largely depends on the charge density on the graphene surface, and so corresponding medicine may be developed to manipulate platelet behaviour.

\section{Summary and outlook}

During the past decade, a variety of 3DGCSs with diverse architectures, various compositions and different properties have been fabricated via a number of strategies. Among all these strategies, template assembly and self-assembly are the most efficient and widely used techniques. Except for the CVD method in template assembly strategy, other methods sourcing from processable graphene are amenable for large-scale production, which can significantly accelerate applications of bulky graphene scaffolds in different fields. However, both template assembly and self-assembly strategies have limited control over scaffold inner structures (pore size, channel size etc.) and capability towards customization. These limitations can be tackled by using of 3D printing strategy, which is applicable for 3DGCS fabrication in any desired hierarchical structure, while preserving multifunctional properties of the printed materials. Promisingly, living cells and other biological factors can be directly incorporated within the graphene-based ink that make cellular components 3D printable under mild printing conditions, which will shed light on direct establishment of artificial graphenebased human tissue and organs.

These as-fabricated 3DGCSs have already found a vast variety of applications from energy storage to bionics, holding promise to revolutionize our daily lives in the future. Especially in tissue engineering applications, 3DGCSs can be modified to resemble extracellular and physiological 
features of in vivo counterparts, which is pivotal for reproduction and regeneration of malfunctioned tissue/organ. In the meantime, the peculiar nature of graphene bestows itself with high affinity to biofactors and capability to modulate properties of other biopolymers. 3DGCS has been found capable of assisting bone, cartilage, neural etc. regeneration. But most of these tests were processed in vitro, therefore further relevant in vivo works are required for the biocompatibility, post-implantation evaluation of the scaffolds.

Meanwhile, implementing intrinsic or engineered properties of graphene and its derivatives in biosensors has endowed them with enhanced selectivity and sensitivity. By taking advantage of its sensing capability in tissue engineering, graphene can achieve efficient in-situ, real-time monitoring during the tissue/organ regeneration process, which can guarantee in-time repair if anything unexpected happens after implantation. Besides, graphene and its derivatives are ideal nanocarriers, which can provide transferring and controllable releasing platforms for ligands, genes, drugs, imaging markers and other materials that can be hardly delivered by traditional methods [211]. All these capabilities of graphene hold potential for establishing a whole graphene structure that can accomplish tissue regeneration, drug delivery, and in-situ monitoring simultaneously.

The toxicity of graphene is an important issue required to be addressed prior to its bio-related application. In order to eliminate possible hazardous elements from the source, green preparation procedure of graphene is developed by utilizing bio-friendly solvent, reductant or methodology to replace the toxic ones [212]. In addition, the biodegradability of 3DGCS should be well investigated to minimize adverse effects during post-surgery scaffold removal to promote broader in vivo application in clinic.

Graphene based materials have opened up new possibilities in bionics, while 3DGCSs can further fulfil the needs in tissue engineering and regenerative medicine. To advance the tissue engineering application of 3DGCS, further collaborative efforts between academic researchers, industry groups and clinicians will be important. 


\section{Acknowledgements}

The authors gratefully acknowledge the Australian Research Council (ARC) Centre of Excellence Scheme for provision of funding (CE140100012) and support from the Australian National Fabrication Facility (ANFF)—Materials Node. Prof. Gordon G. Wallace wishes to acknowledge the financial support from ARC through an ARC Laureate Fellowship (FL110100196). Prof. Gordon G. Wallace and Dr. Xiao Liu would like to acknowledge the support of ARC Industrial Transformation Training Centre in Additive Biomanufacturing (ARC IC160100026). Mr. Jianfeng Li would like to thank ACES and AINSE Ltd for providing financial assistance. The authors would also like to acknowledge Assoc. Prof. Chee O. Too for his comments on the manuscript.

\section{References}

[1] A.K. Geim, K.S. Novoselov, The rise of graphene, Nat Mater 6(3) (2007) 183-191.

[2] K.S. Novoselov, A.K. Geim, S.V. Morozov, D. Jiang, Y. Zhang, S.V. Dubonos, I.V. Grigorieva, A.A. Firsov, Electric Field Effect in Atomically Thin Carbon Films, Science 306(5696) (2004) 666669.

[3] W. Choi, I. Lahiri, R. Seelaboyina, Y.S. Kang, Synthesis of Graphene and Its Applications: A Review, Critical Reviews in Solid State and Materials Sciences 35(1) (2010) 52-71.

[4] K.S. Novoselov, A.K. Geim, S.V. Morozov, D. Jiang, M.I. Katsnelson, I.V. Grigorieva, S.V. Dubonos, A.A. Firsov, Two-dimensional gas of massless Dirac fermions in graphene, Nature 438 (2005) 197.

[5] M.J. Allen, V.C. Tung, R.B. Kaner, Honeycomb Carbon: A Review of Graphene, Chemical Reviews 110(1) (2010) 132-145.

[6] M.S. Fuhrer, C.N. Lau, A.H. MacDonald, Graphene: Materially Better Carbon, MRS Bulletin 35(04) (2010) 289-295.

[7] A.H. Castro Neto, F. Guinea, N.M.R. Peres, K.S. Novoselov, A.K. Geim, The electronic 
properties of graphene, Reviews of Modern Physics 81(1) (2009) 109-162.

[8] A.M. Pinto, I.C. Goncalves, F.D. Magalhaes, Graphene-based materials biocompatibility: a review, Colloids and surfaces. B, Biointerfaces 111 (2013) 188-202.

[9] S. Syama, P.V. Mohanan, Safety and biocompatibility of graphene: A new generation nanomaterial for biomedical application, International Journal of Biological Macromolecules 86 (2016) 546-555.

[10] Y. Zhang, S.F. Ali, E. Dervishi, Y. Xu, Z. Li, D. Casciano, A.S. Biris, Cytotoxicity Effects of Graphene and Single-Wall Carbon Nanotubes in Neural Phaeochromocytoma-Derived PC12 Cells, ACS Nano 4(6) (2010) 3181-3186.

[11] Y. Li, H. Yuan, A. von dem Bussche, M. Creighton, R.H. Hurt, A.B. Kane, H. Gao, Graphene microsheets enter cells through spontaneous membrane penetration at edge asperities and corner sites, Proceedings of the National Academy of Sciences 110(30) (2013) 12295-12300.

[12] K.-H. Liao, Y.-S. Lin, C.W. Macosko, C.L. Haynes, Cytotoxicity of Graphene Oxide and Graphene in Human Erythrocytes and Skin Fibroblasts, ACS Applied Materials \& Interfaces 3(7) (2011) 2607-2615.

[13] O. Akhavan, E. Ghaderi, A. Akhavan, Size-dependent genotoxicity of graphene nanoplatelets in human stem cells, Biomaterials 33(32) (2012) 8017-8025.

[14] J. Mao, R. Guo, L.-T. Yan, Simulation and analysis of cellular internalization pathways and membrane perturbation for graphene nanosheets, Biomaterials 35(23) (2014) 6069-6077.

[15] B. Zhang, P. Wei, Z. Zhou, T. Wei, Interactions of graphene with mammalian cells: Molecular mechanisms and biomedical insights, Advanced drug delivery reviews 105 (2016) 145-162.

[16] F. Banhart, J. Kotakoski, A.V. Krasheninnikov, Structural Defects in Graphene, ACS Nano 5(1) (2011) 26-41.

[17] K.V. Emtsev, A. Bostwick, K. Horn, J. Jobst, G.L. Kellogg, L. Ley, J.L. McChesney, T. Ohta, S.A. Reshanov, J. Rohrl, E. Rotenberg, A.K. Schmid, D. Waldmann, H.B. Weber, T. Seyller, Towards 
wafer-size graphene layers by atmospheric pressure graphitization of silicon carbide, Nat Mater 8(3) (2009) 203-207.

[18] K.S. Kim, Y. Zhao, H. Jang, S.Y. Lee, J.M. Kim, K.S. Kim, J.-H. Ahn, P. Kim, J.-Y. Choi, B.H. Hong, Large-scale pattern growth of graphene films for stretchable transparent electrodes, Nature 457(7230) (2009) 706-710.

[19] D. Li, M.B. Muller, S. Gilje, R.B. Kaner, G.G. Wallace, Processable aqueous dispersions of graphene nanosheets, Nat Nano 3(2) (2008) 101-105.

[20] G. Yazdi, T. Iakimov, R. Yakimova, Epitaxial graphene on SiC: a review of growth and characterization, Crystals 6(5) (2016) 53.

[21] R.M. Jacobberger, R. Machhi, J. Wroblewski, B. Taylor, A.L. Gillian-Daniel, M.S. Arnold, Simple Graphene Synthesis via Chemical Vapor Deposition, Journal of Chemical Education 92(11) (2015) 1903-1907.

[22] M.C.F.d. Costa, H.B. Ribeiro, F. Kessler, E.A.T.d. Souza, G.J.M. Fechine, Micromechanical exfoliation of two-dimensional materials by a polymeric stamp, Materials Research Express 3(2) (2016) 025303.

[23] H. Bai, C. Li, G. Shi, Functional Composite Materials Based on Chemically Converted Graphene, Advanced materials 23(9) (2011) 1089-1115.

[24] J.P.A. de Mendonça, A.H. Lima, J.C. Roldao, J.d.S. Martins, G.M.A. Junqueira, W.G. Quirino, F. Sato, The role of sulfate in the chemical synthesis of graphene oxide, Materials Chemistry and Physics 215 (2018) 203-210.

[25] S. Stankovich, D.A. Dikin, R.D. Piner, K.A. Kohlhaas, A. Kleinhammes, Y. Jia, Y. Wu, S.T. Nguyen, R.S. Ruoff, Synthesis of graphene-based nanosheets via chemical reduction of exfoliated graphite oxide, Carbon 45(7) (2007) 1558-1565.

[26] S. Pei, H.-M. Cheng, The reduction of graphene oxide, Carbon 50(9) (2012) 3210-3228.

[27] Y.-R. Kang, Y.-L. Li, F. Hou, Y.-Y. Wen, D. Su, Fabrication of electric papers of graphene 
nanosheet shelled cellulose fibres by dispersion and infiltration as flexible electrodes for energy storage, Nanoscale 4(10) (2012) 3248-3253.

[28] R. Geetha Bai, N. Ninan, K. Muthoosamy, S. Manickam, Graphene: A versatile platform for nanotheranostics and tissue engineering, Progress in Materials Science 91(Supplement C) (2018) 2469.

[29] O. Akhavan, Graphene scaffolds in progressive nanotechnology/stem cell-based tissue engineering of the nervous system, J. Mater. Chem. B 4(19) (2016) 3169-3190.

[30] G. Jensen, C. Morrill, Y. Huang, 3D tissue engineering, an emerging technique for pharmaceutical research, Acta Pharmaceutica Sinica B 8(5) (2018) 756-766.

[31] S.R. Shin, B. Aghaei-Ghareh-Bolagh, X. Gao, M. Nikkhah, S.M. Jung, A. Dolatshahi-Pirouz, S.B. Kim, S.M. Kim, M.R. Dokmeci, X. Tang, A. Khademhosseini, Layer-by-Layer Assembly of 3D Tissue Constructs with Functionalized Graphene, Advanced Functional Materials 24(39) (2014) 6136-6144.

[32] K.Y. Morgan, L.D. Black, It's all in the timing: Modeling isovolumic contraction through development and disease with a dynamic dual electromechanical bioreactor system, Organogenesis 10(3) (2014) 317-322.

[33] Q. Song, Z. Jiang, N. Li, P. Liu, L. Liu, M. Tang, G. Cheng, Anti-inflammatory effects of threedimensional graphene foams cultured with microglial cells, Biomaterials 35(25) (2014) 6930-6940. [34] M.M. Stevens, Biomaterials for bone tissue engineering, Materials Today 11(5) (2008) 18-25. [35] J.K. Wang, G.M. Xiong, M. Zhu, B. Ozyilmaz, A.H. Castro Neto, N.S. Tan, C. Choong, Polymer-Enriched 3D Graphene Foams for Biomedical Applications, ACS Appl Mater Interfaces 7(15) (2015) 8275-83.

[36] A.R. Amini, C.T. Laurencin, S.P. Nukavarapu, Bone Tissue Engineering: Recent Advances and Challenges, Critical reviews in biomedical engineering 40(5) (2012) 363-408.

[37] N. Dubey, R. Bentini, I. Islam, T. Cao, A.H. Castro Neto, V. Rosa, Graphene: A Versatile 
Carbon-Based Material for Bone Tissue Engineering, Stem cells international 2015 (2015) 12.

[38] W.C. Lee, C.H.Y.X. Lim, H. Shi, L.A.L. Tang, Y. Wang, C.T. Lim, K.P. Loh, Origin of Enhanced Stem Cell Growth and Differentiation on Graphene and Graphene Oxide, ACS Nano 5(9) (2011) 7334-7341.

[39] H. Xie, T. Cao, J.V. Gomes, A.H. Castro Neto, V. Rosa, Two and three-dimensional graphene substrates to magnify osteogenic differentiation of periodontal ligament stem cells, Carbon 93 (2015) 266-275.

[40] W. Wang, G. Caetano, S.W. Ambler, J.J. Blaker, A.M. Frade, P. Mandal, C. Diver, P. Bártolo, Enhancing the Hydrophilicity and Cell Attachment of 3D Printed PCL/Graphene Scaffolds for Bone Tissue Engineering, Materials 9(12) (2016).

[41] W. Wang, J.R.P. Junior, P.R.L. Nalesso, D. Musson, J. Cornish, F. Mendonça, G.F. Caetano, P. Bártolo, Engineered 3D printed poly( $\varepsilon$-caprolactone)/graphene scaffolds for bone tissue engineering, Materials Science and Engineering: C 100 (2019) 759-770.

[42] A.E. Jakus, R.N. Shah, Multi and mixed 3D-printing of graphene-hydroxyapatite hybrid materials for complex tissue engineering, Journal of Biomedical Materials Research Part A 105(1) (2016) 274-283.

[43] J. Li, X. Liu, J.M. Crook, G.G. Wallace, Development of a porous 3D graphene-PDMS scaffold for improved osseointegration, Colloids and Surfaces B: Biointerfaces 159 (2017) 386-393.

[44] S.W. Crowder, D. Prasai, R. Rath, D.A. Balikov, H. Bae, K.I. Bolotin, H.J. Sung, Threedimensional graphene foams promote osteogenic differentiation of human mesenchymal stem cells, Nanoscale 5(10) (2013) 4171-6.

[45] H. Liu, J. Cheng, F. Chen, F. Hou, D. Bai, P. Xi, Z. Zeng, Biomimetic and cell-mediated mineralization of hydroxyapatite by carrageenan functionalized graphene oxide, ACS Appl Mater Interfaces 6(5) (2014) 3132-40.

[46] L. Keheng, Z. Zhenfang, L. Dapeng, Z. Wensi, Y. Xiaoqing, L. Wei, G. Coucong, W. Gang, S. 
Zhiqiang, Biomimetic Ultralight, Highly Porous, Shape- Adjustable, and Biocompatible 3D Graphene Minerals via Incorporation of Self- Assembled Peptide Nanosheets, Advanced Functional Materials 0(0) 1801056.

[47] P. Yu, R.-Y. Bao, X.-J. Shi, W. Yang, M.-B. Yang, Self-assembled high-strength hydroxyapatite/graphene oxide/chitosan composite hydrogel for bone tissue engineering, Carbohydrate Polymers 155(Supplement C) (2017) 507-515.

[48] X. Xie, K. Hu, D. Fang, L. Shang, S.D. Tran, M. Cerruti, Graphene and hydroxyapatite selfassemble into homogeneous, free standing nanocomposite hydrogels for bone tissue engineering, Nanoscale 7(17) (2015) 7992-8002.

[49] Z. Fan, J. Wang, Z. Wang, H. Ran, Y. Li, L. Niu, P. Gong, B. Liu, S. Yang, One-pot synthesis of graphene/hydroxyapatite nanorod composite for tissue engineering, Carbon 66(Supplement C) (2014) 407-416.

[50] S. Dinescu, M. Ionita, A.M. Pandele, B. Galateanu, H. Iovu, A. Ardelean, M. Costache, A. Hermenean, In vitro cytocompatibility evaluation of chitosan/graphene oxide 3D scaffold composites designed for bone tissue engineering, Bio-medical materials and engineering 24(6) (2014) 2249-56. [51] A. Hermenean, A. Codreanu, H. Herman, C. Balta, M. Rosu, C.V. Mihali, A. Ivan, S. Dinescu, M. Ionita, M. Costache, Chitosan-Graphene Oxide 3D scaffolds as Promising Tools for Bone Regeneration in Critical-Size Mouse Calvarial Defects, Scientific Reports 7(1) (2017) 16641.

[52] D. Wu, E. Bäckström, M. Hakkarainen, Starch Derived Nanosized Graphene Oxide Functionalized Bioactive Porous Starch Scaffolds, Macromolecular Bioscience 17(6) (2017) n/a-n/a. [53] A.M. Pandele, M. Ionita, L. Crica, E. Vasile, H. Iovu, Novel Chitosan-poly(vinyl alcohol)/graphene oxide biocomposites 3D porous scaffolds, Composites Part B: Engineering 126 (2017) 81-87.

[54] H. Elkhenany, S. Bourdo, S. Hecht, R. Donnell, D. Gerard, R. Abdelwahed, A. Lafont, K. Alghazali, F. Watanabe, A.S. Biris, D. Anderson, M. Dhar, Graphene nanoparticles as osteoinductive 
and osteoconductive platform for stem cell and bone regeneration, Nanomedicine: Nanotechnology, Biology and Medicine 13(7) (2017) 2117-2126.

[55] S. Kumar, K. Chatterjee, Strontium eluting graphene hybrid nanoparticles augment osteogenesis in a 3D tissue scaffold, Nanoscale 7(5) (2015) 2023-33.

[56] F. Song, W. Jie, T. Zhang, W. Li, Y. Jiang, L. Wan, W. Liu, X. Li, B. Liu, Room-temperature fabrication of a three-dimensional reduced-graphene oxide/polypyrrole/hydroxyapatite composite scaffold for bone tissue engineering, RSC Advances 6(95) (2016) 92804-92812.

[57] R. Wang, F. Song, S. Li, L. Ding, Z. Xu, B. Zhang, J. Wang, M. Li, B. Liu, Y. Qiu, Polydopamine-assisted Sr immobilization to improve the osteogenesis of a three-dimensional reduced graphene oxide/polypyrrole composite scaffold, Materials Letters 246 (2019) 182-185.

[58] Y. Liu, N. Fang, B. Liu, L. Song, B. Wen, D. Yang, Aligned porous chitosan/graphene oxide scaffold for bone tissue engineering, Materials Letters 233 (2018) 78-81.

[59] H. Ma, C. Jiang, D. Zhai, Y. Luo, Y. Chen, F. Lv, Z. Yi, Y. Deng, J. Wang, J. Chang, C. Wu, A Bifunctional Biomaterial with Photothermal Effect for Tumor Therapy and Bone Regeneration, Advanced Functional Materials 26(8) (2016) 1197-1208.

[60] Y. Zhang, D. Zhai, M. Xu, Q. Yao, J. Chang, C. Wu, 3D-printed bioceramic scaffolds with a Fe3O4/graphene oxide nanocomposite interface for hyperthermia therapy of bone tumor cells, Journal of Materials Chemistry B 4(17) (2016) 2874-2886.

[61] W. Nie, C. Peng, X. Zhou, L. Chen, W. Wang, Y. Zhang, P.X. Ma, C. He, Three-dimensional porous scaffold by self-assembly of reduced graphene oxide and nano-hydroxyapatite composites for bone tissue engineering, Carbon 116 (2017) 325-337.

[62] S.L. Levengood, M. Zhang, Chitosan-based scaffolds for bone tissue engineering, J Mater Chem B Mater Biol Med 2(21) (2014) 3161-3184.

[63] A.W. James, G. LaChaud, J. Shen, G. Asatrian, V. Nguyen, X. Zhang, K. Ting, C. Soo, A Review of the Clinical Side Effects of Bone Morphogenetic Protein-2, Tissue engineering. Part B, Reviews 
22(4) (2016) 284-297.

[64] Z. Sheikh, A.M. Javaid, N. Hamdan, R. Hashmi, Bone Regeneration Using Bone Morphogenetic Proteins and Various Biomaterial Carriers, Materials 8(4) (2015).

[65] Q. Yao, J. Jing, Q. Zeng, T.L. Lu, Y. Liu, X. Zheng, Q. Chen, Bilayered BMP2 Eluting Coatings on Graphene Foam by Electrophoretic Deposition: Electroresponsive BMP2 Release and Enhancement of Osteogenic Differentiation, ACS Applied Materials \& Interfaces (2017).

[66] M. Cano, U. Khan, T. Sainsbury, A. O’Neill, Z. Wang, I.T. McGovern, W.K. Maser, A.M. Benito, J.N. Coleman, Improving the mechanical properties of graphene oxide based materials by covalent attachment of polymer chains, Carbon 52 (2013) 363-371.

[67] J. Gao, F. Bao, L. Feng, K. Shen, Q. Zhu, D. Wang, T. Chen, R. Ma, C. Yan, Functionalized graphene oxide modified polysebacic anhydride as drug carrier for levofloxacin controlled release, RSC Advances 1(9) (2011) 1737-1744.

[68] E.A. Makris, A.H. Gomoll, K.N. Malizos, J.C. Hu, K.A. Athanasiou, Repair and tissue engineering techniques for articular cartilage, 11 (2014) 21.

[69] X. Zhou, M. Nowicki, H. Cui, W. Zhu, X. Fang, S. Miao, S.-J. Lee, M. Keidar, L.G. Zhang, 3D bioprinted graphene oxide-incorporated matrix for promoting chondrogenic differentiation of human bone marrow mesenchymal stem cells, Carbon 116 (2017) 615-624.

[70] Z. Cheng, B. Landish, Z. Chi, C. Nannan, D. Jingyu, L. Sen, L. Xiangjin, 3D printing hydrogel with graphene oxide is functional in cartilage protection by influencing the signal pathway of Rank/Rankl/OPG, Materials Science and Engineering: C 82 (2018) 244-252.

[71] A. Nieto, R. Dua, C. Zhang, B. Boesl, S. Ramaswamy, A. Agarwal, Three Dimensional Graphene Foam/Polymer Hybrid as a High Strength Biocompatible Scaffold, Advanced Functional Materials 25(25) (2015) 3916-3924.

[72] A.R. Unnithan, C.H. Park, C.S. Kim, Nanoengineered bioactive 3D composite scaffold: A unique combination of graphene oxide and nanotopography for tissue engineering applications, 
Composites Part B: Engineering 90(Supplement C) (2016) 503-511.

[73] W.C. Lee, C.H. Lim, Kenry, C. Su, K.P. Loh, C.T. Lim, Cell-Assembled Graphene Biocomposite for Enhanced Chondrogenic Differentiation, Small 11(8) (2015) 963-969.

[74] H.H. Yoon, S.H. Bhang, T. Kim, T. Yu, T. Hyeon, B.-S. Kim, Dual Roles of Graphene Oxide in Chondrogenic Differentiation of Adult Stem Cells: Cell-Adhesion Substrate and Growth FactorDelivery Carrier, Advanced Functional Materials 24(41) (2014) 6455-6464.

[75] J. Liao, Y. Qu, B. Chu, X. Zhang, Z. Qian, Biodegradable CSMA/PECA/Graphene Porous Hybrid Scaffold for Cartilage Tissue Engineering, Scientific Reports 5 (2015) 9879.

[76] A. Marrella, A. Lagazzo, F. Barberis, T. Catelani, R. Quarto, S. Scaglione, Enhanced mechanical performances and bioactivity of cell laden-graphene oxide/alginate hydrogels open new scenario for articular tissue engineering applications, Carbon 115 (2017) 608-616.

[77] T. Izumikawa, B. Sato, H. Kitagawa, Chondroitin Sulfate Is Indispensable for Pluripotency and Differentiation of Mouse Embryonic Stem Cells, Scientific Reports 4 (2014) 3701.

[78] N. Garcia-Giralt, R. Izquierdo, X. Nogués, M. Perez-Olmedilla, P. Benito, J.L. Gómez-Ribelles, M.A. Checa, J. Suay, E. Caceres, J.C. Monllau, A porous PCL scaffold promotes the human chondrocytes redifferentiation and hyaline-specific extracellular matrix protein synthesis, Journal of Biomedical Materials Research Part A 85A(4) (2008) 1082-1089.

[79] K. Wang, S.-Z. Fu, Y. Chun Gu, X. Xu, P. Wei Dong, G. Guo, X. Zhao, Y. Quan Wei, Z. Yong Qian, Synthesis and characterization of biodegradable pH-sensitive hydrogels based on poly(??caprolactone), methacrylic acid, and poly(ethylene glycol), 2009.

[80] S.J. Florczyk, K. Wang, S. Jana, D.L. Wood, S.K. Sytsma, J.G. Sham, F.M. Kievit, M. Zhang, Porous chitosan-hyaluronic acid scaffolds as a mimic of glioblastoma microenvironment ECM, Biomaterials 34(38) (2013) 10143-10150.

[81] N. Li, Q. Zhang, S. Gao, Q. Song, R. Huang, L. Wang, L. Liu, J. Dai, M. Tang, G. Cheng, Threedimensional graphene foam as a biocompatible and conductive scaffold for neural stem cells, 
Scientific Reports 3 (2013) 1604.

[82] Y. Qian, X. Zhao, Q. Han, W. Chen, H. Li, W. Yuan, An integrated multi-layer 3D-fabrication of PDA/RGD coated graphene loaded PCL nanoscaffold for peripheral nerve restoration, Nature Communications 9(1) (2018) 323.

[83] A.E. Jakus, E.B. Secor, A.L. Rutz, S.W. Jordan, M.C. Hersam, R.N. Shah, Three-Dimensional Printing of High-Content Graphene Scaffolds for Electronic and Biomedical Applications, ACS Nano 9(4) (2015) 4636-4648.

[84] Y. Qian, J. Song, X. Zhao, W. Chen, Y. Ouyang, W. Yuan, C. Fan, 3D Fabrication with Integration Molding of a Graphene Oxide/Polycaprolactone Nanoscaffold for Neurite Regeneration and Angiogenesis, Advanced Science 5(4) (2018) 1700499.

[85] Q. Ma, L. Yang, Z. Jiang, Q. Song, M. Xiao, D. Zhang, X. Ma, T. Wen, G. Cheng, ThreeDimensional Stiff Graphene Scaffold on Neural Stem Cells Behavior, ACS Applied Materials \& Interfaces 8(50) (2016) 34227-34233.

[86] N. Anh Tuan, M. Sabrina, L. Manuela, C. Eunice, M. DongLiang, C. Philippe, V. Virgile, T. Edwin Hang Tong, L.G. Eyleen, K.F.Y. Evelyn, Human Rett-derived neuronal progenitor cells in 3D graphene scaffold as an in vitro platform to study the effect of electrical stimulation on neuronal differentiation, Biomedical materials 13(3) (2018) 034111.

[87] W. Xie, F. Song, R. Wang, S. Sun, M. Li, Z. Fan, B. Liu, Q. Zhang, J. Wang, Mechanically Robust 3D Graphene-Hydroxyapatite Hybrid Bioscaffolds with Enhanced Osteoconductive and Biocompatible Performance, Crystals 8(2) (2018).

[88] S. Shah, P.T. Yin, T.M. Uehara, S.-T.D. Chueng, L. Yang, K.-B. Lee, Guiding Stem Cell Differentiation into Oligodendrocytes Using Graphene-Nanofiber Hybrid Scaffolds, Advanced materials 26(22) (2014) 3673-3680.

[89] W. Guo, S. Wang, X. Yu, J. Qiu, J. Li, W. Tang, Z. Li, X. Mou, H. Liu, Z. Wang, Construction of a 3D rGO-collagen hybrid scaffold for enhancement of the neural differentiation of mesenchymal 
stem cells, Nanoscale 8(4) (2016) 1897-1904.

[90] K. Zhou, G.A. Thouas, C.C. Bernard, D.R. Nisbet, D.I. Finkelstein, D. Li, J.S. Forsythe, Method to Impart Electro- and Biofunctionality to Neural Scaffolds Using Graphene-Polyelectrolyte Multilayers, ACS Applied Materials \& Interfaces 4(9) (2012) 4524-4531.

[91] O. Akhavan, E. Ghaderi, S.A. Shirazian, R. Rahighi, Rolled graphene oxide foams as threedimensional scaffolds for growth of neural fibers using electrical stimulation of stem cells, Carbon 97 (2016) 71-77.

[92] M.C. Serrano, J. Patiño, C. García-Rama, M.L. Ferrer, J.L.G. Fierro, A. Tamayo, J.E. CollazosCastro, F. del Monte, M.C. Gutiérrez, 3D free-standing porous scaffolds made of graphene oxide as substrates for neural cell growth, Journal of Materials Chemistry B 2(34) (2014) 5698.

[93] C. Martín, S. Merino, J.M. González-Domínguez, R. Rauti, L. Ballerini, M. Prato, E. Vázquez, Graphene Improves the Biocompatibility of Polyacrylamide Hydrogels: 3D Polymeric Scaffolds for Neuronal Growth, Scientific Reports 7(1) (2017) 10942.

[94] H.-Y. Mi, M.R. Salick, X. Jing, B.R. Jacques, W.C. Crone, X.-F. Peng, L.-S. Turng, Characterization of thermoplastic polyurethane/polylactic acid (TPU/PLA) tissue engineering scaffolds fabricated by microcellular injection molding, Materials Science and Engineering: C 33(8) (2013) 4767-4776.

[95] Q. Chen, J.D. Mangadlao, J. Wallat, A. De Leon, J.K. Pokorski, R.C. Advincula, 3D Printing Biocompatible Polyurethane/Poly(lactic acid)/Graphene Oxide Nanocomposites: Anisotropic Properties, ACS Applied Materials \& Interfaces 9(4) (2017) 4015-4023.

[96] B. Lu, T. Li, H. Zhao, X. Li, C. Gao, S. Zhang, E. Xie, Graphene-based composite materials beneficial to wound healing, Nanoscale 4(9) (2012) 2978-2982.

[97] G. Vunjak-Novakovic, N. Tandon, A. Godier, R. Maidhof, A. Marsano, T.P. Martens, M. Radisic, Challenges in cardiac tissue engineering, Tissue engineering. Part B, Reviews 16(2) (2010) 169-187. 
[98] Y. Zhang, X. Liu, K. Michelson, R. Trivedi, X. Wu, E. Schepp, Y. Xing, D. Darland, J.X. Zhao, Graphene Oxide-Based Biocompatible 3D Mesh with a Tunable Porosity and Tensility for Cell Culture, ACS Biomaterials Science \& Engineering 4(5) (2018) 1505-1517.

[99] S.K. Ameri, P. Singh, R. D'Angelo, W. Stoppel, L. Black, S.R. Sonkusale, Three dimensional graphene scaffold for cardiac tissue engineering and in-situ electrical recording, Engineering in Medicine and Biology Society (EMBC), 2016 IEEE 38th Annual International Conference of the, IEEE, 2016, pp. 4201-4203.

[100] R. Paus, J. Klein, P.A. Permana, M. Owecki, G.N. Chaldakov, M. Böhm, G. Hausman, C.M. Lapière, P. Atanassova, J. Sowiński, M. Fasshauer, D.B. Hausman, E. Maquoi, A.B. Tonchev, V.N. Peneva, K.P. Vlachanov, M. Fiore, L. Aloe, A. Slominski, C.L. Reardon, T.J. Ryan, C.M. Pond, T.J. Ryan, What are subcutaneous adipocytes really good for...?, Experimental Dermatology 16(1) (2007) $45-47$.

[101] M. Patel, H.J. Moon, D.Y. Ko, B. Jeong, Composite System of Graphene Oxide and Polypeptide Thermogel As an Injectable 3D Scaffold for Adipogenic Differentiation of TonsilDerived Mesenchymal Stem Cells, ACS Applied Materials \& Interfaces 8(8) (2016) 5160-5169.

[102] M. Loeblein, G. Perry, S.H. Tsang, W. Xiao, D. Collard, P. Coquet, Y. Sakai, E.H.T. Teo, Three-Dimensional Graphene: A Biocompatible and Biodegradable Scaffold with Enhanced Oxygenation, Advanced healthcare materials 5(10) (2016) 1177-1191.

[103] A. Sinha, Y. Choi, M.H. Nguyen, T.L. Nguyen, S.W. Choi, J. Kim, A 3D Macroporous Alginate Graphene Scaffold with an Extremely Slow Release of a Loaded Cargo for In Situ Long-Term Activation of Dendritic Cells, Advanced healthcare materials 8(5) (2019) 1800571.

[104] G. Lalwani, M. D'Agati, A. Gopalan, M. Rao, J. Schneller, B. Sitharaman, Three-dimensional macroporous graphene scaffolds for tissue engineering, Journal of Biomedical Materials Research Part A 105(1) (2017) 73-83.

[105] T.-H. Kim, K.-B. Lee, J.-W. Choi, 3D graphene oxide-encapsulated gold nanoparticles to detect 
neural stem cell differentiation, Biomaterials 34(34) (2013) 8660-8670.

[106] C. Liao, Y. Li, S.C. Tjong, Graphene Nanomaterials: Synthesis, Biocompatibility, and Cytotoxicity, International journal of molecular sciences 19(11) (2018) 3564.

[107] K.K.H. De Silva, H.-H. Huang, M. Yoshimura, Progress of reduction of graphene oxide by ascorbic acid, Applied Surface Science 447 (2018) 338-346.

[108] A. Muñoz, M. Costa, Elucidating the mechanisms of nickel compound uptake: a review of particulate and nano-nickel endocytosis and toxicity, Toxicology and applied pharmacology 260(1) (2012) 1-16.

[109] Q.L. Loh, C. Choong, Three-dimensional scaffolds for tissue engineering applications: role of porosity and pore size, Tissue engineering. Part B, Reviews 19(6) (2013) 485-502.

[110] D. Zhang, B. Chi, B. Li, Z. Gao, Y. Du, J. Guo, J. Wei, Fabrication of highly conductive graphene flexible circuits by 3D printing, Synthetic Metals 217 (2016) 79-86.

[111] Y. Zhuang, W. Song, G. Ning, X. Sun, Z. Sun, G. Xu, B. Zhang, Y. Chen, S. Tao, 3D-printing of materials with anisotropic heat distribution using conductive polylactic acid composites, Materials \& Design 126 (2017) 135-140.

[112] K. Gnanasekaran, T. Heijmans, S. van Bennekom, H. Woldhuis, S. Wijnia, G. de With, H. Friedrich, 3D printing of CNT- and graphene-based conductive polymer nanocomposites by fused deposition modeling, Applied Materials Today 9 (2017) 21-28.

[113] S. Sayyar, S. Gambhir, J. Chung, D.L. Officer, G.G. Wallace, 3D printable conducting hydrogels containing chemically converted graphene, Nanoscale 9(5) (2017) 2038-2050.

[114] X. Wei, D. Li, W. Jiang, Z. Gu, X. Wang, Z. Zhang, Z. Sun, 3D Printable Graphene Composite, Scientific Reports 5 (2015) 11181.

[115] V.G. Rocha, E. García-Tuñón, C. Botas, F. Markoulidis, E. Feilden, E. D’Elia, N. Ni, M. Shaffer, E. Saiz, Multimaterial 3D Printing of Graphene-Based Electrodes for Electrochemical Energy Storage Using Thermoresponsive Inks, ACS Applied Materials \& Interfaces 9(42) (2017) 
37136-37145.

[116] S. Sayyar, M. Bjorninen, S. Haimi, S. Miettinen, K. Gilmore, D. Grijpma, G. Wallace, UV Cross-Linkable Graphene/Poly(trimethylene Carbonate) Composites for 3D Printing of Electrically Conductive Scaffolds, ACS Applied Materials \& Interfaces 8(46) (2016) 31916-31925.

[117] C.L. Manzanares Palenzuela, F. Novotný, P. Krupička, Z. Sofer, M. Pumera, 3D-Printed Graphene/Polylactic Acid Electrodes Promise High Sensitivity in Electroanalysis, Analytical Chemistry 90(9) (2018) 5753-5757.

[118] K. Huang, J. Yang, S. Dong, Q. Feng, X. Zhang, Y. Ding, J. Hu, Anisotropy of graphene scaffolds assembled by three-dimensional printing, Carbon 130 (2018) 1-10.

[119] C. Zhu, T.Y.-J. Han, E.B. Duoss, A.M. Golobic, J.D. Kuntz, C.M. Spadaccini, M.A. Worsley, Highly compressible 3D periodic graphene aerogel microlattices, Nat Commun 6 (2015).

[120] J.H. Kim, W.S. Chang, D. Kim, J.R. Yang, J.T. Han, G.-W. Lee, J.T. Kim, S.K. Seol, 3D Printing of Reduced Graphene Oxide Nanowires, Advanced materials 27(1) (2015) 157-161.

[121] K. Fu, Y. Wang, C. Yan, Y. Yao, Y. Chen, J. Dai, S. Lacey, Y. Wang, J. Wan, T. Li, Z. Wang, Y. Xu, L. Hu, Graphene Oxide-Based Electrode Inks for 3D-Printed Lithium-Ion Batteries, Advanced materials 28(13) (2016) 2587-94.

[122] Y. Yao, K.K. Fu, C. Yan, J. Dai, Y. Chen, Y. Wang, B. Zhang, E. Hitz, L. Hu, ThreeDimensional Printable High-Temperature and High-Rate Heaters, ACS Nano 10(5) (2016) 52725279.

[123] S.D. Lacey, D.J. Kirsch, Y. Li, J.T. Morgenstern, B.C. Zarket, Y. Yao, J. Dai, L.Q. Garcia, B. Liu, T. Gao, S. Xu, S.R. Raghavan, J.W. Connell, Y. Lin, L. Hu, Extrusion-Based 3D Printing of Hierarchically Porous Advanced Battery Electrodes, Advanced materials 30(12) (2018) 1705651. [124] E. García-Tuñón, E. Feilden, H. Zheng, E. D’Elia, A. Leong, E. Saiz, Graphene Oxide: An Allin-One Processing Additive for 3D Printing, ACS Applied Materials \& Interfaces 9(38) (2017) 32977-32989. 
[125] S. Naficy, R. Jalili, S.H. Aboutalebi, R.A. Gorkin Iii, K. Konstantinov, P.C. Innis, G.M. Spinks, P. Poulin, G.G. Wallace, Graphene oxide dispersions: tuning rheology to enable fabrication, Materials Horizons 1(3) (2014) 326-331.

[126] E. García-Tuñon, S. Barg, J. Franco, R. Bell, S. Eslava, E. D'Elia, R.C. Maher, F. Guitian, E. Saiz, Printing in Three Dimensions with Graphene, Advanced materials 27(10) (2015) 1688-1693.

[127] Q. Zhang, F. Zhang, S.P. Medarametla, H. Li, C. Zhou, D. Lin, 3D Printing of Graphene Aerogels, Small 12(13) (2016) 1702-1708.

[128] Y. Jiang, Z. Xu, T. Huang, Y. Liu, F. Guo, J. Xi, W. Gao, C. Gao, Direct 3D Printing of Ultralight Graphene Oxide Aerogel Microlattices, Advanced Functional Materials 28(16) (2018) 1707024.

[129] K. Shen, H. Mei, B. Li, J. Ding, S. Yang, 3D Printing Sulfur Copolymer-Graphene Architectures for Li-S Batteries, Advanced Energy Materials 8(4) (2018) 1701527.

[130] X. You, J. Yang, Q. Feng, K. Huang, H. Zhou, J. Hu, S. Dong, Three-dimensional graphenebased materials by direct ink writing method for lightweight application, International Journal of Lightweight Materials and Manufacture 1(2) (2018) 96-101.

[131] Z. Hu, F. Chen, J. Xu, Q. Nian, D. Lin, C. Chen, X. Zhu, Y. Chen, M. Zhang, 3D printing graphene-aluminum nanocomposites, Journal of Alloys and Compounds 746 (2018) 269-276.

[132] J. Sha, Y. Li, R. Villegas Salvatierra, T. Wang, P. Dong, Y. Ji, S.-K. Lee, C. Zhang, J. Zhang, R.H. Smith, P.M. Ajayan, J. Lou, N. Zhao, J.M. Tour, Three-Dimensional Printed Graphene Foams, ACS Nano 11(7) (2017) 6860-6867.

[133] D.X. Luong, A.K. Subramanian, G.A.L. Silva, J. Yoon, S. Cofer, K. Yang, P.S. Owuor, T. Wang, Z. Wang, J. Lou, P.M. Ajayan, J.M. Tour, Laminated Object Manufacturing of 3D-Printed Laser-Induced Graphene Foams, Advanced materials 30(28) (2018) 1707416.

[134] D. Wang, X. Huang, J. Li, B. He, Q. Liu, L. Hu, G. Jiang, 3D printing of graphene-doped target for "matrix-free" laser desorption/ionization mass spectrometry, Chemical communications 54(22) 
(2018) 2723-2726.

[135] S. Sayyar, D.L. Officer, G.G. Wallace, Fabrication of 3D structures from graphene-based biocomposites, Journal of Materials Chemistry B 5(19) (2017) 3462-3482.

[136] S. Sayyar, E. Murray, B.C. Thompson, J. Chung, D.L. Officer, S. Gambhir, G.M. Spinks, G.G. Wallace, Processable conducting graphene/chitosan hydrogels for tissue engineering, J. Mater. Chem. B 3(3) (2015) 481-490.

[137] F. Del Giudice, A.Q. Shen, Shear rheology of graphene oxide dispersions, Current Opinion in Chemical Engineering 16 (2017) 23-30.

[138] X. Xie, Y. Zhou, H. Bi, K. Yin, S. Wan, L. Sun, Large-range Control of the Microstructures and Properties of Three-dimensional Porous Graphene, Scientific Reports 3 (2013) 2117.

[139] J.H.Y. Chung, S. Naficy, Z. Yue, R. Kapsa, A. Quigley, S.E. Moulton, G.G. Wallace, Bio-ink properties and printability for extrusion printing living cells, Biomaterials Science 1(7) (2013) 763773.

[140] Z. Li, H. Wang, B. Yang, Y. Sun, R. Huo, Three-dimensional graphene foams loaded with bone marrow derived mesenchymal stem cells promote skin wound healing with reduced scarring, Materials science \& engineering. C, Materials for biological applications 57 (2015) 181-8.

[141] Z. Yang, C. Yan, J. Liu, S. Chabi, Y. Xia, Y. Zhu, Designing 3D graphene networks via a 3Dprinted Ni template, RSC Advances 5(37) (2015) 29397-29400.

[142] J.L. Vickery, A.J. Patil, S. Mann, Fabrication of Graphene-Polymer Nanocomposites With Higher-Order Three-Dimensional Architectures, Advanced materials 21(21) (2009) 2180-2184.

[143] A. Chavez-Valdez, M.S.P. Shaffer, A.R. Boccaccini, Applications of Graphene Electrophoretic Deposition. A Review, The Journal of Physical Chemistry B 117(6) (2013) 1502-1515.

[144] H. Wang, G. Wang, Y. Ling, F. Qian, Y. Song, X. Lu, S. Chen, Y. Tong, Y. Li, High power density microbial fuel cell with flexible 3D graphene-nickel foam as anode, Nanoscale 5(21) (2013) 10283-10290. 
[145] X. Cao, Y. Shi, W. Shi, G. Lu, X. Huang, Q. Yan, Q. Zhang, H. Zhang, Preparation of Novel 3D Graphene Networks for Supercapacitor Applications, Small 7(22) (2011) 3163-3168.

[146] C. Zhao, K. Shu, C. Wang, S. Gambhir, G.G. Wallace, Reduced graphene oxide and polypyrrole/reduced graphene oxide composite coated stretchable fabric electrodes for supercapacitor application, Electrochimica Acta 172 (2015) 12-19.

[147] J. Ge, H.-B. Yao, W. Hu, X.-F. Yu, Y.-X. Yan, L.-B. Mao, H.-H. Li, S.-S. Li, S.-H. Yu, Facile dip coating processed graphene/MnO2 nanostructured sponges as high performance supercapacitor electrodes, Nano Energy 2(4) (2013) 505-513.

[148] K. Sohn, Y. Joo Na, H. Chang, K.-M. Roh, H. Dong Jang, J. Huang, Oil absorbing graphene capsules by capillary molding, Chemical communications 48(48) (2012) 5968-5970.

[149] X. Huang, K. Qian, J. Yang, J. Zhang, L. Li, C. Yu, D. Zhao, Functional Nanoporous Graphene Foams with Controlled Pore Sizes, Advanced materials 24(32) (2012) 4419-4423.

[150] L. Estevez, A. Kelarakis, Q. Gong, E.H. Da'as, E.P. Giannelis, Multifunctional Graphene/Platinum/Nafion Hybrids via Ice Templating, Journal of the American Chemical Society 133(16) (2011) 6122-6125.

[151] Z. Chen, W. Ren, L. Gao, B. Liu, S. Pei, H.-M. Cheng, Three-dimensional flexible and conductive interconnected graphene networks grown by chemical vapour deposition, Nat Mater 10(6) (2011) 424-428.

[152] X.-C. Dong, H. Xu, X.-W. Wang, Y.-X. Huang, M.B. Chan-Park, H. Zhang, L.-H. Wang, W. Huang, P. Chen, 3D Graphene-Cobalt Oxide Electrode for High-Performance Supercapacitor and Enzymeless Glucose Detection, ACS Nano 6(4) (2012) 3206-3213.

[153] X. Yu, B. Lu, Z. Xu, Super Long-Life Supercapacitors Based on the Construction of Nanohoneycomb-Like Strongly Coupled CoMoO4-3D Graphene Hybrid Electrodes, Advanced materials 26(7) (2014) 1044-1051.

[154] M. Zhang, K. Chen, C. Wang, M. Jian, Z. Yin, Z. Liu, G. Hong, Z. Liu, Y. Zhang, Mineral- 
Templated 3D Graphene Architectures for Energy-Efficient Electrodes, Small 14(22) (2018) 1801009.

[155] G. Huang, J. Han, F. Zhang, Z. Wang, H. Kashani, K. Watanabe, M. Chen, Lithiophilic 3D Nanoporous Nitrogen-Doped Graphene for Dendrite-Free and Ultrahigh-Rate Lithium-Metal Anodes, Advanced materials 31(2) (2019) 1805334.

[156] Y. Chen, X. Zhang, P. Yu, Y. Ma, Electrophoretic deposition of graphene nanosheets on nickel foams for electrochemical capacitors, Journal of Power Sources 195(9) (2010) 3031-3035.

[157] X. Xia, J. Tu, Y. Mai, R. Chen, X. Wang, C. Gu, X. Zhao, Graphene Sheet/Porous NiO Hybrid Film for Supercapacitor Applications, Chemistry - A European Journal 17(39) (2011) 10898-10905. [158] T. Zhai, F. Wang, M. Yu, S. Xie, C. Liang, C. Li, F. Xiao, R. Tang, Q. Wu, X. Lu, Y. Tong, 3D MnO2-graphene composites with large areal capacitance for high-performance asymmetric supercapacitors, Nanoscale 5(15) (2013) 6790-6796.

[159] L. Zhang, F. Zhang, X. Yang, G. Long, Y. Wu, T. Zhang, K. Leng, Y. Huang, Y. Ma, A. Yu, Y. Chen, Porous 3D graphene-based bulk materials with exceptional high surface area and excellent conductivity for supercapacitors, Sci Rep 3 (2013) 1408.

[160] S.-M. Yoon, W.M. Choi, H. Baik, H.-J. Shin, I. Song, M.-S. Kwon, J.J. Bae, H. Kim, Y.H. Lee, J.-Y. Choi, Synthesis of Multilayer Graphene Balls by Carbon Segregation from Nickel Nanoparticles, ACS Nano 6(8) (2012) 6803-6811.

[161] J. Sha, C. Gao, S.-K. Lee, Y. Li, N. Zhao, J.M. Tour, Preparation of Three-Dimensional Graphene Foams Using Powder Metallurgy Templates, ACS Nano 10(1) (2016) 1411-1416.

[162] X. Xiao, T.E. Beechem, M.T. Brumbach, T.N. Lambert, D.J. Davis, J.R. Michael, C.M. Washburn, J. Wang, S.M. Brozik, D.R. Wheeler, D.B. Burckel, R. Polsky, Lithographically Defined Three-Dimensional Graphene Structures, ACS Nano 6(4) (2012) 3573-3579.

[163] X. Yu, B. Wang, D. Gong, Z. Xu, B. Lu, Graphene Nanoribbons on Highly Porous 3D Graphene for High-Capacity and Ultrastable Al-Ion Batteries, Advanced materials 29(4) (2016) 1604118. 
[164] F. Zhang, E. Alhajji, Y. Lei, N. Kurra, H.N. Alshareef, Highly Doped 3D Graphene Na-Ion Battery Anode by Laser Scribing Polyimide Films in Nitrogen Ambient, Advanced Energy Materials 8(23) (2018) 1800353.

[165] Z.-Q. Feng, F. Wu, L. Jin, T. Wang, W. Dong, J. Zheng, Graphene Nanofibrous Foam Designed as an Efficient Oil Absorbent, Industrial \& Engineering Chemistry Research 58(8) (2019) 3000-3008. [166] Z. Chen, W. Ren, B. Liu, L. Gao, S. Pei, Z.-S. Wu, J. Zhao, H.-M. Cheng, Bulk growth of mono- to few-layer graphene on nickel particles by chemical vapor deposition from methane, Carbon 48(12) (2010) 3543-3550.

[167] O.C. Compton, Z. An, K.W. Putz, B.J. Hong, B.G. Hauser, L. Catherine Brinson, S.T. Nguyen, Additive-free hydrogelation of graphene oxide by ultrasonication, Carbon 50(10) (2012) 3399-3406. [168] H. Bai, C. Li, X. Wang, G. Shi, On the Gelation of Graphene Oxide, The Journal of Physical Chemistry C 115(13) (2011) 5545-5551.

[169] H. Bai, C. Li, X. Wang, G. Shi, A pH-sensitive graphene oxide composite hydrogel, Chemical communications 46(14) (2010) 2376-2378.

[170] Y. Xu, G. Shi, X. Duan, Self-Assembled Three-Dimensional Graphene Macrostructures: Synthesis and Applications in Supercapacitors, Accounts of Chemical Research 48(6) (2015) 16661675.

[171] Y. Zhao, J. Liu, Y. Hu, H. Cheng, C. Hu, C. Jiang, L. Jiang, A. Cao, L. Qu, Highly Compression-Tolerant Supercapacitor Based on Polypyrrole-mediated Graphene Foam Electrodes, Advanced materials 25(4) (2013) 591-595.

[172] Y. Xu, K. Sheng, C. Li, G. Shi, Self-Assembled Graphene Hydrogel via a One-Step Hydrothermal Process, ACS Nano 4(7) (2010) 4324-4330.

[173] P. Chen, J.-J. Yang, S.-S. Li, Z. Wang, T.-Y. Xiao, Y.-H. Qian, S.-H. Yu, Hydrothermal synthesis of macroscopic nitrogen-doped graphene hydrogels for ultrafast supercapacitor, Nano Energy 2(2) (2013) 249-256. 
[174] J.-Z. Wang, C. Zhong, D. Wexler, N.H. Idris, Z.-X. Wang, L.-Q. Chen, H.-K. Liu, GrapheneEncapsulated Fe3O4 Nanoparticles with 3D Laminated Structure as Superior Anode in Lithium Ion Batteries, Chemistry - A European Journal 17(2) (2011) 661-667.

[175] W. Wei, S. Yang, H. Zhou, I. Lieberwirth, X. Feng, K. Müllen, 3D Graphene Foams Crosslinked with Pre-encapsulated Fe3O4 Nanospheres for Enhanced Lithium Storage, Advanced materials 25(21) (2013) 2909-2914.

[176] Z.-S. Wu, S. Yang, Y. Sun, K. Parvez, X. Feng, K. Müllen, 3D Nitrogen-Doped Graphene Aerogel-Supported Fe3O4 Nanoparticles as Efficient Electrocatalysts for the Oxygen Reduction Reaction, Journal of the American Chemical Society 134(22) (2012) 9082-9085.

[177] T. Sun, Z. Zhang, J. Xiao, C. Chen, F. Xiao, S. Wang, Y. Liu, Facile and Green Synthesis of Palladium Nanoparticles-Graphene-Carbon Nanotube Material with High Catalytic Activity, Scientific Reports 3 (2013) 2527.

[178] Z. Tang, S. Shen, J. Zhuang, X. Wang, Noble-Metal-Promoted Three-Dimensional Macroassembly of Single-Layered Graphene Oxide, Angewandte Chemie International Edition 49(27) (2010) 4603-4607.

[179] Y. Xu, X. Huang, Z. Lin, X. Zhong, Y. Huang, X. Duan, One-step strategy to graphene/ $\mathrm{Ni}(\mathrm{OH}) 2$ composite hydrogels as advanced three-dimensional supercapacitor electrode materials, Nano Research 6(1) (2013) 65-76.

[180] H.-P. Cong, X.-C. Ren, P. Wang, S.-H. Yu, Macroscopic Multifunctional Graphene-Based Hydrogels and Aerogels by a Metal Ion Induced Self-Assembly Process, ACS Nano 6(3) (2012) 2693-2703.

[181] K.-x. Sheng, Y.-x. Xu, C. Li, G.-q. Shi, High-performance self-assembled graphene hydrogels prepared by chemical reduction of graphene oxide, New Carbon Materials 26(1) (2011) 9-15.

[182] X. Zhang, Z. Sui, B. Xu, S. Yue, Y. Luo, W. Zhan, B. Liu, Mechanically strong and highly conductive graphene aerogel and its use as electrodes for electrochemical power sources, Journal of 
Materials Chemistry 21(18) (2011) 6494-6497.

[183] H.D. Pham, V.H. Pham, T.V. Cuong, T.-D. Nguyen-Phan, J.S. Chung, E.W. Shin, S. Kim, Synthesis of the chemically converted graphene xerogel with superior electrical conductivity, Chemical communications 47(34) (2011) 9672-9674.

[184] W. Chen, L. Yan, In situ self-assembly of mild chemical reduction graphene for threedimensional architectures, Nanoscale 3(8) (2011) 3132-3137.

[185] W. Chen, S. Li, C. Chen, L. Yan, Self-Assembly and Embedding of Nanoparticles by In Situ Reduced Graphene for Preparation of a 3D Graphene/Nanoparticle Aerogel, Advanced materials 23(47) (2011) 5679-5683.

[186] X. Song, L. Lin, M. Rong, Y. Wang, Z. Xie, X. Chen, Mussel-inspired, ultralight, multifunctional 3D nitrogen-doped graphene aerogel, Carbon 80 (2014) 174-182.

[187] T. Liu, M. Huang, X. Li, C. Wang, C.-X. Gui, Z.-Z. Yu, Highly compressible anisotropic graphene aerogels fabricated by directional freezing for efficient absorption of organic liquids, Carbon 100 (2016) 456-464.

[188] L.-Z. Guan, J.-F. Gao, Y.-B. Pei, L. Zhao, L.-X. Gong, Y.-J. Wan, H. Zhou, N. Zheng, X.-S. Du, L.-B. Wu, J.-X. Jiang, H.-Y. Liu, L.-C. Tang, Y.-W. Mai, Silane bonded graphene aerogels with tunable functionality and reversible compressibility, Carbon 107 (2016) 573-582.

[189] W. Li, F. Wang, S. Feng, J. Wang, Z. Sun, B. Li, Y. Li, J. Yang, A.A. Elzatahry, Y. Xia, D. Zhao, Sol-Gel Design Strategy for Ultradispersed TiO2 Nanoparticles on Graphene for HighPerformance Lithium Ion Batteries, Journal of the American Chemical Society 135(49) (2013) 1830018303.

[190] Y. Sun, Q. Wu, G. Shi, Supercapacitors based on self-assembled graphene organogel, Physical Chemistry Chemical Physics 13(38) (2011) 17249-17254.

[191] K. Chen, L. Chen, Y. Chen, H. Bai, L. Li, Three-dimensional porous graphene-based composite materials: electrochemical synthesis and application, Journal of Materials Chemistry 22(39) (2012) 
20968-20976.

[192] Q. Zhou, Y. Li, L. Huang, C. Li, G. Shi, Three-dimensional porous graphene/polyaniline composites for high-rate electrochemical capacitors, Journal of Materials Chemistry A 2(41) (2014) 17489-17494.

[193] K. Sheng, Y. Sun, C. Li, W. Yuan, G. Shi, Ultrahigh-rate supercapacitors based on eletrochemically reduced graphene oxide for ac line-filtering, 2 (2012) 247.

[194] Y. Li, K. Sheng, W. Yuan, G. Shi, A high-performance flexible fibre-shaped electrochemical capacitor based on electrochemically reduced graphene oxide, Chemical communications 49(3) (2013) 291-293.

[195] F. Liu, T.S. Seo, A Controllable Self-Assembly Method for Large-Scale Synthesis of Graphene Sponges and Free-Standing Graphene Films, Advanced Functional Materials 20(12) (2010) 19301936.

[196] Z. Zhang, L.-L. Kong, S. Liu, G.-R. Li, X.-P. Gao, A High-Efficiency Sulfur/Carbon Composite Based on 3D Graphene Nanosheet@Carbon Nanotube Matrix as Cathode for Lithium-Sulfur Battery, Advanced Energy Materials 7(11) (2017) 1602543.

[197] M.-Q. Yang, N. Zhang, Y. Wang, Y.-J. Xu, Metal-free, robust, and regenerable 3D grapheneorganics aerogel with high and stable photosensitization efficiency, Journal of Catalysis 346 (2017) 21-29.

[198] G. Fu, X. Yan, Y. Chen, L. Xu, D. Sun, J.-M. Lee, Y. Tang, Boosting Bifunctional Oxygen Electrocatalysis with 3D Graphene Aerogel-Supported Ni/MnO Particles, Advanced materials 30(5) (2017) 1704609.

[199] M. Zhao, Y. Cao, H. Gong, Y. Sun, J. Deng, D. Li, R. Wan, H. Gu, Enhanced cell growth on 3D graphene scaffolds implanted with nitrogen ions, Biointerphases 13(4) (2018) 041001.

[200] N. Pramanik, S. Bhattacharya, T. Rath, J. De, A. Adhikary, R.K. Basu, P.P. Kundu, Polyhydroxybutyrate-co-hydroxyvalerate copolymer modified graphite oxide based 3D scaffold for 
tissue engineering application, Materials Science and Engineering: C 94 (2019) 534-546.

[201] P. Li, Z. Jin, L. Peng, F. Zhao, D. Xiao, Y. Jin, G. Yu, Stretchable All-Gel-State Fiber-Shaped Supercapacitors Enabled by Macromolecularly Interconnected 3D Graphene/Nanostructured Conductive Polymer Hydrogels, Advanced materials 30(18) (2018) 1800124.

[202] C. Luo, C.-N. Yeh, J.M.L. Baltazar, C.-L. Tsai, J. Huang, A Cut-and-Paste Approach to 3D Graphene-Oxide-Based Architectures, Advanced materials 30(15) (2018) 1706229.

[203] Y. Li, H. Wang, L. Xie, Y. Liang, G. Hong, H. Dai, MoS2 Nanoparticles Grown on Graphene: An Advanced Catalyst for the Hydrogen Evolution Reaction, Journal of the American Chemical Society 133(19) (2011) 7296-7299.

[204] M.-H. Lim, I.C. Jeung, J. Jeong, S.-J. Yoon, S.-H. Lee, J. Park, Y.-S. Kang, H. Lee, Y.-J. Park, H.G. Lee, S.-J. Lee, B.S. Han, N.W. Song, S.C. Lee, J.-S. Kim, K.-H. Bae, J.-K. Min, Graphene oxide induces apoptotic cell death in endothelial cells by activating autophagy via calcium-dependent phosphorylation of c-Jun N-terminal kinases, Acta biomaterialia 46(Supplement C) (2016) 191-203. [205] Q. Mu, G. Su, L. Li, B.O. Gilbertson, L.H. Yu, Q. Zhang, Y.-P. Sun, B. Yan, Size-Dependent Cell Uptake of Protein-Coated Graphene Oxide Nanosheets, ACS Applied Materials \& Interfaces 4(4) (2012) 2259-2266.

[206] G.P. Kotchey, B.L. Allen, H. Vedala, N. Yanamala, A.A. Kapralov, Y.Y. Tyurina, J. KleinSeetharaman, V.E. Kagan, A. Star, The Enzymatic Oxidation of Graphene Oxide, ACS Nano 5(3) (2011) 2098-2108.

[207] W. Xing, G. Lalwani, I. Rusakova, B. Sitharaman, Degradation of Graphene by Hydrogen Peroxide, Particle \& Particle Systems Characterization 31(7) (2014) 745-750.

[208] Y. Li, L. Feng, X. Shi, X. Wang, Y. Yang, K. Yang, T. Liu, G. Yang, Z. Liu, Surface CoatingDependent Cytotoxicity and Degradation of Graphene Derivatives: Towards the Design of NonToxic, Degradable Nano-Graphene, Small 10(8) (2014) 1544-1554.

[209] K. Rajendra, B. Fanny, R. Julie, r. suresh babu adukamparai, M.-M. Cécilia, K. Kostas, B. 
Alberto, 2D Materials (2017).

[210] S.K. Singh, M.K. Singh, M.K. Nayak, S. Kumari, S. Shrivastava, J.J.A. Grácio, D. Dash, Thrombus Inducing Property of Atomically Thin Graphene Oxide Sheets, ACS Nano 5(6) (2011) 4987-4996.

[211] J. Liu, L. Cui, D. Losic, Graphene and graphene oxide as new nanocarriers for drug delivery applications, Acta biomaterialia 9(12) (2013) 9243-57.

[212] J. Zhang, H. Yang, G. Shen, P. Cheng, J. Zhang, S. Guo, Reduction of graphene oxide vialascorbic acid, Chemical communications 46(7) (2010) 1112-1114. 


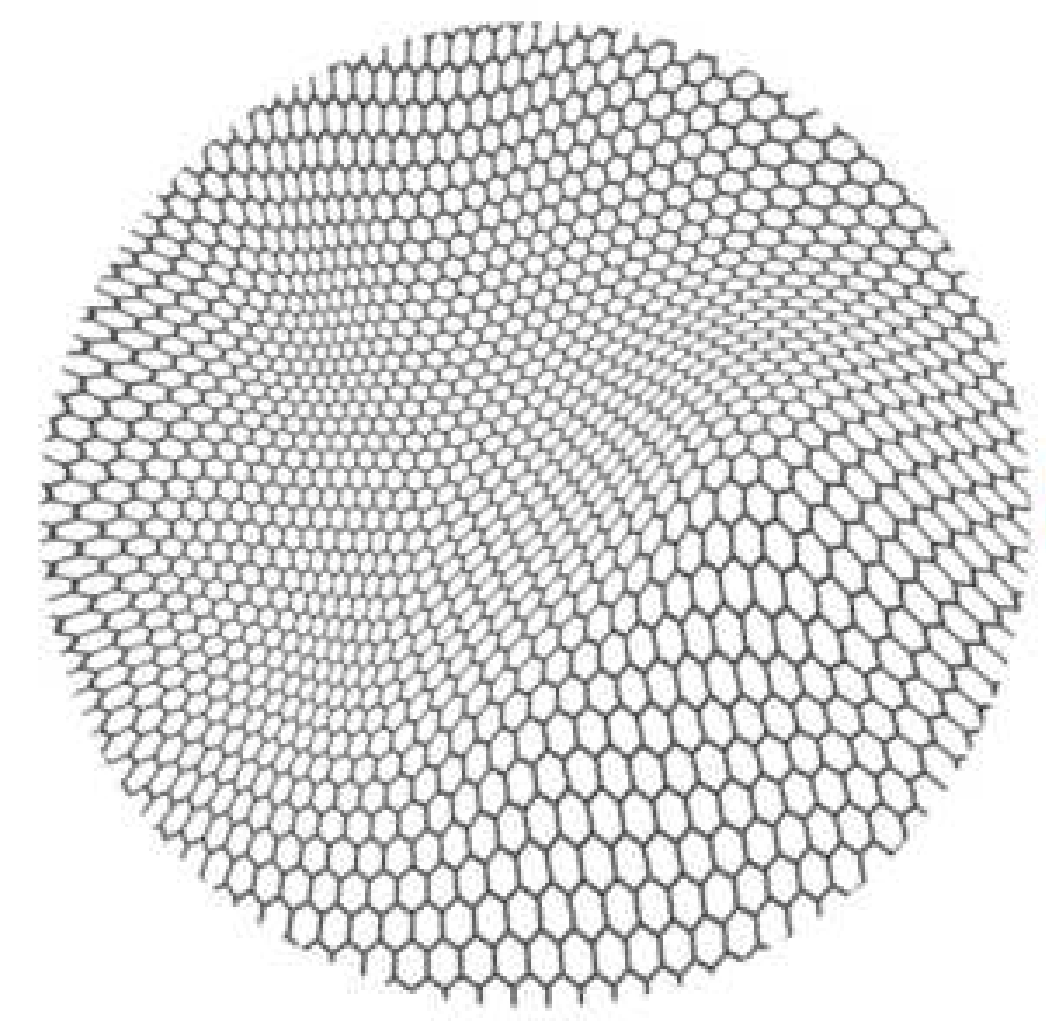

$>$ Flexible

$>$ Light

$>$ Thin

$>$ Robust

$>$ Transparent

$>$ Thermally conductive

$>$ Electrically conductive

$>$ Surface modifiable... 
(a)

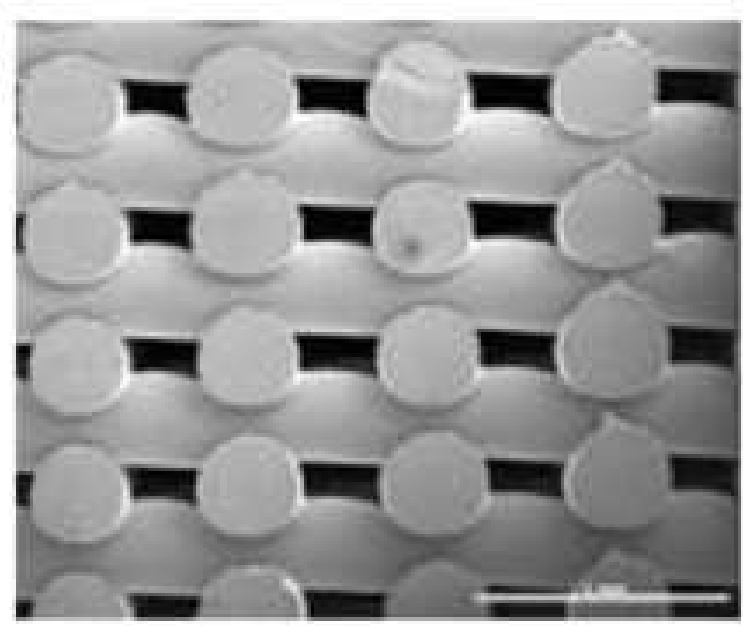

(c)

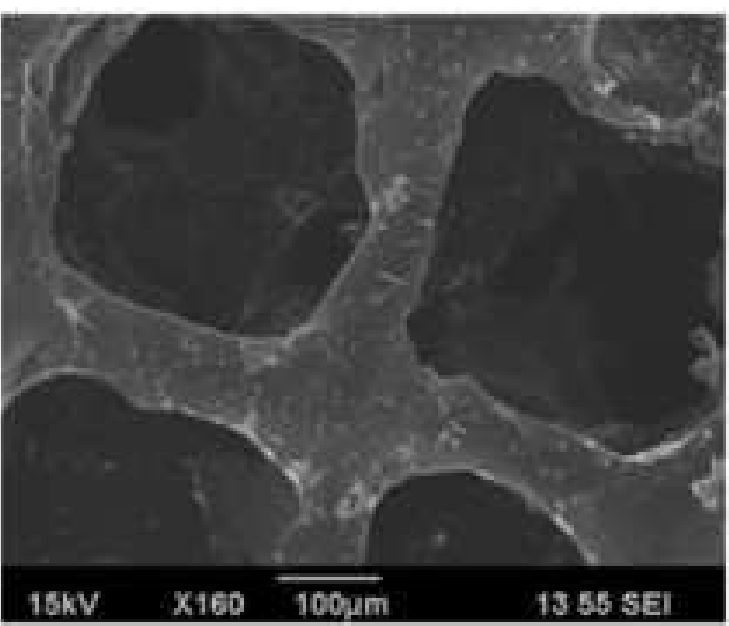

(e)

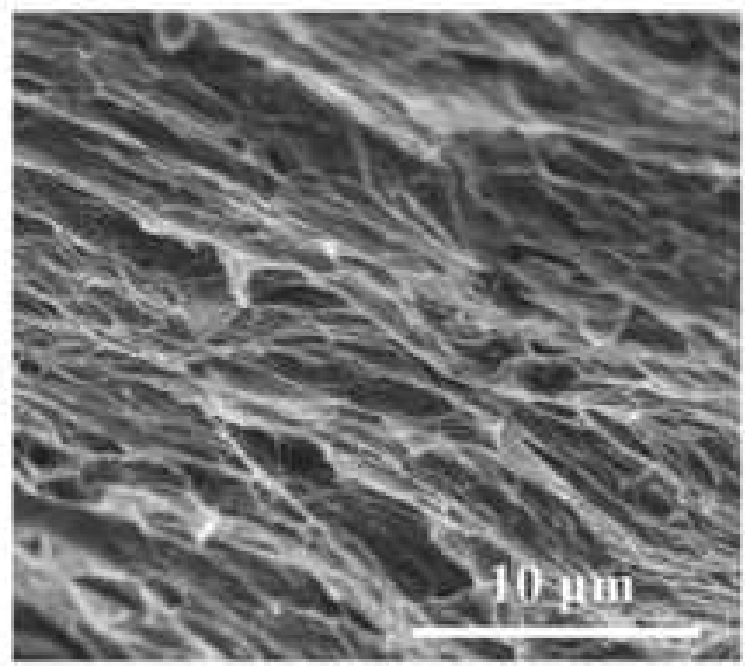

(b)

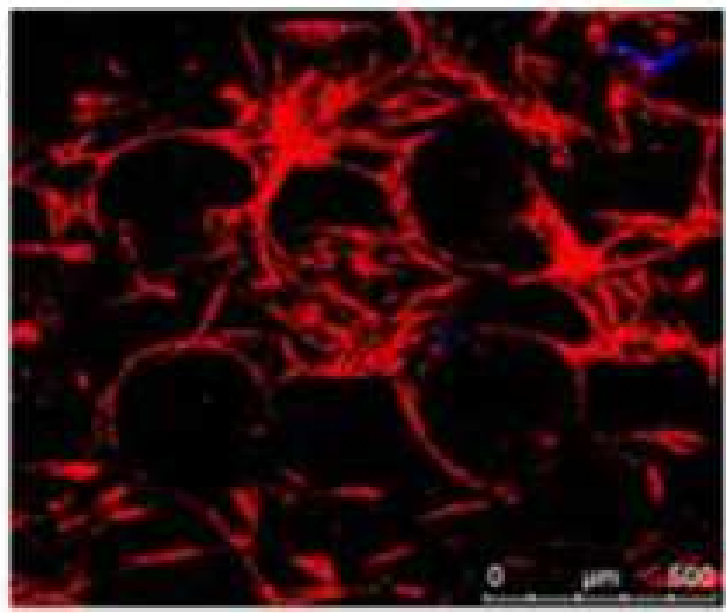

(d)

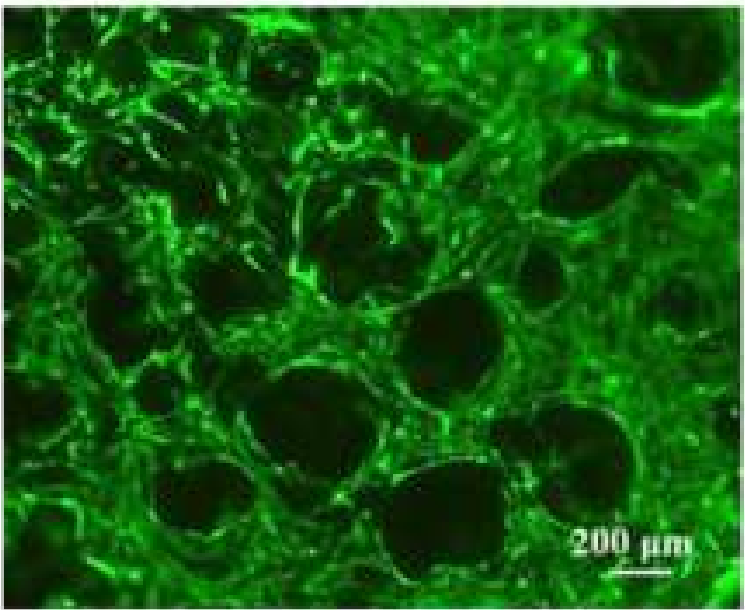

(f)

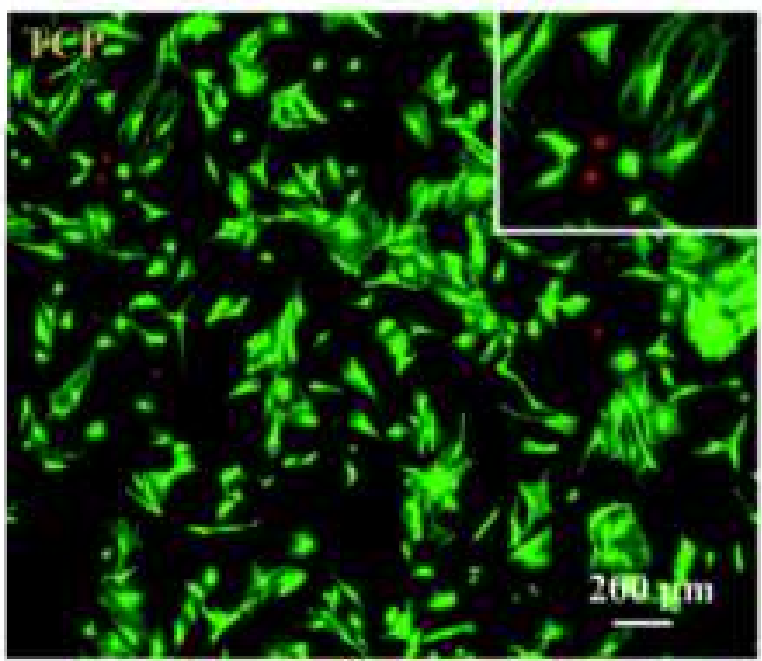



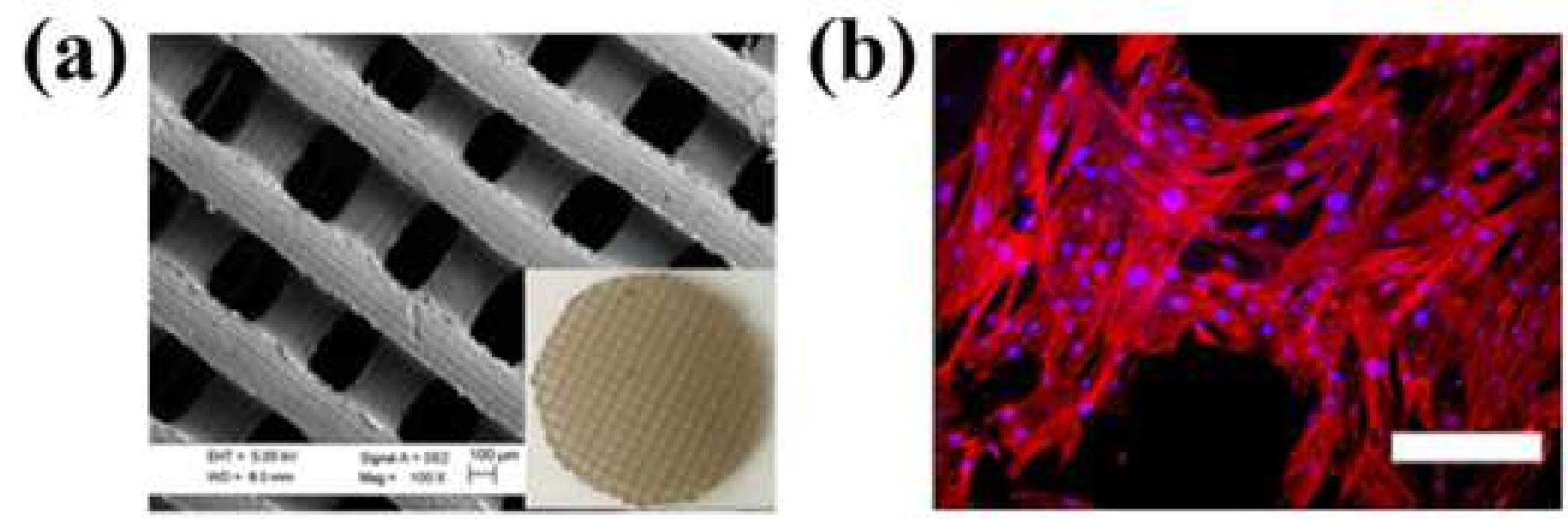

(c)

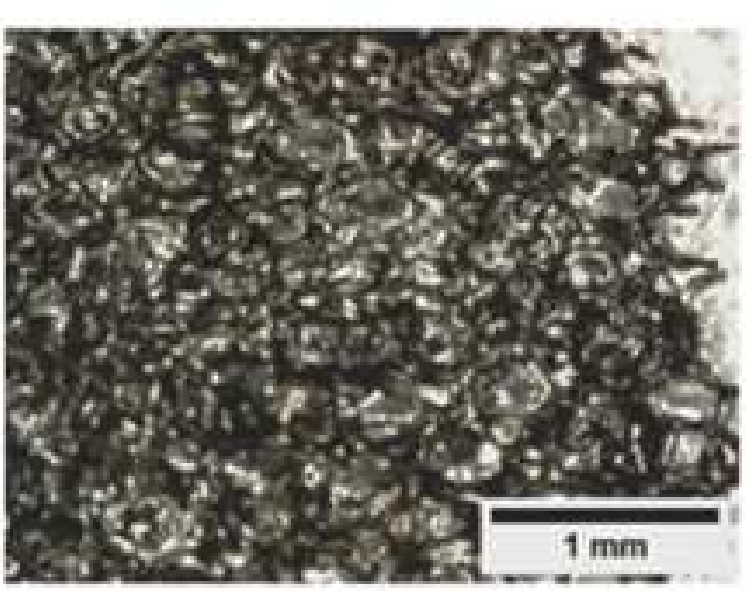

\section{(d)}

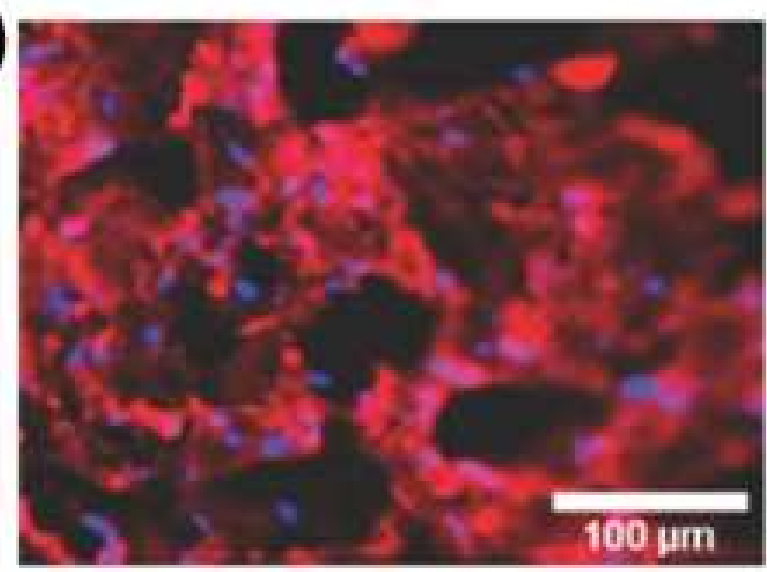

(e)

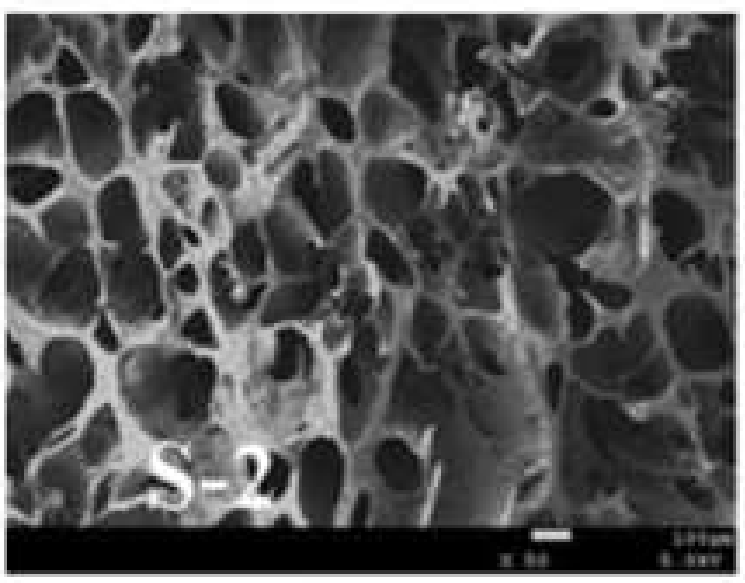

(f)

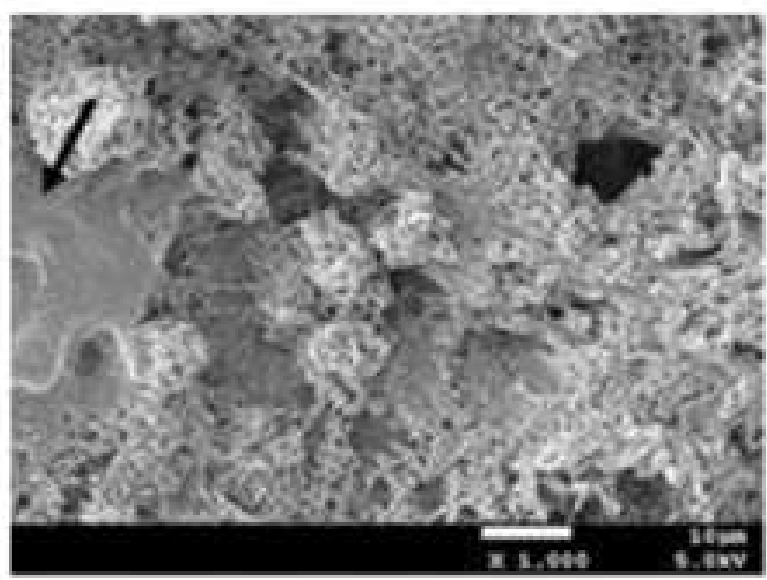




\section{(a)}

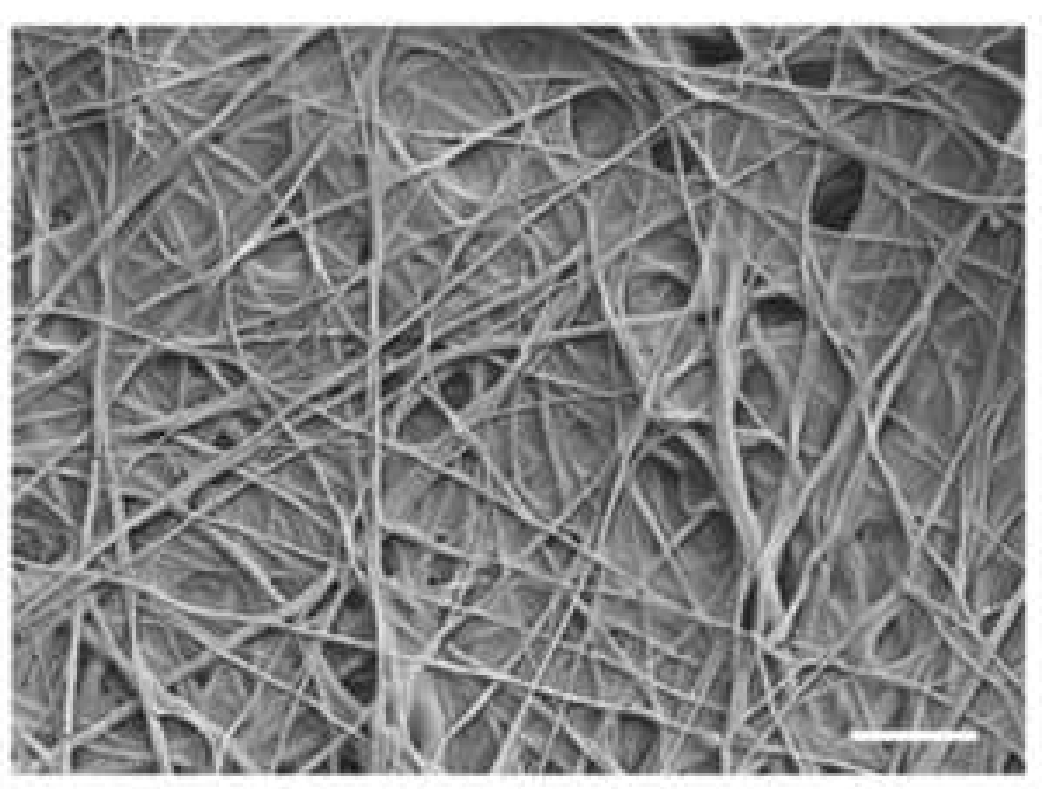

(b)

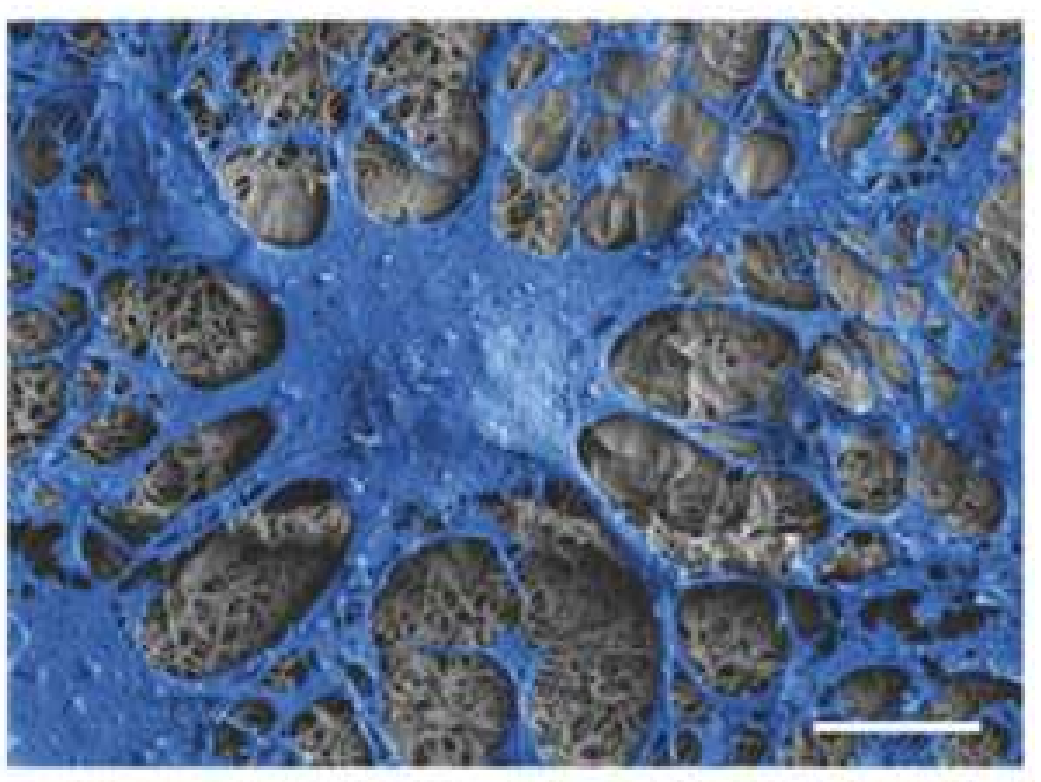

(c)

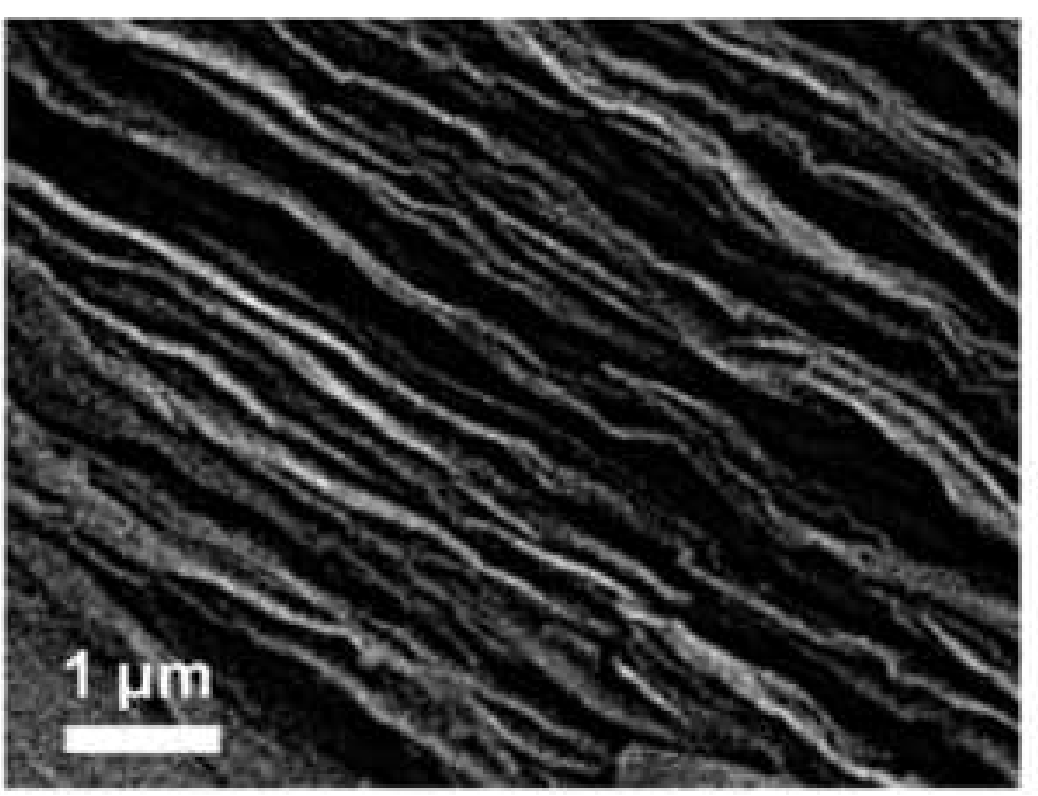

(d)

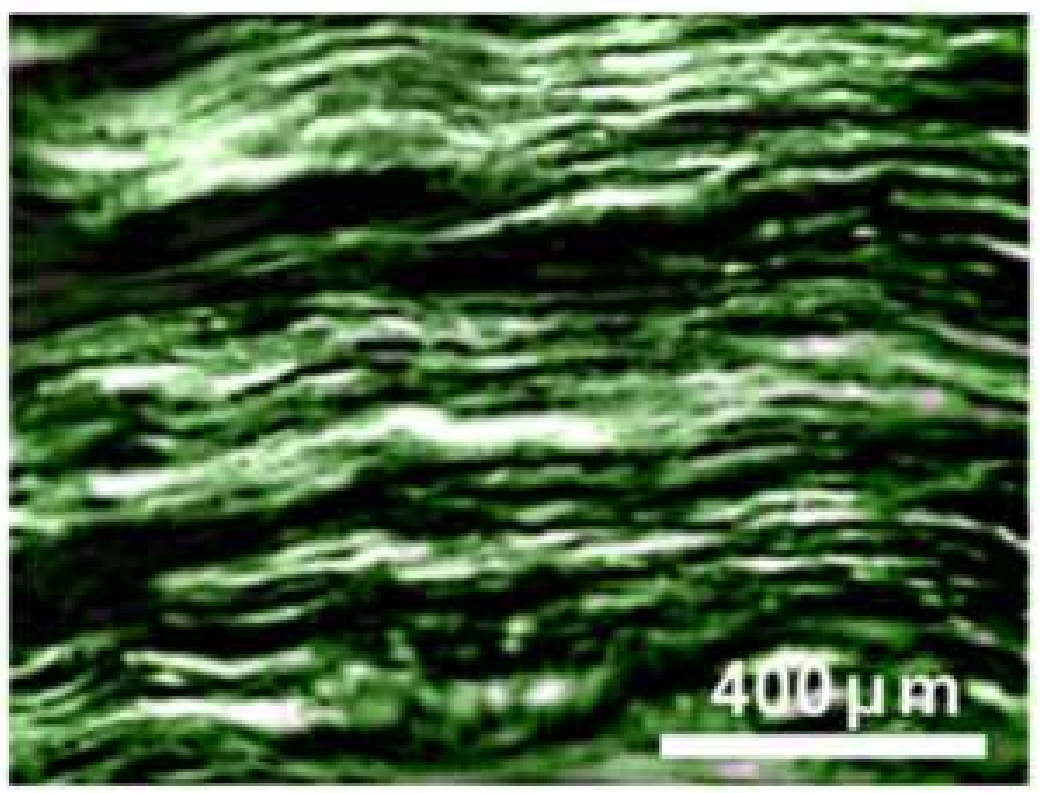


(a)

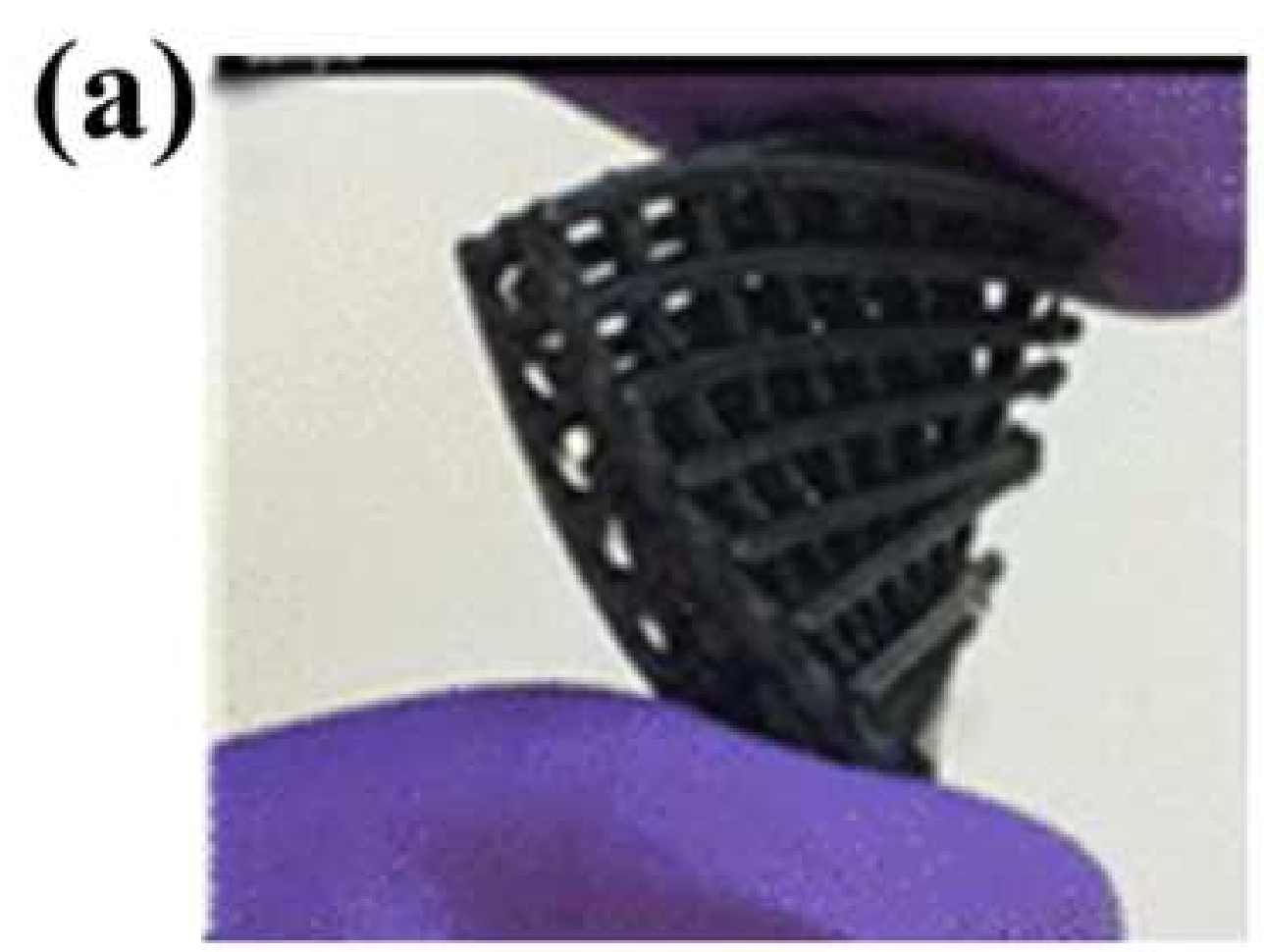

(b)

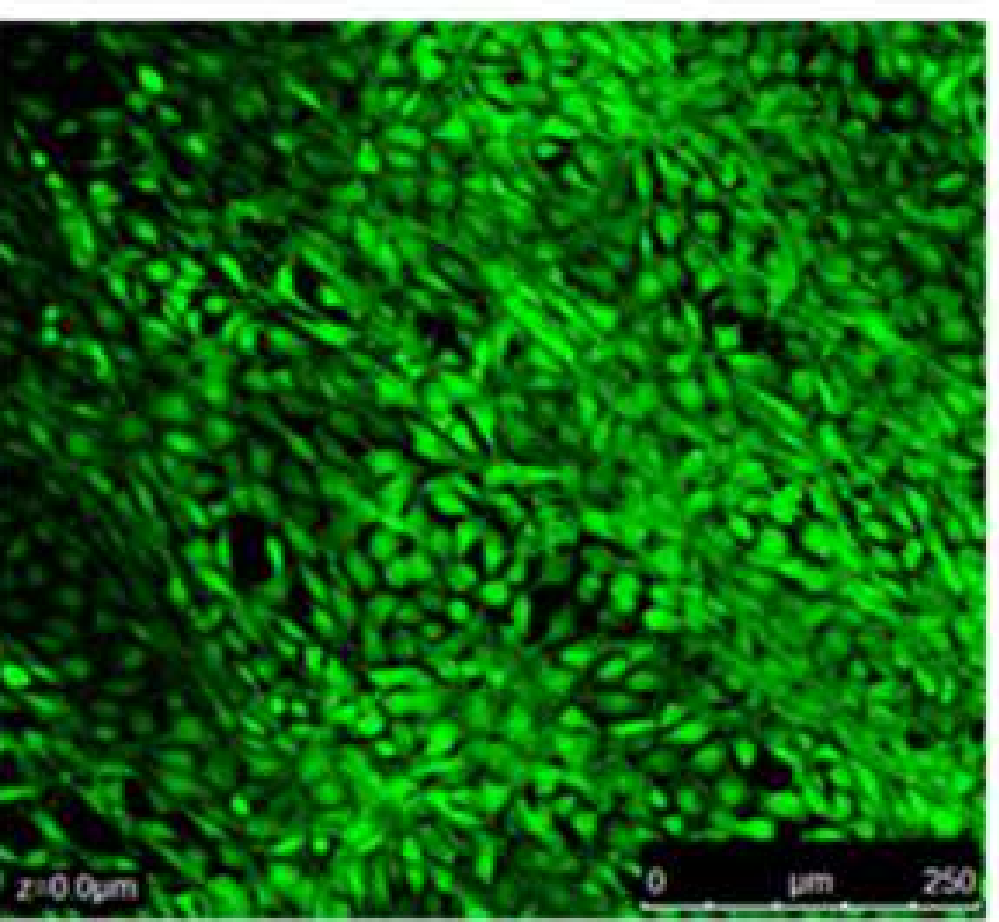




\section{(a)}

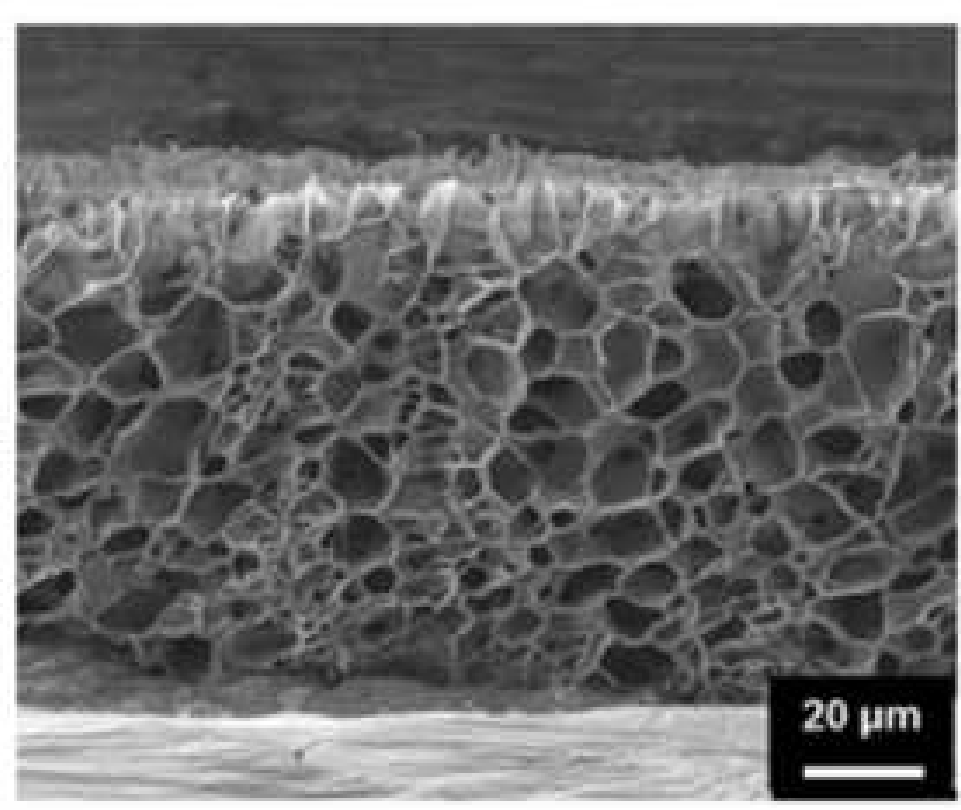

\section{(b)}

(c)
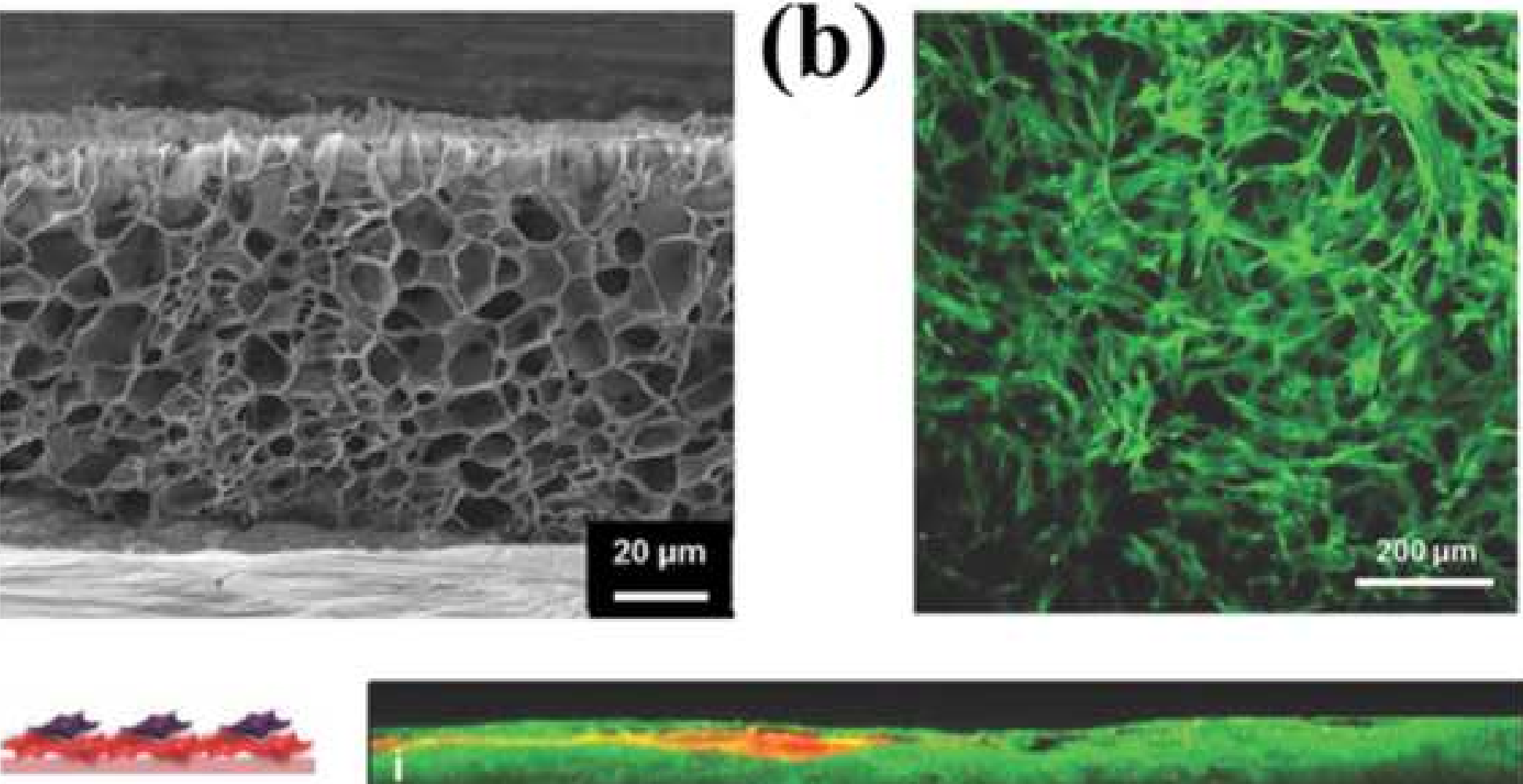

tonstenct

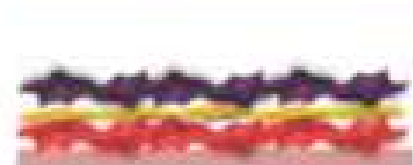

$\frac{5}{9}$
$\frac{2}{5}$
$\frac{5}{7}$
$\frac{5}{7}$
$\frac{5}{6}$
0

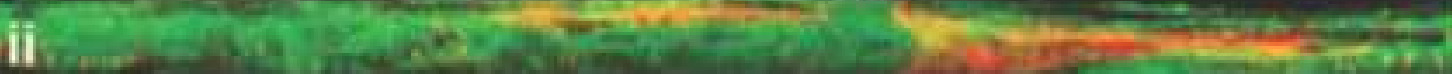
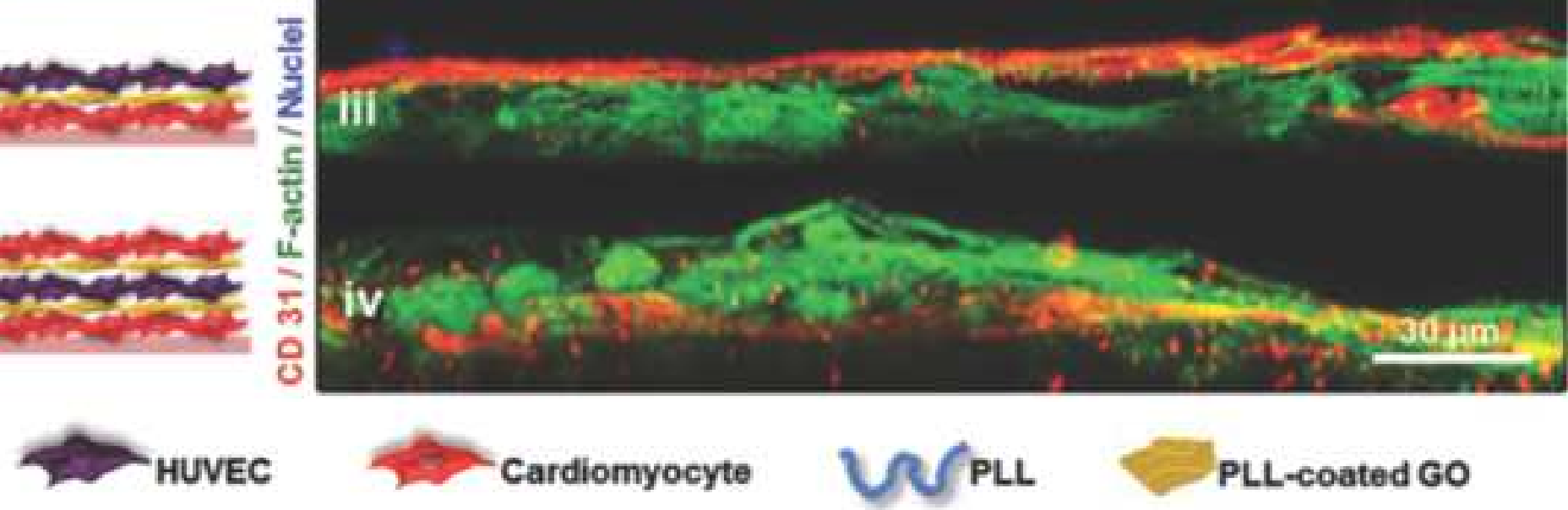

PLL-coated GO 
(a)

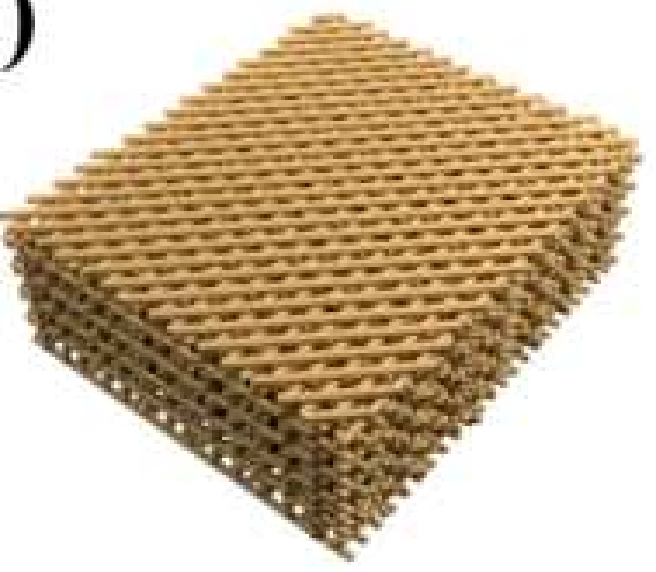

(d)

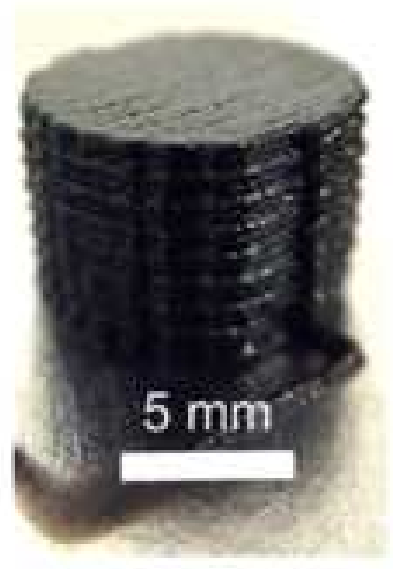

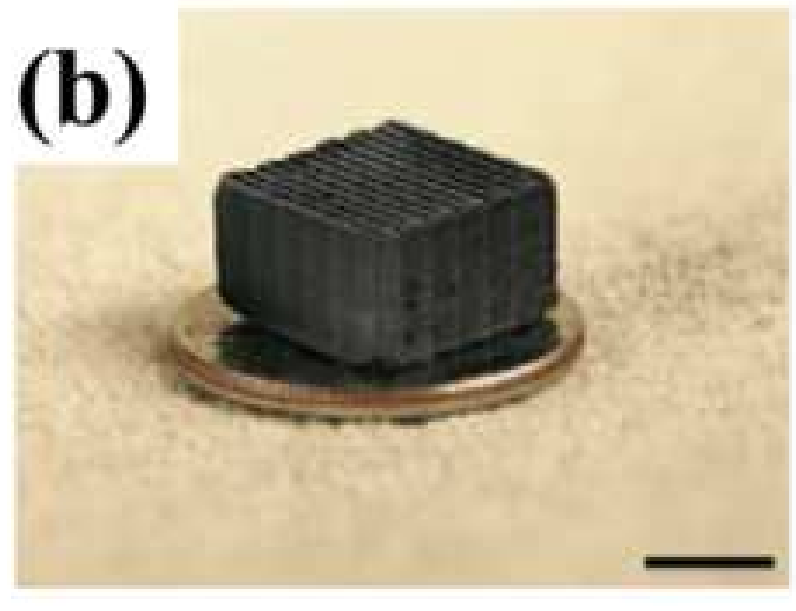

(e)

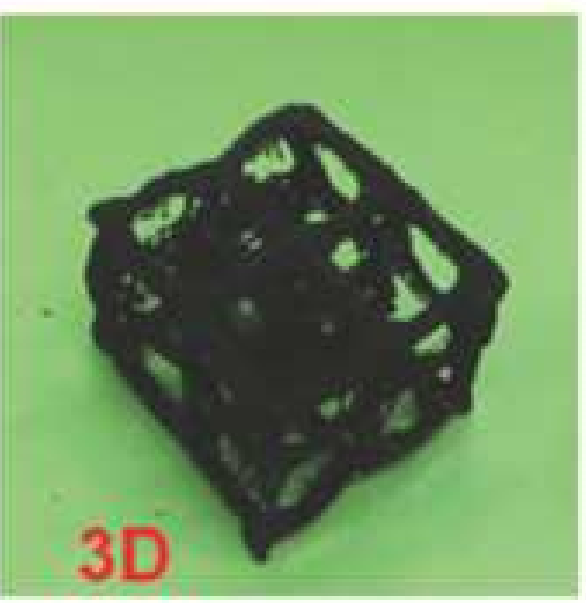

(c)

$1 \mathrm{~mm}$

(f)

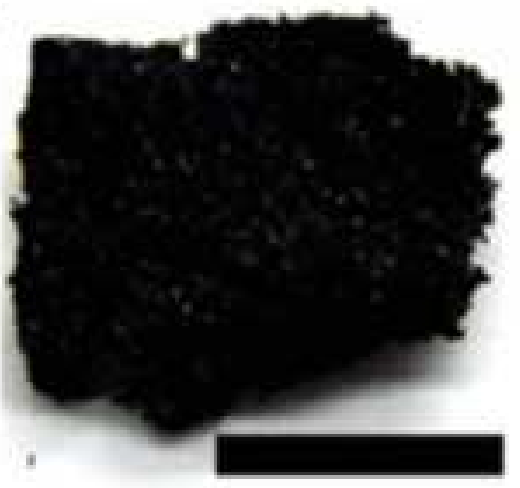


(a)

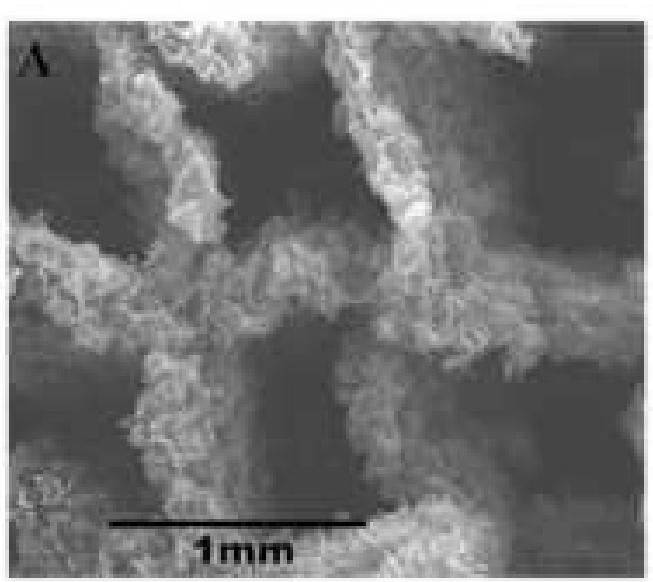

(b)

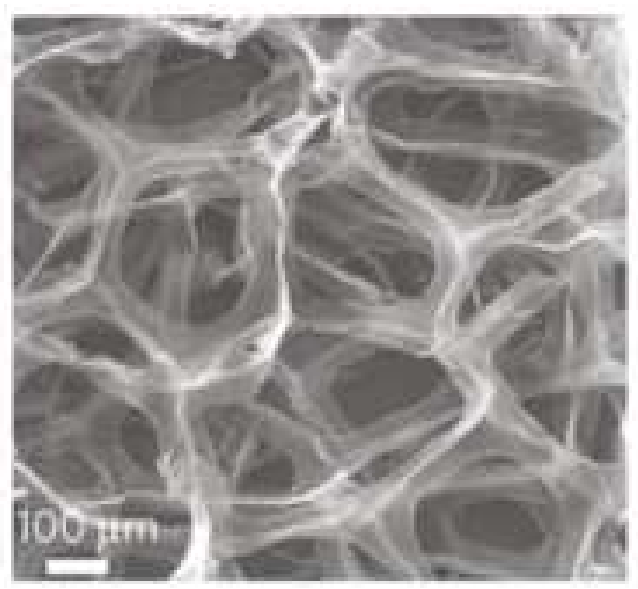

(c)

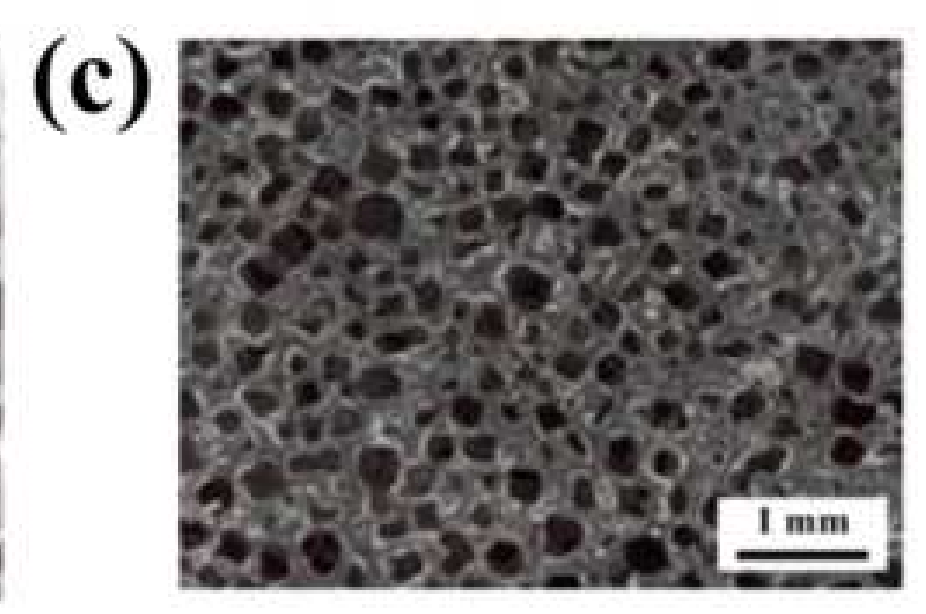


(a)

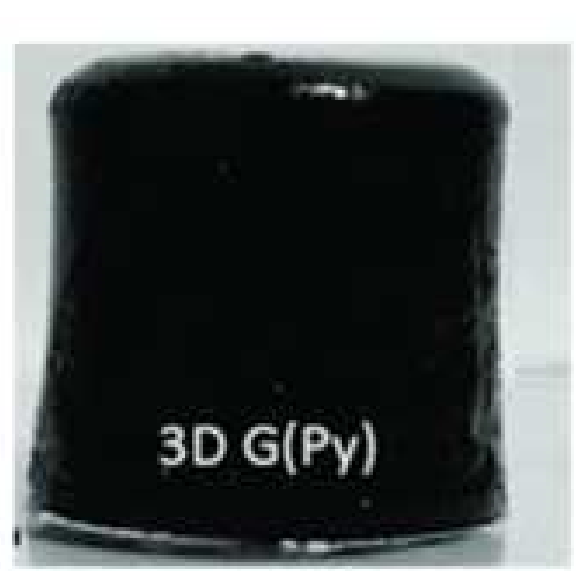

(b)

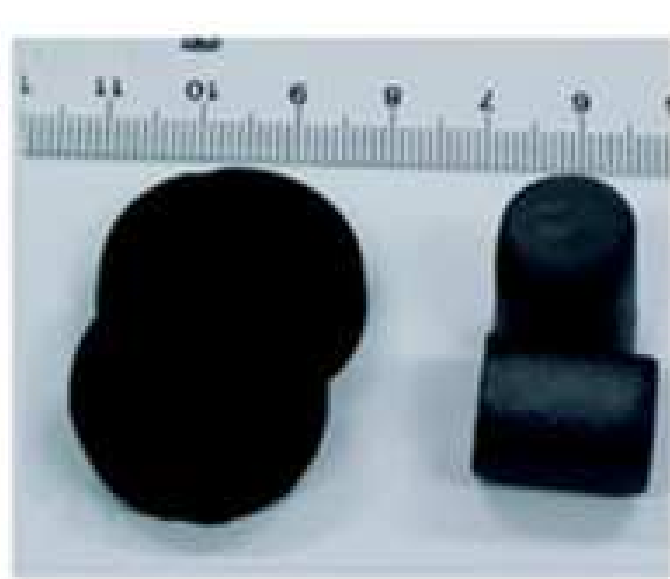

(d)

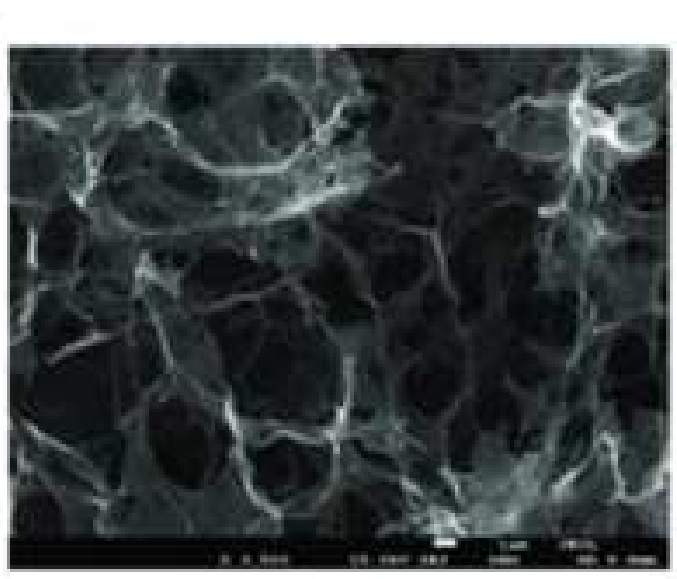

(e)

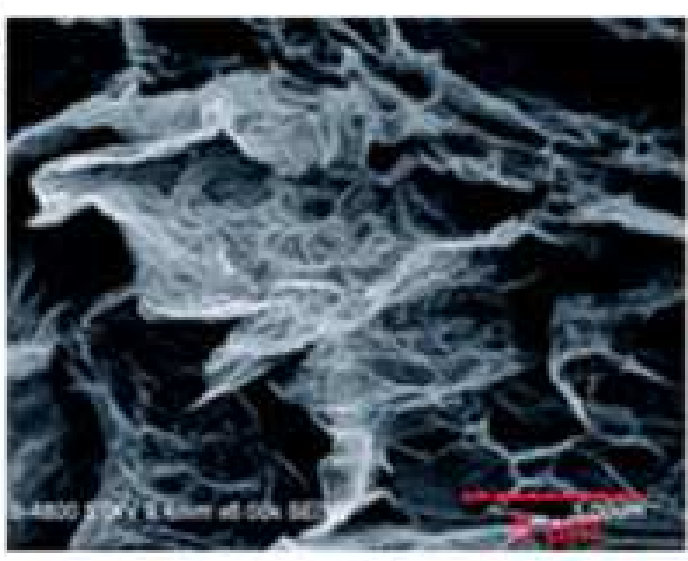

(c)

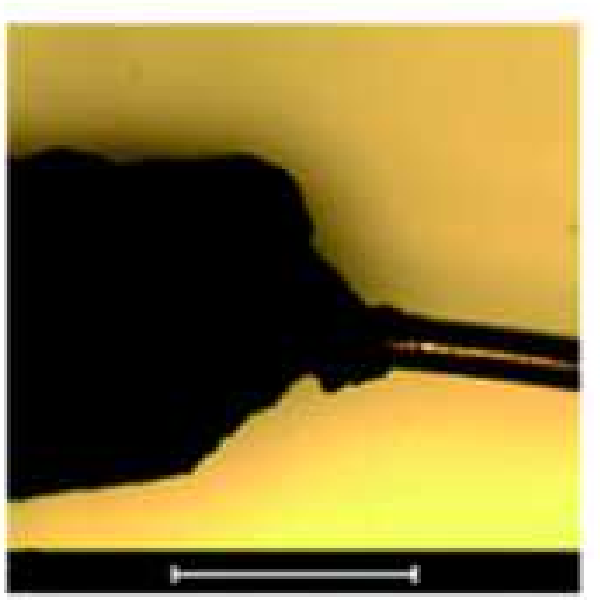

(f)

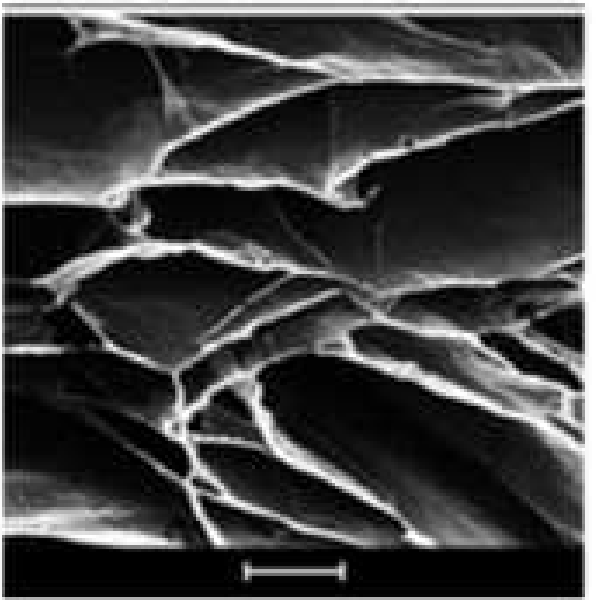

